\title{
Technological Transitions: A Semiotic Analysis of Newspaper Advertisements for the Television Remote Control (1975-1985)
}

\author{
By Lauren Cheal, B.A. (Hons.) \\ A thesis submitted \\ to the Faculty of Graduate Studies and Research \\ in partial fulfillment of the requirements for the degree of \\ Master of Arts
}

School of Journalism and Communication

Carleton University

Ottawa, Ontario

July 2009

(C2009, Lauren Cheal 


$\begin{array}{ll}\begin{array}{l}\text { Library and Archives } \\ \text { Canada }\end{array} & \begin{array}{l}\text { Bibliothèque et } \\ \text { Archives Canada }\end{array} \\ \begin{array}{l}\text { Published Heritage } \\ \text { Branch }\end{array} & \begin{array}{l}\text { Direction du } \\ \text { Patrimoine de l'édition }\end{array} \\ \begin{array}{l}\text { 395 Wellington Street } \\ \text { Ottawa ON K1A ON4 } \\ \text { Canada }\end{array} & \begin{array}{l}\text { 395, rue Wellington } \\ \text { Ottawa ON K1A ON4 } \\ \text { Canada }\end{array}\end{array}$

Your file Votro référence

ISBN: 978-0-494-60300-0

Our file Notre référence

ISBN: 978-0-494-60300-0

NOTICE:

The author has granted a nonexclusive license allowing Library and Archives Canada to reproduce, publish, archive, preserve, conserve, communicate to the public by telecommunication or on the Internet, loan, distribute and sell theses worldwide, for commercial or noncommercial purposes, in microform, paper, electronic and/or any other formats.

The author retains copyright ownership and moral rights in this thesis. Neither the thesis nor substantial extracts from it may be printed or otherwise reproduced without the author's permission.
AVIS:

L'auteur a accordé une licence non exclusive permettant à la Bibliothèque et Archives Canada de reproduire, publier, archiver, sauvegarder, conserver, transmettre au public par télécommunication ou par l'Internet, prêter, distribuer et vendre des thèses partout dans le monde, à des fins commerciales ou autres, sur support microforme, papier, électronique et/ou autres formats.

L'auteur conserve la propriété du droit d'auteur et des droits moraux qui protège cette thèse. Ni la thèse ni des extraits substantiels de celle-ci ne doivent être imprimés ou autrement reproduits sans son autorisation.
In compliance with the Canadian Privacy Act some supporting forms may have been removed from this thesis.

While these forms may be included in the document page count, their removal does not represent any loss of content from the thesis.
Conformément à la loi canadienne sur la protection de la vie privée, quelques formulaires secondaires ont été enlevés de cette thèse.

Bien que ces formulaires aient inclus dans la pagination, il n'y aura aucun contenu manquant. 


\section{Acknowledgments}

I would like to thank the professors in the Department of Communication at Carleton for their guidance and mentorship. Dr. Ira Wagman, my supervisor, gave me a great gift in the freedom to the project in my own way and with my own ideas. His excitement for the project helped sustain my own over a long process. Dr. Joshua Greenberg, my second reader, also provided a great deal of support, especially when I was lost on a methodological approach. His guidance in the first year of the program also made this thesis possible. I would also like to thank Dr. Sheryl Hamilton for her general mentorship over the two-year process of the program. Her ability to understand the graduate student experience and guide me through it was beyond helpful. Another thank you goes to Dr. Marc Furstenau, my external examiner, whose thoughtful questions and comments helped me tighten up my final argument.

I would also like to acknowledge Carleton University and the School of Journalism and Communication for giving me the opportunity to undertake this program. The freedom that is built into the Master of Arts program at Carleton is one of its great assets and I appreciated having that freedom in my academic work.

I could not have accomplished this without the financial and emotional support from my parents, Cameron and Candace Cheal. Their belief in my ability to complete the program has meant the world to me and I can't thank them enough for allowing me to not worry about finances while I was working on my thesis. My Dad has always been willing to distract me with a game of golf or a quick road trip. My Mom has been the reassuring voice on the other end of the phone that knew I could do this before I did. I would also like to thank my sisters, Jenna and Taryn, for always making me laugh and being willing to engage in a philosophical debate over Potter. For the record, I do not have a heart of stone.

I would also like to thank my good friend, Heather Gilberds for her friendship and willingness to listen to me talk about remote controls over the past year. If she hadn't kept asking me "So, why does anyone care about this?," I may never have figured that out. I believe that it was our mutual goal for sno-cones at the end of the process that got us both through it in the end. Her intellect and shared appreciation for the absurd made the process a lot more fun. 


\begin{abstract}
This thesis investigates the way histories of communication technology are communicated. The project considers the problem of "new" technology and argues that technology is better understood through a continuum that highlights the importance of previous technologies. Using a semiotic analysis of newspaper advertisements from 1975 to 1985 that feature the remote control and a review of literature that focuses on use studies of the remote control in the 1980s, I argue that the way remote controls are historicized does not fit with how they were represented to consumers. In order to address the disparity I found between the academic literature and the media representation of the technology, I propose a life cycle model of the history of the remote control.
\end{abstract}




\section{Table of Contents}

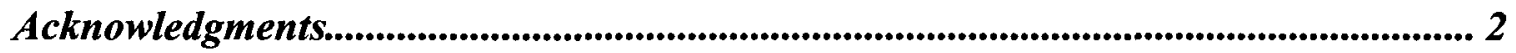

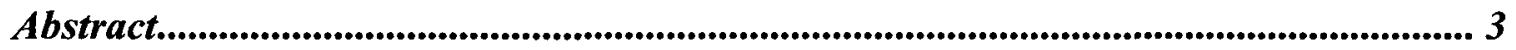

Table of Contents ........................................................................................................................... 4

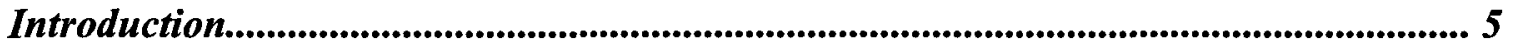

A. Linear History of the Remote Control Device................................................................................8

B. The Life Cycle of the Remote Control Device ................................................................................10

C. The Framework of the New ..............................................................................................................12

Chapter 1: Adjunct Television Technologies, the Academic Perspective........................ 22

A. RCD Research .................................................................................................................................22

B. VCR Studies.oon.............................................................................................................................32

Chapter 2: Technological Determinism: Driving History..................................................... 41

Chapter 3: Considering Methodology: Representation and Semiotics............................ 53

A. Methodology Review: Strengths and Weaknesses of the Semiotic Approach ........................56

B. The Lens of the New...............................................................................................................................61

C. My Semiotic Approach: Saussure and Barthes................................................................................64

Chapter 4: Case Study: Newspaper Advertisements for the Remote Control Device.... 69

A. Sample .............................................................................................................................................69

B. Analysis of Overall Content.................................................................................................... 72

C. Semiotic Analysis ....................................................................................................................................... 77

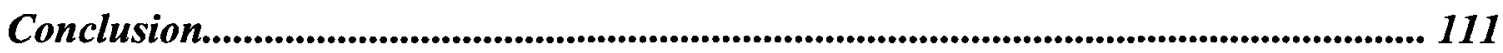

Appendix A: Semiotic Questions for the Sample.................................................................. 123

Appendix B: Newspaper Advertisements ......................................................................... 125

References ................................................................................................................................................ 142 


\section{Introduction}

This project reconsiders the way technologies are categorized and understood in academic work through an analysis of print advertisements. The research question for my project is: how are technologies represented to consumers, and what do those representations imply about the relationship between technology and users? This question will be asked in the context of a larger argument about the representation of old and new technologies in popular media. The specific case I will investigate in this project is the introduction and popularization of the remote control device (RCD) in the late 1970s and early 1980s in the United States. This case study is informative because the issues that arose around the introduction of this technology within the industry and in academic work on the topic speak to an underlying tension between new technology and established ways of living.

The case of the RCD involves several areas of discussion relevant to the topic of technology: usage, technology (the physical object), and advertising. The first area of discussion (usage) is well represented through existing academic literature on the RCD. In fact, usage studies are the only perspective addressed by the academic literature I found on the topic of the RCD. The RCD reflects a certain moment in the industry of television; its introduction to the marketplace coincides with a new distribution method in cable television. This project also involves a discussion about how technologies are developed and used. Not coincidentally, the television RCD increased in popularity at a time when VCRs (with RCD capabilities) became prevalent in American homes. The codevelopment of these adjunct television technologies is significant in that it informs how the technology was advertised to consumers. The final area that I will address in terms of the RCD is the advertising of the remote to consumers of televisions. An understanding 
of how the technology was promoted and sold informs a larger discussion about how people relate to technology.

There is a connection between the American technocracy and advertising that warrants mention here. According to Smith (1994) "early in the twentieth century, as artists and writers continued to tout the machine as the premium mobile of society, technocratic thinking received an enormous boost from the bourgeoning field of professional advertising" (p. 13). The connection between advertising and technocracy is interesting because advertising is in the position to influence thoughts and feelings about a product, and because the ideology behind a technocratic society is one that could also be sold. Given this connection, it can be assumed that advertising might help foster an atmosphere of technological advancement by creating dynamic ads that sell the product by touting its new and innovative qualities (precisely the research question of this project). And given the technologically deterministic literature available on the remote control, and the orientation towards newness present, I expected to find this focus on innovation in my case study of advertisements. As Smith (1994) asserts, "advertising agencies, in short, not only sold the products of industrial capitalism but also prompted a way of thinking about industrial technology" (p. 13). This characteristic of advertising, that it sells more than just material goods, is the reason for its selection in this project. It is very possible that within the realm of remote control technology, advertisers sold not only the product, but also an ideology about how the product could change people's lived experience.

The three areas I identify here (usage, technology and advertising) are addressed throughout this project, and I use the three to argue that the way remote control 
technologies are historicized is distinctly different from the way they are represented to consumers in advertising. Going into the project, I expected to find that within advertisements for remote controls there would be a focus on why consumers need this device and what the remote could do for the user's television viewing experience. I did not find this; instead, I found that remote controls were advertised as static features of the television set. Remote controls are historicized as technological catalysts for major changes in user behavior, but they are represented to consumers as part of a routine viewing experience-as part of the everyday, mundane features of the television set. This difference can be accounted for by looking at a life cycle model of the history of the remote that I propose in the next section.

It is my contention that a preoccupation with the "new" directs a great deal of our interactions with technologies and that this preoccupation has particularly affected the case of the remote control. We expect that a new technology will give us a new way of interacting with media, and the case of the remote control is a prime example of this. In this project, I compare the academic literature on the subject of the remote control device (published primarily in the 1990s - a decade after the time of popularization and distribution of the remote control to consumers) with newspaper advertisements from the 1970s and 1980s. These two points of analysis show two very different understandings of this technology. The academic literature is concerned with the ways in which users of the time were accessing and using the "new" technology. This concern with the new is also reflected in debate surrounding technological determinism and its role in understanding historical technologies. In contrast, the symbols in the advertisements I analyzed did not 
focus on the "new" in any substantial way. By and large, the advertisements I saw focused on the banal, the mechanical and the technical features of the remote controls.

It is my contention that the academic perspective and the consumer perspective represent two different types of thinking about technology. The academic material is indicative of how we think we think about technology at a particular moment in a technology's history. It shows what we expect to find when we look at technological history and is representative of the theoretical questions asked and answered in studies of technology. On the other hand, the consumer realm represents a different discourse about technology. While no more rooted in a tangible "reality", advertisments provide a different perspective on the technology. I contend that these products demonstrate the kinds of messages that everyday people interact with about technology and that those messages speak to how consumers feel about the technology at that time in history. This project investigates the ways we understand technology and historicize technology. I argue that looking at technologies as part of a longer continuum of development provides a more complete understanding of the role they play in our lives.

\section{A. Linear History of the Remote Control Device}

This section focuses on the history of remote control technology and takes a critical standpoint on the way histories of technology are traditionally communicated in academic literature and to the public. Most histories of technology are written within a chronological framework, and this history is no different. The problem with chronological histories is that no technology is created on the spot, out of thin air. A more in-depth discussion of this perspective follows in my discussion of the framework of the "new", but it is worth mentioning here because it affects how I choose to communicate 
the history of the remote. The creation of technology, much like the creation of an idea, is an ever-evolving process that builds on past situations and products (Gitelman, 2006 and Crane, 2003). The iPhone did not appear in Steve Jobs' mind one day out of the blue; it was an amalgamation and extension of many technologies that came before it (the cellular phone, the telephone, the telegraph, the $\mathrm{CD}$ player, the record player, the victrola, wax cylinders and the human voice are just a few of the technologies that directly influenced the creation of the iPhone). The point is that all technology is built on a potentially endless succession of earlier technologies. The remote control is no different, and following the traditional model of histories of technology, I start by explaining that the impetus for remote control technology existed in the time of radio. As consumers used radios in their kitchens and living rooms, the desire to control the technology from a physical distance of a few feet away spawned attempts at both wired and wireless remote control technology (Benjamin, 1993).

As television became prevalent in American homes, several wired devices were invented to help the viewer control the television from across the room. An engineer named Robert Adler who worked for Zenith developed one of the first wireless RCD models in 1956. The "Zenith Space Command" was Eugene F. McDonald's (founder and president of Zenith) answer to a major problem he saw in the television industry. McDonald believed that "unless viewers could somehow circumvent commercials, the ads would kill television" (Benjamin, 1993, p. 18). It is interesting to note that the device was developed with the explicit purpose of avoiding commercials (at least in this caseother models developed at the same time without proof of this intent). Other early 
versions of the wireless remote control were sound-activated; but their functionality was limited and caused problems when other loud noises activated the devices.

\section{B. The Life Cycle of the Remote Control Device}

The linear history of the remote is informative, but I propose looking at the remote control through a different model. I chose the life cycle model for this discussion because the three stages of life have similarities to stages that media technologies go through. The childhood of a technology involves its creation, its redesign (when features are found not to work correctly) and its introduction to the consumer's experience. I am using the term adolescence to describe the time period in a media technology's life when it is being accepted by users, but there is a struggle and negotiation for how it will be used and what that use will do to a mediated experience. In my model, the adulthood of a media technology means that the technology is stable, the way it is used is settled and there are no great changes to its design or function. One important characteristic of the life cycle model is that, like a human life cycle, change is always taking place. The difference between adolescence and adulthood is the rate and type change that are likely. A person between the ages of twelve and eighteen is more likely to fundamentally change their personality than is an adult between the ages of twenty-five and sixty. The scale of changes I talk about with the remote control correspond to the scale of change in human life.

As will be made clear in the literature review that follows this introduction, the academic work that discusses the impact of the remote control (written mostly in the 1990s) focuses on the 1970s and 1980s as the time period where remotes became popular and an accepted part of the television viewing experience. I argue that the literature 
focuses on when remote control devices were "new". The life cycle reflected by the

literature on RCDs is represented in the following table:

\begin{tabular}{|l|l|l|}
\hline Life Cycle & Description & Time Period \\
\hline Childhood & $\begin{array}{l}\text { Early models of the remote controls are } \\
\text { designed and tested; a few are sold with } \\
\text { advanced television sets. }\end{array}$ & $1950-1960 \mathrm{~s}$ \\
\hline Adolescence & $\begin{array}{l}\text { The remote control is a new technology } \\
\text { present in the home. Users negotiate how the } \\
\text { technology will be applied to their experience; } \\
\text { there is a struggle to adjust to the new } \\
\text { technology and its effects. }\end{array}$ & $1970 \mathrm{~s}-1980 \mathrm{~s}$ \\
\hline Adulthood & $\begin{array}{l}\text { The remote control is a standard feature with } \\
\text { television sets; functionality of the device } \\
\text { expands and it is accepted as part of the } \\
\text { television package and viewing experience. It } \\
\text { has a relatively static impact. }\end{array}$ & $1990 \mathrm{~s}$ - Present \\
\hline
\end{tabular}

Table 1: Traditional History of the Remote, Life Cycle Model

My case study did not reflect the fact that the remote control was a new

technology in the advertisements I looked at from 1975-1985. Instead, I found evidence

of a technology that was stable, everyday and accepted. This discovery led me to rethink

the life cycle model of the remote control's lifespan and reassign the adolescence to the time period of the 1950s and 1960s. As the table below demonstrates, this shift puts the period of my research into the category of adulthood, not adolescence as expected given the literature on the RCD that I read. I propose the following new categorization of the RCD's lifespan: 


\begin{tabular}{|l|l|l|}
\hline Life Cycle & Description & Time Period \\
\hline Childhood & $\begin{array}{l}\text { The idea of remotely controlling technology } \\
\text { exists in the minds of consumers and is } \\
\text { developed by inventors. }\end{array}$ & - 1950 \\
\hline Adolescence & $\begin{array}{l}\text { Early models of the remote controls are } \\
\text { designed and tested; a few are sold with } \\
\text { advanced television sets. Users negotiate how } \\
\text { the technology will be applied to their } \\
\text { experience; there is a struggle to adjust to the } \\
\text { new technology and its effects. }\end{array}$ & $\mathbf{1 9 5 0 - 1 9 6 0 s}$ \\
\hline Adulthood & $\begin{array}{l}\text { The remote control becomes a widely used } \\
\text { consumer product; it is sold as part of the } \\
\text { television package. Functionality of the device } \\
\text { slowly expands and few changes to the user's } \\
\text { experience occur as a result of the technology. }\end{array}$ & \\
\hline
\end{tabular}

\section{Table 2: Revised Life Cycle Model of RCD Technology}

The consumers who were looking to purchase televisions in the 1970s and 1980s were quite familiar with the idea of the remote control, even though they may not have owned one previously. And if they had been hearing about the technology for some twenty plus years, it makes sense that they would not regard it as "new" at all. The ambiguous terminology surrounding the new will be further explored in the next section, and will also be used as lens through which I conduct my case study analysis. The relationship between consumers and technologies is greatly affected by the idea of the new and that is why this life cycle model helps to make sense of the surprising results of this project.

\section{The Framework of the New}

In reading through literature focused on the relationship between "new" and "old" technology, I came to one overarching conclusion that informs the way I approach the topic. My idea is this: technology is a unique combination of the new and the old. Context and content change, but form, purpose and use stay remarkably stable. This claim is supported by the literature I have reviewed on the idea of "new media" and 
"media in transition". Thorburn and Jenkins' work Rethinking Media Change is filled with examples of how the "new" is nothing more than the "old" with a few changes to the packaging, location of use, or application. Gregory Crane (2003) examines the history of the written word and argues that the codex is no more inherently valuable than the scrolls or tablets that preceded it. Histories of technologies often omit other preceding ideas that contributed to the "new" technology's development.

Many of the contributors to Spigel and Olsson's (2004) Television After TV focus on specific technologies as a catalyst for major change. They identify the technology as the causal factor in major social and political movements that affected the course of western history. An example of this is William Boddy's (2004) essay on interactive television, which focuses on the changes brought about by the Tivo: "in 2001, the deteriorating advertising market and the technological threat of ad-thwarting personal video recorder had combined to create a climate of increased network accommodation to advertiser wishes" (p. 121). The cause and effect scenario laid out by Boddy is characteristic of many accounts of technological history across genres. This approach underestimates the cultural context and social climate that existed when the technology was invented. David Edgerton's (2007) work offers a strong counterargument to the viewpoint present in the collection from Spigel and Olsson. Edgerton (2007) finds fault in the innovation-centered approach to history that we are used to. He argues that investigating use based history of different technologies reveals a more accurate picture of their role in our society because examining use provides historians the opportunity to talk about what people did, not just what they think happened. Use studies allow researchers to do more than speculate on what the effects of technology might have been. 
I used this body of literature and the assumptions presented within the works as my starting point for this project. This literature is indicative of academic thought on the subject of media in transition and the history of technology. As Spigel and Olsson's work indicates, the new, the changed and the progressive are the ideas that drive much academic work on the subject of technology and media (a view contested by Thorburn and Jenkins).

This project is a departure from the usage studies employed by so many of the other RCD scholars in that it addresses the remote control from the perspective of the consumer and the companies that advertise televisions. The semiotic analysis that I undertake is based on a theory of representation, where the cultural artifact of a newspaper advertisement represents a host of themes that users and consumers interacted with at the time of their viewing the ad and buying the product. The act of representation is significant here. As Stuart Hall (1997) notes, "it is by our use of things, and what we say, think, and feel about them —how we represent them—-that we give them a meaning" (p. 3). As Hall points out, use is certainly important to an understanding of the impact of a technology on a society, but more than that, how we choose to represent the technology is also important because it defines and is defined by the actual role the technology plays in our lives. This view is characteristic of social constructivism in that "representation is conceived as entering into the very constitution of things; and thus culture is conceptualized as a primary or 'constitutive' process...not merely a reflection of the world after the event" (Hall, 1997, p. 5,6). Social constructivism holds that social life is a constructed reality, one that is created through processes of language and symbolic form. It is this view that underpins my semiotic analysis. 
The process of representation (which semiotics seeks to denaturalize) is a point of connection between objects and their meanings. Hall (1997) states that representation is "the link between concepts and language which enables us to refer to either the 'real' world of objects, people or events, or indeed to imaginary worlds of fictional objects, people and events" (p. 17). It is this point of interaction that interests the semiotician and those who seek to understand symbolic meaning through text. The work of Judith Williamson (1978) showcases one type of theory about representation. The relevance of her work comes from her specific analysis of advertising as a representational medium. What interests me about Williamson's work is the theoretical orientation it takes and where it places advertising and representation in the process of making meaning. Williamson's (1978) argument is that beyond working to sell goods, "advertising creates structures of meaning" (p. 12). These structures of meaning are the messages that go beyond the literal meanings presented in the ads. She clarifies that, "the components of advertisements are variable....and not necessarily all part of one 'language' or social discourse. Advertisements rather provide a structure which is capable of transforming the language of objects to that of people, and vice versa" (p.12). In this way, advertisements can personify products, compare them to human feelings or emotions and create structures of meaning that go far beyond the simple use of the item.

Williamson's orientation supports the stance that I take by choosing advertising as my data sample. Williamson (1978) outlines the core of her approach to representation; "advertisements are selling us something else besides consumer goods: in providing us with a structure in which we, and those goods, are interchangeable, they are selling us ourselves" (p.13). This cyclical idea, that we are created by the advertising texts we view 
(which then impacts how the advertisements are crafted, which again impacts our social selves) demonstrates Williamson's belief that the advertisements are only effective in so much as they mirror what we think and believe. We see in the advertisements pieces of ourselves that already existed and because of that, we buy into the ideas being sold. I want to stress the importance of Williamson's contribution here. She holds that advertising sells us the things we already believe about our life and experience. Advertising is a reflection of our beliefs, which means that whatever I find in my analysis of the ads for remote controls represents what consumers at that time believed about the product.

Advertising is a type of representation, whether that representation is carried out through print, television images, audio materials or through the internet. Advertising as an industry has an interesting history and is connected to the funding and privatization of communications media like newspapers. Leiss, Kline and Jhally (1990) outline the origin of the newspaper as a part of the technological development of the printing press. According to their history, the newspaper began as a communal medium that was shared by participants in coffee house settings. As the cost of newspapers dropped, people began to access the information in an individual setting, and the newspaper industry began to focus on attracting specific readerships through targeted content. According to Leiss, Kline and Jhally (1990), "all subsequent media developments have extended this trend toward communication as a privately owned and personally used household good" (p. 97).

Leiss, Kline and Jhally (1990) create a typology of the different stages of advertising in the United States. Each of those stages is loosely correlated with a 
communicative format for advertising products. The first is a product-oriented approach (most popular from 1890-1925). This approach to advertising focused on a descriptive account of the product's features and specifications, it employs rational logic to provide information that will convince the consumer that the product fulfills their need. The second stage of advertising was most commonly used from 1945-1965 and is called the product-image format. Product-image advertising involves a relationship between the product, the setting or context in which it is used and a symbol that speaks to the reputation of the product. This type of advertising is the first to use branding practices that help establish symbolic meaning in the product beyond its use. Stage three of this scheme is called the personalized format (most popular from 1945-1965) and it is the result of the influence of television in advertising. Television allowed for a much more personal approach to advertising than had come before in print and radio, and in this form, the product "no longer stands as an autonomous object independent of the human world, but rather is displayed as an integral part of the codification of human existence and interaction" (Leiss, Kline and Jhally, 1990, p. 254).

The final stage in the categorization of advertising types presented by the authors is called the lifestyle format, most prevalent from 1965-1985, which encompasses the time period relevant to the research sample in this project. The lifestyle format involves specifically targeting types of consumers that fit into different specialized lifestyle markets (as opposed to one homogenous mass market) and relies on advertising that sells the image and cache that accompanies a certain product. In this stage of advertising, the brand represents symbolic meaning beyond the use value of the product. These four stages are not bounded categories; different advertisements can easily fall into two or 
more of the stages because of the type of product they are selling. This scheme does not indicate that the types of ads identified in each era were the only kind printed, but rather that the type of ads described most aptly categorizes that era. According to this typology, I would expect to see that the ads for remote control devices in the 1980s were targeted at specific populations and used imagery and language that invoked feelings about certain lifestyles or identities. As will be apparent in my semiotic analysis, I did not find that to be the case.

There is a connection between the material and the symbolic that informs this project. To underscore the importance of advertising in making social meaning, Leiss, Kline and Jhally (1990) characterize advertising as "the privileged discourse for the circulation of messages and social cues about the interplay between persons and objects" (p. 50). The idea that advertising is the privileged discourse for how people understand goods in western society highlights the consumerist view taken by advertising scholars. This positioning of advertising as the authoritative communication on cultural artifacts negates other forces like social interaction, educational programs, family and cultural group influences. Leiss, Kline and Jhally (1990) indicate that "advertisements as a system may well anticipate and amplify certain value changes that are in progress and deemed relevant for ads to particular segments of the population" (p. 271). These authors imply that advertisements have the power to shape the values of the people who read them. This assumes a great deal of influence that the advertising industry (and the products and companies that fuel that industry) has on cultural experiences of a consumer population. Having established my research questions, I will now briefly outline the form the rest of this argument takes. Chapter 1 of this project is a literature review that 
encompasses material that deals with the academic study of the RCD and (to a lesser extent) the VCR. I have chosen to include the two devices together because their development came about at a similar point in history and because the use of one helped encourage the use of the other. All of the works I review are use-based studies that focus on how often and in what ways people used the RCD technology. The focus on use implies a technologically deterministic frame on which the study of technology (within the social science and about RCDs specifically) rested. It also underscores the idea that remote control technology was new at this time and therefore worthy of systematic study. It is this orientation in the literature that I set this project up against. Using a representational analysis in combination with the revised life cycle model of the history of RCDs that I propose contributes to a more complete understanding of the technology at this time. The remote control was not advertised as part of the revolution scholars discussed at the time and because of this, I argue that the remote control in the 1970s and 1980s was in the life cycle stage of adulthood, not adolescence.

The second chapter in this project is a discussion of one theory that I use to investigate the communication of this technology. It focuses on the theoretical framework of technological determinism, using a history of the theory and a brief review of some interpretations of the theory to explain its significance to this project. I discuss the context of the American Revolution and the subsequent development of a new nation that was tied up in technological developments. This period impacted the American understanding of technology's role in society in significant ways, and some of the views around technology that developed at this time still affect the way advertisers represent 
technology in their advertisements and are part of the way we still think about technology.

The third chapter in this project explains my methodological approach to the case study I investigate. I outline the major concepts of semiotic analysis and discuss the implications of this approach at the levels of epistemology and ontology. The concepts I identify as significant for my approach include Saussure's notions of the signified and signifier (which comprise the sign), Barthes' conception of myth and the use of literary devices. Through a brief methodological review, I conclude that the most effective semiotic analyses use a particular concept as a lens through which to view the texts. The lens chosen for this project is the notion of the new that I established as part of the discourse surrounding contemporary technologies and that is present in the literature on the remote control device. This focused approach gives more structure to a methodology that is based on a close understanding of social history and context.

The fourth chapter contains my semiotic analysis of the advertisements for the remote control device. I begin the chapter by outlining the exact sample and applied method that I will use for the case study in this project. In the analysis that follows, I draw connections between some of the signs I identify in each of the articles and the theoretical notions of representation and technological determinism that have been outlined in my theory section. The analysis in my case study (compared with the academic literature I found on the RCD and the linear history of the remote control) backs up the major argument I make in this project. The academic literature available on the RCD suggests that the scholars who focused on it did so from a use-oriented perspective. This perspective is indicative of deterministic attitudes that underpin how 
technologies are thought about and theorized. My case study shows that the ways the technologies are communicated to consumers differs greatly from this academic perspective; the technology of the remote control is not sold through rhetorical devices that stress the importance of the new, the changing or the innovative. As indicated by my sample, they are sold through very mundane, functional terms that describe very little about the use value of the product. Highlighting the tension that exists between the academic literature and the consumer texts from the same time is one contribution this project makes to the field of technology research.

In the final chapter of this project, I expand on and attempt to elucidate some of the significance behind this tension. I use the theoretical background of the project to discuss why the disparity might exist and what that says about our relationship to technology. We are at once the creators of technology and the victims of it-it is an extension of our prized rational thought, but one that we do not fully understand or control. Technology is surprisingly personal because of this relationship to rational thought that has been lauded in our society since the Enlightenment. It is this particular feature of technology, the combination of the personal and the impersonal, that contributes to the tensions I identify in this project. My attempt to understand technology is likewise a product of this tension. This project shows that the way we think we think about technology (or the way we would like to think we think about technology) differs from how we actually interact with it. I can only begin to investigate and understand the nuances of this difference, but this project allows me to participate in a discourse about these ideas and consider what these observations might mean in a society fully preoccupied with technology. 


\section{Chapter 1: Adjunct Television Technologies, the Academic Perspective}

\section{A. RCD Research}

This literature review will focus on three major works in the area of RCD

research. The work done in this area is limited, and none of the sources I have identified originate in Canada. Due to the limited amount of research on the topic of the RCD specifically, I have also included a review of work that deals with the VCR. The literature on the VCR is relevant to my study because it also addresses the issues that surround other peripheral devices that are used to enhance or alter the television experience, advertising and audience behaviour. The two areas of research combined provide a broad basis on which the analysis of this technology is made. Also, the two technologies are linked to each other because they were introduced at similar times and their functions both contributed to the increased use of the other. It is worth noting that all of the research reviewed here is from the late 1980s and 1990s. The time period is important because the work within it is likely speaking to the time of popularization of the remote control that I focus on in my case study (the 1970s and 1980s). This is the case because of the time lag between the point of research and the point of publication in scholarly work. The research presented here understands both the remote control and the VCR as new technologies that had new and unexplained impacts on the users who purchased them. These two devices are part of a larger discourse about products and services that enhance or change the viewing experience (gaming systems, satellite and cable television and DVD players are other examples). The overall finding of this review is that, for the most part, social studies of RCD technology are use-oriented. Most research is concerned with finding out where, when and how the RCD or VCR is used. Some of the studies referenced here also take up the question of why these technologies are used, but that 
work is certainly in the minority. This review shows that in the early 1990s, research on the RCD focused on use, not on representation of the device. This is very likely because the use data was important to the companies that rely on advertising revenue from commercials in television programming. At this time in social science research, there was also an inclination towards audience research and audience ethnography which likely influenced the work. Their financial interest in audience research combined with the tendency in communications research at the time to use social science methodology probably contributed to this amount of use-based research. The first work I will incorporate into this review is Video Playtime: The Gendering of a Leisure Technology by Ann Gray. Gray approaches the subject of VCR use in the home through an extensive amount of interview research conducted in the homes of thirty British families in 1984. Her investigation centers on gender, and she speaks to the women in the households who each report their families' VCR usage. While the work focuses more directly on the VCR, it also addresses the RCD in one particular chapter, and the discussion of the VCR is also informative for an understanding of RCD use because the two technologies implicate similar arguments and ideas. I have chosen to include this work here because I feel it is representative of the types of studies I have found on the RCD (which are fairly rare). The interviews conducted by Gray and her team took place in the home, and as she explains, "what the women said to me does not directly reflect their experience, but it is their way of articulating that experience" $(1992$, p. 33). Gray (1992) readily admits that this type of study has both strengths and weaknesses due to the influence of interpretation (both the interpretation that happens at the level of the interview subject and at the level of the interviewer who records the information). 
I found two themes pertinent to my own project that emerged from Gray's book. The first theme I found is that many of the households used the VCR technology to engage in time-shifting of their television programming. According to Gray (1992) timeshifting is the "recording from broadcast or narrowcast television for viewing at a different time" (p. 191). Many women reported using the VCR to time-shift programs they liked to watch but that their husbands or families did not want to see. Michelle, for example, explains, "I tape sort of medical things...the AIDS programme and things like that, I will watch when he isn't in because he won't want to watch them" (Gray, 1992, p. 200). The concept of time-shifting draws on one of the major fears expressed by television network executives-that the VCR and RCD combined would give the viewer the power to change the television schedule and therefore direct their own experience. When a technology gives the viewer the power to control more of their media experience, it significantly changes the relationship between the audience and the network. Gray's discussion of time-shifting is a good example of some of the effects of the changing relationship between the consumer and the producer. Gray's work shows where the fears about the changing television landscape expressed by network executives were coming from.

The second theme I identify as pertinent to my project is one that Gray touches on only briefly. She asked participants to describe how the household came to the decision to purchase or rent the VCR. Most often, the decision to invest in the technology was instigated by the male in the family. Based on the responses she gathered from the participants, Gray (1992) infers that "the ways in which consumers are addressed through advertisements on television, in the press, and in magazines would seem to have an effect 
in terms of the assumed knowledge and use of specific pieces of equipment in the home" (p. 189). The advertisements Gray addresses here are precisely the focus of this project; she draws a connection between the reputation of the technology and the decision in the home to purchase it.

Gray used audience research to investigate the gendered nature of both leisure time and a leisure technology (the VCR). Her use of interviews allows her to present a large amount of in-depth data that relates to specific people and very specific familial situations. The women who self-reported their VCR usage were able to relate how they thought and felt about the technologies in their homes. The interview approach adds value to the conclusions drawn by Gray because it expands on usage data to include how people felt about their experiences. Her work lays a useful foundation for my study because it establishes that people did use remote control and VCR technologies; it also establishes that there is a great deal of meaning-making going on in the home and in front of the television that warrants further investigation.

The second text I investigate is Bellamy and Walker's Television and the Remote Control: Grazing on a Vast Wasteland. The book is largely an analysis of audience use data on the remote control Bellamy and Walker carried out in the early 1990s. The time period here is significant in that Bellamy and Walker performed their research ten years after the point I identify as the time of popularization and use of the device. Their work assumes the RCD is in an adolescent stage of life (just after the infancy of introduction). My own categorization marks this time period as adulthood, not adolescence and challenges the assumptions they make about the conditions in which people used the technologies. They tracked how often an RCD device was used in both a laboratory and 
home setting. They also incorporate large samples of other academic and non-academic studies on this same phenomenon (for example, they cite Ferguson (1994), Kaye and Sapolsky (1995), Heeter et al. (1988), Bryant and Rockwell (1993) and Eastman and Newman (1995)). The summary of this large amount of data leads Bellamy and Walker (1996) to report that RCDs are definitely being used in the home, and that their presence significantly affects user-television interactions.

Bellamy and Walker identify three major uses of the remote control that correspond with different audience behaviors. The most common use they identify is "zapping (using the RCD to avoid advertising and other undesirable content)" (Bellamy and Walker, 1996, p. 3). The second type of application for the RCD they talk about is "zipping (avoiding content by fast-forwarding through recorded programming)" (Ibid., p. 3). And the final use they describe is "grazing (combining disparate program elements into an individualized program mix that serves a wide range of gratification from amusement to information seeking)" (Ibid., p.3).

Of these three, the television industry is mostly concerned with the first, zapping, because it has a direct impact on the amount of advertising being seen by the viewer (which negatively affects the ability of a station or network to fund their television programs). I believe that Bellamy and Walker's discussion of grazing is a somewhat failed attempt to show that the audience has a new type of control over their media sources. Throughout this work and their edited collection that I will review next, Bellamy and Walker seem to be trying to make the case that the RCD allows the user to create an utterly new viewing experience for themselves. They refer to this quote from Umberto Eco: the remote control can be used as a paintbrush "to make the television into a 
Picasso" (Bellamy and Walker, 1993, p. 115). I think their explanation of grazing greatly overstates the impact of the RCD. Yes, it changes some parts of the relationship between user and content, but the overall viewing experience is still tied to the content produced by the networks and their subsidiaries. This disagreement I have with their view can be explained, in part, by my altered categorization. I think Bellamy and Walker are assuming that this technology is in adolescence. In their view, the remote control is going through the process of having its purpose and agency defined. Users are finding new ways to employ it to their own advantage and are using it in new and dynamic ways. If I apply my own categorization and say that the remote at this time period is in adulthood, a stage when its uses are established and understood by the users, the idea that grazing allowed viewers to define their own viewing experience is less likely. Perhaps people were not using their remote controls as artistic paintbrushes, but simply using the devices they were quite familiar with to change the channels and watch different programs. The fundamental shift (if there was one) would have occurred ten or twenty years before this study when the adolescence I propose took place.

In addition to the useful typology they establish and discuss, Bellamy and Walker also highlight a connection that provides background information for this project. They demonstrate the simultaneous expansion of the cable industry and VCR production with that of the RCD. They go on to further explain the threat this new technology posed to the television industry; Bellamy and Walker (1996) claim that "although advertisers had long been aware that viewers avoid television commercials by leaving the room, talking, reading or simply day dreaming during commercial breaks, the RCD posed a clear threat to television's captive audience" (p. 28). 
The third work in this literature review is an edited collection focusing on the RCD by Bellamy and Walker. This book is called The Remote Control in the New Age of Television. An important contribution of this volume is a study of RCD use by Bellamy, Walker and Traudt. In this study, they expanded on their previous work to include a more direct measure of adult use of the RCD in the home. Bellamy, Walker and Traudt (1993) conducted telephone interviews about RCD use in the home with a particular focus on the different gratifications sought through use. Bellamy, Walker and Traudt (1993) isolated six main gratifications employed by RCD users: "selective avoidance, getting more out of television, accessing music videos, annoying others, avoiding commercials, and finding out what's on television" (p. 104). The findings in this updated study reaffirm some of the conclusions drawn by Bellamy and Walker in their 1991 study, and also shed further light on the area of advertising avoidance. Their results show that "two of the higher ranking gratification items concerned commercial avoidance; of the seven gratifications identified, avoiding commercials was the third most strongly related to RCD use" (Bellamy, Walker and Traudt, 1993, p. 111). Again, this type of study establishes what both advertisers and industry executives had long suspected: people use their RCDs to avoid the advertising that finances television production.

The next work relevant to my study of the RCD is an article published in 1988 in Channels magazine. Almost all of the academic works that I read on this topic reference this work in some way or another. It is a useful piece because it represents one aspect of the popular discourse engaged in by consumers in the late 1980s. The title of the entire supplement is "How Americans Watch TV", and there are several subsections dealing with different themes. The first section I will discuss is called "The New TV Viewer". In 
this part of the article, Ainslie (1988) profiles the changed nature of the average television viewer at this time; "Channels discovers that today's audience is a highly critical, highly mobile lot, but plagued by the same old ambivalence toward the medium" (p. 53). Ainslie (1988) positions the audience as the active force in the world of television; they are smart, on the go, and familiar with the technology in a way that previous generations of television viewers were not. In this section, Ainslie (1988) outlines the methodology used for the study published in the article. The data were collected through 650 telephone interviews of approximately thirty minutes in length each over a period of five days in 1988. As with any interview data, it is possible that respondents misremembered their actual RCD usage or chose to exaggerate or understate some part of their interaction with the technology.

The major thesis of Ainslie's (1988) article is that America is a "Nation of Grazers" (p. 54). He boldly categorizes the power the remote control device gives the viewer; "now viewers are using their ubiquitous remote controls, presently in the TV rooms of some 66 million American homes, to play program judge, jury and executioner" (Ainslie, 1988, p. 54). The language used by Ainslie reflects the fact that this work was published in a popular magazine to a general audience. The active, dynamic viewer profiled by Ainslie is one that fits with life cycle stage of adolescence. The new viewer that Ainslie talks about is the result of the "new" technology of the remote control-a technology that is being integrated into consumer experience.

The reasons for grazing identified by Ainslie (1988) are reported as enjoyment of grazing, dissatisfaction with programming, avoiding commercials, boredom and watching more than one television program at a time. The data collected are further broken down 
into categories of male, female, age ranges, incomes, geographic location and type of technology used. This set of data provides evidence that in the 1980s people were certainly using the remote control to change their viewing experiences. The impacts of these new ways of viewing are not as clearly supported by Ainslie's study. The conclusions drawn by Ainslie are as follows: "inadequate programming is clearly the greatest tune-out factor, not commercials... and grazing is only likely to grow" (p. 56). Improved content (of both programming and advertisements) is heralded as the means by which the audience can be lured back to a single-channel experience. Former NBC president Grant Tinker is quoted in the article as saying, "and now the technology and shorter attention spans and perhaps the boredom factor are causing the audience to be highly mobile. It behooves us therefore to make better and more appealing programs, but it's a tough assignment" (Ainslie, 1988, p. 62). Then vice-president of CBS, David Poltrack also weighed in on what the future of television programming looked like in the new remote control world; "the higher [the] level of viewer involvement, the more secure you are against the grazing effect. That level of intensity, watching two shows at once, is fabulous. And as long as we keep our breaks at the same time, you can't run away from the commercials" (Ainslie, 1988, p. 62). The focus of both of these testimonials is on the importance of the economic system underpinning the television industry. The networks have a financial bottom line and they recognize that the only way to deal with the RCD is to embrace it as a fact of viewing and to work with the new system it helped create. This industry perspective of the issue of remote control technology and what its perceived effects were at this time period is a valuable contribution of this work. This is evidence 
that the industry reacted to the studies put forth by Ainslie and other researchers noted in this literature review.

The works that discuss the RCD construct the new viewer of this time as a product of the technology and of the changing industry. Both the academic work and the evidence from within the industry use the mythology of an ideal viewer to talk about the consequences of new technology. In the academic works (specifically in Bellamy and Walker (1993)), the ideal audience member is one who actively participates in the creation of their viewing experience. Remote control in hand, they are able to create a televisual landscape that reflects their own personality and viewing style. The viewer is given the power to create their own experiences because they control the technology. In the industry interview I reviewed above (from Channels Magazine), it is clear that top executives also constructed an ideal viewer for their medium. Their version of the ideal viewer is highly intelligent, also in control of their viewing experience, but ultimately susceptible to the power of the creative content that the industry can produce. Together, these two camps create an image of the ideal television viewer that suggests that remote control technology puts the power in the hands of the audience. This idea will be investigated further in my case study, where I look at how remote controls are advertised during this time and whether those ads reflect these discourses. I contend that this ideal viewer fits in the adolescence stage of the life cycle model of the technology I explained earlier. This type of person is able to use the technology to create their own viewing experience and that is made possible in a time of change and unsettled boundaries. 


\section{B. VCR Studies}

The next few works I discuss here stray slightly from the topic of the remote control specifically and focuses on a closely related technology: the VCR. The VCR is implicated in this discussion because it too caused controversy in the world of television viewing in the 1980s when it became a part of many people's viewing habits. The most relevant part of the VCR controversy to this project is the fears that arose around the practice of "zipping". For the most part, "zipping" refers to the process of fast-forwarding through a taped program (either to avoid commercials or to skip portions of content, and the former is more commonly the reason). Some authors refer to "zipping" and "zapping" (the use of a television RCD to change channels and zap away commercials) interchangeably or with reversed meanings from what I describe here, but the majority of references to the two terms highlight the uses described. The act of zipping was as much a cause for concern within the literature as was zapping. The reason I choose to highlight studies that focus on the VCR and zipping is that while it may be a process made possible by the VCR, it is unlikely that audiences would zip without the use of a remote control. It is the remote control (in conjunction with the VCR) that profoundly impacts the viewing of television in this case.

Given this, my discussion of VCR technology here will be focused on how the VCR is used and where that use is impacted by the remote control itself. The first book I review in this section is Social \& Cultural Aspects of VCR Use (1990) edited by J. R. Dobrow. This book is a collection of essays from various scholars on different topics related to VCR use. Of greatest relevance to this project are chapters on the history of the technology and on audience activity and VCR use. Eugene Secunda contributes a chapter 
that integrates a history of the television industry with the rise of VCR ownership in the American household. As with most histories, Secunda (1990) presents a linear timeline of the development of different types of recording technology; he notes that a strong competition for market share began between American companies and Japanese manufacturers. Japanese companies (like Sony and later JVC) dominated the market early on; this left American companies the option to become little more than distributors. According to this history, the eventual domination of the VHS format (over the Betamax) came about because Sony underestimated the potential popularity of being able to record television programs in the home. According to Secunda (1990), "Sony's management...continued to believe that the majority of potential customers would be content with one hour of recoding and playback capability. This view proved devastatingly wrong, as JVC and other competitors in the consumer electronics field later established" (p. 15, 16). Secunda's (1990) chapter points out that the issue of home recording was a key factor in the commercial success of the VCR. The ability of consumers to participate in home recording played a large part in the success of the Japanese technologies over the American ones. Home recording is made attractive to viewers through the advent and implementation of the RCD.

The second part of this work that is relevant to this project is the audience use data collected by Carolyn Lin. Lin (1990) used a telephone survey to assess VCR use among suburban residents of the American Midwest. She measured selectivity (how participants chose their viewing material, whether they used program guides etc.), involvement (how much zapping a participant did) and utility (how often participants discussed material with co-viewers). Lin (1990) also measured VCR-use activity through 
asking how often participants recorded programming and how many times recorded material was played back. Two additional measures were recorded; VCR-use satisfaction and TV-viewing quality. All of the measures listed above were taken in order to get a firm understanding of quantity and quality of use of the VCR and television programming through the VCR. Lin (1990) argues that, "audience activities comprise the selectivity, involvement, and utility aspects of the media process, which may reflect an audience member's cognitive, affective and behavioural involvement with the process itself' (p. 77). The questions she addresses allow her to make arguments about how people use this technology. A relevant finding of the study is that fifty to sixty percent of the participants were involved with the viewing process, meaning that they zapped commercials, changed channels and reselected viewing choices. The data show that people at this time were involved in the process of viewing television and that their involvement often included the use of a remote control device. Another result from the study indicates that although people do record programming, only fifty-six percent of people play back any of that material (Lin, 1990). This indicates that time-shifting is perhaps not as influential as industry executives feared. Lin (1990) argues that, "VCRs may transform TV from a mass to an individually or perhaps family-oriented medium. And, because VCRs are the most widely diffused of the new technologies, most people are getting their first experience with enhanced audience control through that medium" (p. 90). Lin (like many other authors referenced here) speaks to a shift in control for the users. The remote control plays a significant role in this shift because of the convenience it provides. Playing back recorded material would be a much greater hassle if the viewer had to kneel at the TV cabinet and hold the button down. The ability to skim material 
using the fast-forward or rewind controls from a comfortable position across the room brings a different level of control (and utility) to the television viewing experience through the VCR.

Lindlof and Shatzer (1990) contribute a chapter to Jennings' text on television and the family that focuses specifically on VCR use in the home. After reviewing the selfreport studies available on this topic, Lindlof and Shatzer (1990) chose to use a qualitative methodology to discern six family's recent VCR usage. They combined survey data, diaries recording usage, interviews and observational visits to the home to create a reliable measure of usage. Their findings suggest that families make recording decisions based on the emotional needs of the children as well as through family alignments which determine which people like to watch which shows. Lindlof and Shatzer (1990) conclude that, "it seems that the VCR introduces a qualitatively different access element by allowing participants greater control over the available resources of the viewing situation...The nature of the content is part of [the] determination, but does not in itself determine access" (p. 101). The theme of a struggle for control over the technology and over the content of the television medium reappears throughout the RCD research and the VCR research I consider here. The idea of a struggle for control is best reflected in the life cycle categorization of the adolescence. As mentioned before, the adolescence is a time when technology users attempt to carve out the roles and uses their technology will perform within their media experiences. A struggle for control certainly fits within this idea.

A related work in the field of VCR research is Mark Levy's 1989 work The VCR Age. The title of the book orients the reader towards the stance taken by Levy; television 
and film viewed through the mechanism of the VCR represented the defining characteristic of an entire age. Levy (1989) talks about the VCR as not quite a "revolutionary technology" because it fails to meet two conditions: it "has not achieved any special priority in terms of its perceived utility to gratify various needs and has thus not established an identity separate from television and movies" nor has it "lived up to its potential to provide an increased range and diversity of program content"' (p.11). Revolution aside, Levy argues that the study of the VCR is a useful one because at the time, the study of communication was focused on mass media, a term that the existence of home video viewing begins to challenge.

One of the chapters featured in Levy's edited collection discusses the way people use the different technological features of the VCR. Akiba Cohen and Laura Cohen (1989) believe that the power of the remote control is fairly benign; they hold that, "even a remote control unit does not allow for more features; it simply allows the viewer to operate the set from the sofa or bed" (p. 136). This perspective on remote control use is important to include here because, while I argue that the remote signifies a great deal more than its simplest utility, there are those like Cohen and Cohen (1989) who would counter that, "a television is a television is a television" (p. 135). The idea that all television sets are pretty much equal to one another and that their use can be discussed in all or nothing terms holds some value. There are not major differences between television sets that affect viewing behavior.

The researchers concluded that many people have an incomplete knowledge of the workings of VCR technology. Cohen and Cohen argue that, "these findings reinforce the thesis that the VCR age has not brought with it a profound change in the use of mass 
media technology" (p. 145). This study is important because it highlights the fact that the mere existence of a new technology (with all of its functions) does not always translate to use of the technology or all of its features. Just because people can program the VCR to record a show for later viewing does not mean that they will. It is an important difference to establish because of the tendency in media studies to assume this relationship is a given. The same critical view can be applied to the study of the remote control. Simply because people have the capacity to surf channels and zap commercials, it is problematic to assume that they do this with any frequency. I think the studies identified here support an argument that says people do surf and zap, but the point is to be careful when attempting to discuss these types of problems and not assume that the incidence of this behavior drastically affects the user's experience.

Sapolsky and Forrest (1989) focus on the measurement of VCR "ad-voidance". They investigated the practices of zipping and zapping of taped television material in a laboratory setting, which gives their study the advantage of being able to record the exact amount of avoidance behaviour (versus the self-report models that many other studies reviewed here employed). The disadvantage with a laboratory study is that it takes the participants out of their natural viewing environment (the home) and increases the likelihood that the behavior will change because the participants are being directly observed (and because they know this). Sapolsky and Forrest (1989) gave participants a videotape of The Cosby Show with different commercials edited into the tape at the point where the original commercials aired (this was done in order to control and measure the types of commercials that were responded to with avoidance behaviour). The results indicate that adults zipped through more minutes of commercials than did adolescents. 
Sapolsky and Forrest (1989) state in their conclusion that, "a large share of viewers avoid much of the advertising accompanying television programming" (p. 163). The research conducted by Sapolsky and Forrest (1989) also shows that people who like commercials are equally as inclined to zip past them as those who say they dislike commercials. While the theoretical focus of Sapolsky and Forrest's chapter differs greatly from the focus of this project, their data is useful in investigating ad avoidance behavior enabled by technology (the VCR and RCD in combination). They place greater weight on the technology of the VCR in this process, whereas I see a more direct link between the $\mathrm{RCD}$ that allows the zipping. It is less important to decipher which technology enables this phenomenon, and more important to evaluate this study in terms of what it does say about zipping behavior. In line with other studies investigated here, Sapolsky and Forrest (1989) demonstrate use of the technology specifically with the intent to avoid commercials.

I have necessarily given a selective and incomplete summary of the works I have found relevant to the study of the RCD. In my selections, I have attempted to highlight the major methodological strategy employed by RCD researchers. Overwhelmingly, the existing research on this subject relies on audience studies that work generally within a framework of uses and gratifications theory. Some of the work does have a slightly different focus; Gray, for example, frames her study against gender relations, but her methodology of interviewing women and measuring the frequency of their VCR use falls under the same umbrella as the others investigated here. These works all reflect the adolescent stage of the life cycle model I propose by addressing themes of newness, struggle and negotiation of use. And while I see the value in this type of research, I 
believe that if I successfully build on this research and incorporate my own methodology of semiotic analysis (which I describe in more detail in the fourth and fifth chapters of this project), I can draw useful conclusions based on an interpretive method. Uses and gratifications research effectively addresses the question of use (a question that absolutely needs to be answered when talking about "new" technology), but it is unable to speak to other, broader processes that incorporate a dialogue about the symbolic significance of technology within a media-based culture. It is here that I believe a close examination of themes in advertising of the technology will add to the existing discourse. Analyzing advertisements from the era will illuminate another important dimension of the cultural space in which the RCD came into prominence.

The works presented in this literature review give a broad overview of what is available in the academic literature about the topic of the RCD. It is telling that so many of these studies focus on the practices of zipping and zapping. These are the uses of the RCD and VCR which directly "threaten" the television industry. Commercials are the financial backbone of the medium and the concerns that arise around their demise in the 1980s signify the importance of their success to the industry. Some of these studies (like the Channels magazine study) were funded in part by interested industry parties. As much as the RCD is a topic of academic interest, it has a greater relevance to the advertising community who worried about its effects on their television ad revenues. It is this relationship that inspired my project. The research done in this time period covers the areas of RCD usage, social impacts of the RCD and implications for the family. Given the benefit of historical distance from this time-period and from the debates and issues that surrounded the topic of RCDs in the 1980s, I aim to look at the bigger picture and 
observe the situation from a different point of view. My project's investigation into the advertisement of remote control technology will give a perspective on the situation that I see is currently lacking in the research. The use of the device has been well-established here; I will compare the perspective taken by these studies to the messages being advertised to consumers at this time. These studies imply that the user is an active part of the viewing experience and that the remote control is an essential part of their new power. As mentioned previously, the active viewer is part of an ideal used in both the academic literature and by the industry executives at this time, and that ideal fits into the adolescent stage of development of the technology. Going into the case study portion of this project, I expected that the advertisements I found would reflect these themes and mirror the adolescence I read in this academic literature on the subject. 


\section{Chapter 2: Technological Determinism: Driving History}

This study is an investigation of the relationship between technology and representation. One of the major themes in technology research is technological determinism, a concept I explore here. The advertisements I evaluate in my case study contain themes that both tie into and refute technological determinism, and establishing this theory provides a background for how I read the advertisements. The theory of technological determinism brings certain terms and concepts to the discussion that help clarify and explain the key debates that arise within this project. Technological determinists view technology as the driving force behind all society. All social structures, political actions and economic outcomes depend on the existence of certain kinds of technology. For technological determinists, technology is the impetus behind all that we experience.

The concepts of technological determinism warrant explanation and investigation before I use them in my analysis of the advertisements. Technologically determinist ideas are present in our society. Western governments and media systems rely on technology to great extent in their communications systems which fuel democracy, and this reliance coincides with other firmly held beliefs and ingrained norms about cultural life in western society. An example of the technology obsession present in our culture is the recent release of Apple Inc.'s iPhone. An electronics blog for June, 2007 reported that customers in New York City began lining up to purchase their new iPhone four days before the release date (MacNN, 2007). This kind of chaotic consumer behavior can be found with the sale of many popular technological items (the Wii gaming console, "early bird" sales on televisions and other entertainment hardware, and new releases of computer software and games are all examples of recent, lineup-inducing technologies). 
People feel that they need to have the newest and latest technology, and news coverage that surrounds these events lends itself to a technologically determinist analysis.

The second reason I am addressing the theory of technological determinism is that it is a theoretical orientation present in most of the remote control device literature I have found and analyzed in the previous chapter. The usage studies carried about by Gray (1992), Bellamy and Walker (1996), Lin (1990), Levy (1989) and Sapolsky and Forrest (1989) all draw from an effects research tradition in communication. These studies assume that usage drives meaning, and that the introduction of the remote into the home fundamentally shifts the relationship between consumer and product, consumer and technology, or the relationships within a family around the technology. These relationships hold at their core the belief that the technology is the actor, the driving force. It is significant that all of the research I have found on the RCD falls into this category. In communication and media studies, these assumptions about use bring with them assumptions about technological determinism. The explanation I give here of the history of this theory and its use in modern discussions around technology gives some background to how this orientation came to exist and why this project is choosing to investigate the remote control from another (more interpretive) angle. The interpretive approach allows me to ask questions of the text and of the situation that a technologically deterministic approach would not allow for. If I take for granted that technology drives history, I might miss out on a more nuanced understanding of the communication situation of the remote control that allows for other cultural or economic factors that played a major role in its development and popularity. The interpretive approach provides another perspective and makes up for some of the limitations in use-based research. 
Scholars have given technological determinism many different definitions and stipulations but by and large, the term refers to a theory or outlook that puts the piece of technology in the position of affecting change within a society. A simple example of this is to say that when steam engines were developed and put to heavy use in America in the nineteenth century they changed American industry, its political position in the world, the type of work Americans undertook on a daily basis and so on. The crucial point here is that the steam engine is placed in the role of the causal factor for these other changes. Simply stated, "according to technological determinism, as technology develops and changes, the institutions in the rest of society change, as does the art and religion of the society" (Dusek, 2006, p. 84).

Where did technological determinism come from? What do these origins have to do with my project? What does it imply for this study of the remote control device? In response to my first question I employ the arguments of James Carey, Leo Marx and Merrit Roe Smith, scholars who directly address the question of the origin of this theory. These three scholars highlight early American democracy as one of the key historical periods in which the development of technological determinism took place. According to Smith (1994), technological determinism is rooted in the Enlightenment, when scholars and thinkers began to place agency in technologies as major forces of change in the social world. These roots are of course not all-encompassing, as the paradigm of rationality and an interest in technology have been part of human life for centuries. The Enlightenment simply represents one time in history when these ideas permeated American culture to the extent that they can be categorized as an important theoretical perspective. 
This origin of technological determinism as a theory comes from the industrial era, but the concepts are applicable to an information-based society where the remote control emerged. Carey presents a similar approach to Smith in terms of understanding the historical development of technological determinism. Carey (1989) uses the creation of the modern American government as an example of the power of technology to shape society. The founding fathers included the communications technology of the time (newspapers) in the constitution through the idea of a free and open press, which positioned technology as an essential part of the new democracy. And as Carey (1989) points out, technology was given special treatment when "the Bill of Rights guaranteed constitutional protection to technology with its clause on freedom of the press" (p. 120). The centrality of technology to the creation of a new government is underscored further by Smith's (1994) account of the factory system in America.

According to Smith (1994), American politicians and thinkers like Thomas Jefferson and Benjamin Franklin wrote about the value of progress in the new nation; theirs was an understanding of progress that could be achieved with invention and technology. Smith (1994) points out the relationship between social problems and technological solutions; “...writers expressed a seemingly unbounded enthusiasm for the machine age, so much so that one gets the impression that heavier and heavier doses of technology are being prescribed for the solution of societal ills" (p. 8). This statement shows the weight carried by technologies in American life at this time. We can see the relationship between social problems and technological solutions throughout $20^{\text {th }}$ century American history as well. Wars and political crises often lead to the development of new and "better" technology (the atomic bomb, satellite-guided missiles, surveillance 
technology and even communications technology like the internet are all examples of technologies that developed in response to political or social problems). The notion of a better future is tied very much to technology. In the late 1800 s, at a time of global recession, "preachers and politicians appealed to Americans to retain faith in the future as such; they appealed to the future as a solvent and asked the public to believe that the latest technology or social project would fully justify past sacrifices and the endurance of present turmoil" (Carey, 1989, p. 178). Technology seems to be the first resort humans go to when faced with a serious social problem. Smith (1994) argues that this type of thought has its origins in the new democracy and machine age in America. He claims that, "...technology became idolized as the force that could fix the economy and deliver on the legendary promise of American life. Such technocratic pitches constituted a form of technological determinism that embedded itself deeply in popular culture" (Smith, 1994, p. 13). Technocracy is a concept that warrants some additional explanation.

Technocracy is a term used to describe a system of government where political power is reserved for people who have technical knowledge. It is predicated on valuing efficiency, rationality and an overall emphasis on technology as a fundamental institution. The idea that scientific or technical experts should make decisions on behalf of the people puts into perspective the power of technology and those who can access it. Early American democratic government represented its people through inventors like Benjamin Franklin and agriculturists like Thomas Jefferson. These and other technocratic leaders shaped America in a way that greatly depends on technology and progress.

This technologically-driven model of political government was not without its detractors. Critics of technologically determinist social policy and technocracy in the 
early 1800 s expressed concern that the American obsession with progress and technology sacrificed a moral progress (Smith, 1994). Henry David Thoreau, Jefferson, Ralph Waldo Emerson and Mark Twain are among the outspoken critics of this view identified by Smith (1994). Again, there is connection between technology and moral correctness. The issue of technology is one that gets wrapped up in debates around moral character. These examples, which show both a positive outlook for moral virtue by way of technology and a negative outlook for moral progress because of the dominance of technology, illustrate the close connections issues of technology have to everyday life.

This relates to Marshall McLuhan's (1964) notion that technologies are extensions of man. McLuhan's (1964) explanation of this phenomenon is that, "rapidly, we approach the final phase of the extensions of man-the technological simulation of consciousness, when the creative process of knowing will be collectively and corporately extended to the whole of human society, much as we have already extended our senses and our nerves by the various media" (p. 19). We are not talking about a piece of steel or plastic that is separate from our own lives. Technologies make up large parts of lived experience, and while McLuhan's understanding of the concept goes somewhat over the edge, it makes sense that the reason people are as concerned about the effects of technology is that they see the impacts these items have on their lives. Ask anyone who has had their computer crash whether it affected his or her everyday experience. Technologies are certainly more than the physical materials that comprise them. They are a vehicle for our thoughts and feelings, a mechanistic storage device for our intellectual or creative lives.

There is a connection between culture and technology that technological determinism helps elucidate. James Carey (1989) places technology in a cultural studies 
context. His orientation can be seen here: "technology, the hardest of material artifacts, is thoroughly cultural from the outset: an expression and creation of the very outlooks and aspirations we pretend it merely demonstrates" (p. 9). Carey furthers this deterministic line of argument in his discussion of the role played by electricity in twentieth century America. Speaking specifically about the 1980s and 1990s, Carey (1989) describes "an increasingly prevalent and popular brand of the futurist ethos is one that identifies electricity and electrical power, electronics and cybernetics, computers and information with a new birth of community" (p. 114). In Carey's history, electricity replaces the machine as the technology of the day that will bring change and hope to communities. In fact, electricity was called upon to fix some of the problems that the machine era created. Carey (1989) reports that when the machinery used to build America led to industrialization and to a harsher social environment, "in electricity was suddenly seen the power to redeem all the dreams betrayed by the machine" (p. 121). As with the factory system, electrical technologies in America were viewed as the harbingers of a new social era-a new way of living that promised better working conditions, easier household chores, and a revolutionized economic system that underscored progress and development.

Technological determinism as a framework is well suited to the discussion of my project because it, too, is concerned with the idea of "revolution"--whether that revolution is one of mechanism, electricity, digital computing technology or any other technologically-based change in society. The idea of revolution is important to technological determinism because it is a way of marking history and understanding of social progress. The theorists who discuss the electrical revolution (like Carey and 
McLuhan) use it to frame the shifts in society taking place in the early 1900 s and throughout the century. Revolution implies a complete shift or change in fundamental pieces of reality; the revolution of electricity is as suspect as any claims of a revolution brought on by television technologies.

In the interest of showcasing of a more determinist theory, I will now discuss the views of Robert Heilbroner. Heilbroner (1994) looks at technological determinism through the lens of socioeconomics. He investigates whether "we can explain technological determinism historically as well as explain history by technological determinism" (Heilbroner, 1994, p. 55). Heilbroner believes that technology occurs in a sequence, not by chance, but because it is necessary. The three reasons he uses to support this claim are the simultaneity of invention, the absence of technological leaps, and the predictability of technology. The first two arguments are self-explanatory, but the third warrants clarification. Heilbroner (1994) claims that scientists and inventors are often quite correct in their predications of future technologies based on the existence and form of current technology. These claims are, for the most part, logical and I am inclined to agree with him. My view is that technologies are developed in a continuum, where old ideas and technologies are adapted, restructured and reused to make the new. Where my project and Heilbroner's ideas diverge is at his position that because of these factors, technological forces determine the entire trajectory of a culture.

Heilbroner (1994) asserts, "I do not think it is just by happenstance that the steammill follows the hand-mill...the development of technology of production seems bounded by the constraints of knowledge and capability and thus, in principle at least, open to prediction as a determinable force of the historical process" (p. 59). Again, I agree with 
Heilbroner's observation that there are clear patterns and trends in the history of the development of technologies and that those patterns often suggest that older technologies are reshaped and upgraded and transformed into the newer technologies. His claim that this is a "determinable" factor in the historical process is problematic because it assumes that technologies exist outside of culture (and can therefore act on culture). This debate is not just an argument about semantics; the decision to place technology within a cultural context or outside of that context has real implications for how history is understood and for how research can then be conducted. It is my contention that the cultural context tells us a great deal more than the invention process ever could. It is on this assumption, that technology is a product of invention and cultural context, that this project is grounded. As a technology scholar, it is easy to become overwhelmed by the paradoxes and competing ideas that lie within theories of technological determinism. Smith (1994) identifies the dilemma of technological determinism when he asks, "who among us would deny that it is easy to be drawn into technology-driven explanations of cultural and historical processes? The frustration we experience is as much with ourselves as it is with the large societies in which we live" (p. 35). This statement is particularly apt because it identifies the tension that exists around ideas about technology.

If I take a few steps down the road of technological determinism, things start to make sense. The iPhone really does impact the way people communicate with one another, the types of messages that are exchanged between people and the content of those messages (perhaps one friend emails another a cool new YouTube video they find while browsing Facebook). The danger of technological determinism exists where the physical technology itself (the index card sized piece of plastic, metal and silicon that 
makes up the iPhone) is compounded with the social actions that create the situation of the email I just proposed. There are many more cultural and social forces at work than can be accounted for by the technology alone. And, as Dusek (2006) points out, "there is an inextricable feedback from technology to culture and from culture to technology" (p.85). This is the message I see from the theories (and critiques of those theories) of technological determinism that I have examined here. Understanding technology means understanding the context and process in which it is used and the relationship between the technology and that context. It is my contention that the method used in this project (semiotic analysis of advertising) begins to address some of this social context.

The link between American democracy and technologically determinist thought is not only interesting, it is an important part of the story of technology in America (and North America) today. It is no surprise that the rhetoric about new technology and innovation permeates popular thought about technology when so much of North American history can be tied to the ideas about progress and technological innovation alluded to above. Further examples of this origin can be found in the work of Leo Marx and Merrit Roe Smith (1995). They point out that historical narratives are often imbued with technologically determinist examples. For Marx and Smith (1995), "technology is conceived in almost exclusively artifactual terms, and its materiality serves to reinforce a tangible sense of its decisive role in history" (p. xi). The point they make is that the very materiality of technology makes it an easy target for assigning historical importance. If we know the steam-mill existed, we can draw conclusions about what it did and did not do in the society with some confidence. It is harder to prove the existence and relevance of, for example, a capitalist ideology that made the steam mill necessary in American 
industry. It is interesting to keep in mind that the reason we talk about certain technologies may be because of this materialist orientation in traditional histories.

Marx and Smith (1995) argue that the existence of a technology does not necessarily tell us anything about how or why people chose to use it. In the preface to their edited collection on technological determinism, they point out that, "people seem all too willing to believe that innovations in technology embody humanity's choice of its future" (Marx and Smith, 1995, p. xiv). By the examples given in this edited collection, it seems that American history is particularly bound up in notions of technical progress. The various authors cite the founding fathers, the Ford Model T, steam-mills and rail systems as different examples of technologies that, in one way or another, shaped the American cultural and physical landscape. This ongoing relationship between technological progress and American success reinforces the relevance of my study of remote control devices in American advertising.

The technologically deterministic outlook that underpins American society may be a factor in the problematic life cycle model that I discussed in the introduction to this project. If it is assumed that technologies drive history, it logically follows that scholars would look at the point of its introduction and diagnose that time period as the point that impacted the rest of the history. Given the technologically deterministic thought that American scholars are exposed to, it makes sense that they might consider the 1970s and 1980s as the time of the new technology of the RCD. This perspective does not allow for the understanding that technologies are always new and changing as I propose; in a technologically deterministic history, technologies either are or are not—-they are created and then exist and impact other things. According to the perspective of technological 
determinism, the moment when the RCD enters the home it impacts the experience of the user and the history of that use from that moment on. My redefinition of the life cycle of the remote includes a continuum of development that goes back to long before the twentieth century. I believe that understanding the history of the technology in this broader scale of time more accurately accounts for all of the processes that go into an invention and its eventual use. It also gives a different perspective on the advertising of the technology at an interesting point in the history of the device. 


\section{Chapter 3: Considering Methodology: Representation and Semiotics}

In order to set up a methodological framework through which to investigate the remote control, I address the implications that arise from using a theory of representation that I discussed in the introduction. I draw from cultural studies theorist Nick Couldry the idea that an approach to understanding a cultural product involves three fundamental questions based on the concepts of ontology, epistemology and methodology. At the level of ontology, he asks, "what is a text, when considered as a social object" (Couldry, 2000, p. 69)? At the level of epistemology, he asks, "how are we in a position to know about texts" (Ibid.)? And at the level of methodology, he asks "how best, in practice, should we analyse texts" (Ibid.)? I address these questions here as a way of mapping out the specific methodology I am using.

The first question - what is a text, can be answered for this project in terms of the unit of analysis I am investigating. The text in this case is a selection of print advertisements from three different newspapers. Couldry further asks the researcher to consider the text as a social object, which reflects the cultural studies approach to analysis. The advertisements I am looking at are not just printed words and images, they are indicative of a communication situation (a textual event to use Couldry's terms). They exist in a social world that defines them and use a language system imbued with cultural meanings. Based on the conclusions I have drawn here about what constitutes a text and what is significant about these texts, my approach is one that values the text as a representation of social processes.

The epistemological question asked by Couldry-how are we in a position to know about texts, is more difficult to answer directly. This method is not without its limitations and problems, but one advantage of this approach is that it places me in the 
position to know about texts. I am a product of a cultural environment that I live in and interact with everyday. I have the ability to make interpretations and analysis based on my experience of this culture and language and also based on my in-depth historical research on the subject. My understanding of the history of the topic combined with my ability to think critically given my education gives me the authority to make this analysis. Of course, my unique life experiences will direct my analysis in ways that may not be replicated by another researcher, but that does not invalidate any conclusions I draw. There is room for personal interpretation within this kind of research; I would argue that any research project is imbued with the personality and experience of its author. This does not mean I should be unconcerned about the effects a person's experience, just that being aware that this is an inherent part of a research process will ultimately strengthen the research and the conclusions drawn.

The third methodological question asked by Couldry builds on the other two-how best, in practice, should we analyze texts? Given the answers I have provided to those first two questions, I believe that semiotic analysis is the best way to analyze the texts I have selected. I understand the text to be a symbolic representation of reality imbued with social and cultural meaning and I believe that the researcher has the authority to make a meaningful analysis of the object at hand based on their specific experience of a culture and their ability to think critically about symbols in that culture. These two conditions lead to the area of textual analysis and semiotics for my project's methodology. It is difficult to fully accept Couldry's term and claim that this is the "best" approach to analyzing a text. In fact, there are other methodological approaches that would better answer a different set of research questions for this material. A content 
analysis, for example, would provide a more valid analysis if I was interested in questioning the major trends in the entire population of remote control advertisements. As it stands, I am choosing to focus on the symbolic meaning at the expense of asking questions about the trends in the larger sample of advertisements because I think the symbolic interpretation better addresses the question of what the representation of these technologies said about the time period. I can say with confidence that semiotics best addresses the phenomenon of representation in a printed text. According to Chandler (2007) semiotics focuses on and problematizes the process of representation-this makes it an extremely useful tool for me as I who wish to question texts specifically in light of how they represent reality.

According to McKee (2003), textual analysis is one method of investigation that looks at how people make sense out of different texts. This methodology takes an anthropological approach to culture and cultural products and allows the researcher to evaluate a moment in history. Textual analysis is interested in the context in which a text arises, so that in looking at an advertisement, the researcher can infer beyond just the words and images on the page and into the social and cultural climate in which the text was created. This methodology will allow me to look at not only the specific medium of advertising, but also the varied discourses implicated by the historical subject of the remote control device.

Within the broader category of textual analysis, I am selecting the specific method of semiotic analysis for this project. Semiotics, when used as a methodology, allows the researcher to investigate the signs displayed in a text in terms of their significance beyond their literal meaning. The advantage of this methodology is that "semiotics can assist us 
to become more aware of the mediating role of signs and of the roles played by ourselves and others in constructing social realities" (Chandler, 2007, p.10). The semiotic approach specifically highiights the fact that our experience of reality is mediated through symbols. I believe that it is in the process of mediation that meaning is created and that this process warrants my attention.

A semiotic approach to this project dictates that the text is a representation of reality. This approach reflects the idea that "...much of our knowledge is indirect; we experience many things primarily (or even solely) as they are represented to us within our media and communication technologies" (Chandler, 2007, p. 81). It is a symbolic object that communicates a reality through signs and symbols. This fundamental orientation (viewing language and image as representational, meaning-making processes) means that the text can be investigated in terms of these meanings and representations, which places responsibility on the researcher as an analyst of media texts. I will use the tools of semiotics to analyze the advertisements and to draw out meanings and conclusions beyond the face value of the text.

\section{A. Methodology Review: Strengths and Weaknesses of the Semiotic Approach}

In this section, I will review four texts that use semiotics to investigate advertised products. I will evaluate the strengths and weaknesses of their approaches, paying particular attention to the degree to which the author's argument is supported by their methodology. Mortelmans (1997) analysis of the concept of luxury in print advertisements for jewelry is one example of a semiotic analysis similar to my case study. He gives a detailed explanation for his choice to use the concept of luxury as a lens 
through which to examine the advertisements. This lens helps him establish a logical background for the choices he makes in his actual semiotic analysis. He is only investigating concepts that relate to luxury, which allows him to focus his argument and frees him from the burden of having to cover all potential areas of symbolic meaning in the advertisements. Mortelmans (1997) sets up the theoretical basis that his argument rests on in one specific sentence: "in using the constructed world of advertisers, we try to make contact with the underlying sign systems society uses to create a luxury cachet around certain consumer durables" (p. 75). Mortelmans (1997) then lays out his exact methodological approach, including sample selection, assigning particular categories of analysis to the group of advertisements (coding), and evaluating the paradigmatic structures that are common to many of the advertisements. His approach focuses on broader systems of meaning across the whole body of work. As Mortelmans (1997) points out, "rather than looking at denotated meanings of these signs, we are looking for a reasonable interpretation of the signs, a reasonable set of possible connotations" (p. 77). This research method sacrifices investigation of the more literal meanings of the symbols and language in favour of a more interpretive analysis of connotated meanings.

The semiotic analysis Mortelmans (1997) carries out of the advertisements closely follows the methodology and theoretical approach he outlines in the early part of the article. The theoretical perspective supports the interpretations made and many of the conclusions drawn follow from this perspective (and are thus supported in the argument). One weaker area of Mortelmans' (1997) conclusion is where he tries to extrapolate the argument out to highlight some of the motivations of the advertisers. An example of this is: 
Primarily, advertisers urge men to buy jewelry as a present. In doing so, they are in fact changing the sign status of the product. Instead of selling clothing accessories, the sign value changes to a symbolic meaning transmitter. The commodity, whatever it may be, is turned into a sign deprived of all instrumentality. (Mortelmans, 1997, p. 86)

Mortelmans' methodology does not allow him to comment on the motivations behind advertisers' decisions in marketing a product in a certain way. To claim that the advertisers willfully change the sign status of jewelry is unfounded, and it weakens the overall argument about the prominence of luxury-related concepts in the advertisements. Another example of a conclusion that is not supported by the methodology is "on a manifest, denotated level, one could argue that a diamond is forever, or at least will last longer than the owner will live. When a man gives such a diamond to a woman, he is in fact symbolically exchanging the eternity of their relation" (p. 87). The weakness of this argument is that Mortelmans is commenting on what the exchange might mean, going outside of what is evident from the text being examined. This approach leaves him open to criticism because the methodology of semiotics relies so heavily on the researcher's interpretations, straying from what is actually present in the text is problematic.

The next work I review here is Jane Marcellus' semiotic analysis of advertisements aimed at woman working in clerical fields in the 1920s. Marcellus (2006) uses a semiotic analysis that focuses on the placement of the women in ads for typewriters as compared to their surroundings. Her analysis focuses on a specific moment in history (when women were encouraged to do work in clerical fields after World War I). She also draws on some techniques from discourse analysis to further explain her interpretations. She highlights the women's body positioning, the direction of their gaze and their physical actions within the advertisement (are they typing, are they 
talking to other women or men in the office?) as a way of discerning the symbolic meaning of the advertisements. Her approach is anchored in a visual analysis methodology that focuses more on the physical structure of the print advertisements than on the meanings denoted and connoted by the written text.

Marcellus (2006) combines semiotics and discourse analysis to make broad statements about the changes that occurred in the advertising of this material over a period of time. The advantage of her method is that she can make broader, more generalized claims that support an historical argument. The disadvantage of her approach is that her semiotic analysis is brief and the justifications she provides for her particular points of analysis are not well-explained. Marcellus (2006) mentions certain theorists who directed her choice to look at certain features of the ads, but this section is brief and gives her analysis inadequate foundation. This text offers very little theoretical background to support the choices made, leaving it open to criticism about how and why certain assumptions were made and certain questions were asked. One conclusion drawn in this analysis is that, "in representations aimed at men, the secretary was locked into a system that incorporated her femininity and nullified her individuality, recasting her as an interchangeable, though sexual, office part" (Marcellus, 2006, p. 110). This is a potentially interesting analysis, but because the terms through which the ads were viewed were not clearly outlined, this conclusion can be dismissed as opinion. Because semiotics is a subjective methodology, appropriate reasoning behind any analytical decisions made is crucial to an argument that holds up under criticism. This article is a very good example of the some of the potential pitfalls of using semiotic analysis. It lends itself to the analyst's own interpretation, which is at the same time its strength and weakness. 
Being able to justify not only the terms of evaluation, but also the conclusions drawn based on those terms is a difficult, but necessary, part of conducting a successful semiotic analysis.

The third text I review is Hirschman's look at the advertising of "rugged individualism" in print advertisements for guns and cars. The author uses a semiotic analysis to evaluate magazine advertisements that appear in publications predisposed towards individualized narratives. Hirschman (2003) takes a similar approach as Mortelmans in that she uses an overarching theme (rugged individualism) as a concept through which to understand the advertisements. This concept is thoroughly developedthe theoretical and historical perspective within which the concept is situated is explained in detail. Having established this frame, Hirschman (2003) gives this analysis, "through its visual rhetoric of man and horse, solitude, and nature, the ad suggests the protagonist is returning with his trophy, his meat provisions, and his selfhood gained" (p. 13). Where Marcellus' statement came off as simply her opinion, Hirschman's statement holds more meaning because she set up the lens through which her analysis was made.

The second part of Hirschman's article focuses on seven different bipolar parings that she identifies as part of many of the ads. Examples of the pairings include things like individual freedom versus rule of law, instrumentalism versus anthropomorphism and nature versus culture (Hirschman, 2003). These pairings allow the author to investigate themes among the different ads that are identified as part of the rugged individualism theme. They work in the same way as the overall theme, giving the analyst a structure on which to place and evaluate the advertisements. It also gives the analyst a means to talk about interesting contradictions and unexpected findings. Hirschman (2003) describes the 
ironic tension in ads for certain handguns displayed on top of images of the American flag. The strategy of highlighting images that seem to contradict the theme of rugged individualism adds another layer of analysis to Hirschman's argument. The conclusions drawn are generally supported by the data she draws from and the type of analysis she makes. One example of this is "as the advertising and other texts I have examined here indicate, those who embrace the ethos of rugged individualism view themselves and their lifestyle as under attack" (Hirschman, 2003, p. 20). The attack she speaks of is evident in her analysis of the sample of ads (and in editorial comments noted from readers of the magazines). The amount of work done in the theoretical discussion about the concepts being investigated hold Hirschman's argument to a higher standard than some of the other articles reviewed here. Her work is more compelling and meaningful because of this theoretical background.

The strongest semiotic analyses in this small review are those that employ a certain concept to the body of texts that are under investigation. The concepts behind both Mortelmans' and Hirschman's arguments help each author frame their analysis in a specific way that focuses the analysis and strengthens the arguments each make.

Marcellus' argument lacked an appropriate frame that set up the direction of her analysis. Semiotics as a methodology is best used when a frame of analysis is thoroughly explained and applied to the sample.

\section{B. The Lens of the New}

In my project, the lens used to view the advertisements is the idea of "the new". The debate about old and new technology is wrapped up in ideas about what it means for something to be new and why those meanings might be important for consumers. The 
academic debate around media and technologies in transition was presented in the introduction to this project, but I will reiterate some of the main points here as they inform the lens through which I am performing a semiotic analysis. Thorburn and Jenkins (2003) discuss the ways in which media are conceptualized (particularly when it comes to themes of change and transition). Their edited collection gives many different examples of how media are understood in terms of the new and the changing. One example is from Gitelman (2003) who explains that new technologies are adopted not because they are more convenient, but because there is a social condition in place that makes them work within a society. She argues that the idea of new media is problematic by stating, "media themselves are denizens of the past. Even the newest media today came from somewhere, whether that somewhere gets described broadly as a matter of supervening social necessity, or narrowly in reference to some proverbial drawing board and a round or two of beta testing" (Gitelman, 2006, p. 5). Gregory Crane (2003) argues that newer forms of writing technology are not inherently more valuable than the forms of writing that preceded them. According to him, the book is no more valuable than a scroll or a clay tablet, it is simply better suited to how we access words today. It could be argued that electronic text has supplanted the book as the dominant mode of written communication, but that newer technology should not be looked at as more valuable. Another interesting point made by Crane (2003) is that there is always more history than we see at first glance when considering a technology. The narrative form of television sitcoms have an extensive history that often goes unexplored because they are categorized as being "new" in the 1950s-when the technology was "new". Humans have been storytelling for much 
of their history, but this is disregarded in most discussions of the development of television sitcoms.

Recent academic literature on the subject of television commonly addresses with the notion of change, upheaval, and transition (all concepts that deal with newness). Examples include Henry Jenkin's 2003 book, Rethinking Media Change: The Aesthetics of Transition, as well as his 2006 contribution, Convergence Culture: Where Old and New Media Collide, Amanda Lotz' 2007 book, The Television Will be Revolutionized, and Jostein Gripsrud's 2004 work, Television After TV: Essays on a Medium in Transition (Console-ing Passions). This body of work is just a sample of the literature currently being produced on the subject of television, but it is indicative of some of the major trends found not only in academic discourse about the topic, but also in popular conversation about media.

Given the literature on technology and television that I have reviewed throughout this project, I believe that the concept of the new is the most appropriate lens through which to perform this semiotic analysis. The theories about technology that I reviewed in the previous chapter, the scholars who talk about current media in transition, and the works reviewed for their previous research on the RCD all underscore this theme of the new in one way or another. Technological determinism implies that the development of a new technology should changes the social world by its very existence; thus, the new technology should be highlighted. Many of the transition theorists I reference talk about technology as an ever-evolving invention process, but one that is often mistakenly presented as revolutionary. The work of the RCD scholars also points to a great interest in the development of the remote as a new part of television viewing in the 1970s and 
1980s. The popularization and use of this device spawned a body of research that tried to address the way people used it and what that meant for the television industry. These different focal points in this project all point to the theme of the new as the most appropriate lens through which to conduct this semiotic analysis.

\section{My Semiotic Approach: Saussure and Barthes}

In terms of my specific approach to the texts I am investigating, I am going to use a combination of Roland Barthes' ideas about myth and a classic Saussurean semiotic analysis. Both approaches to semiotic analysis strive to denaturalize signs-a process that involves making people aware of the symbolic meanings that they have come to take for granted (Chandler, 2007). Denaturalizing the sign means shaking it out of its everyday context and investigating it—turning it on its head and seeing what meaning falls out. This deconstruction process allows me to access the kinds of meanings being communicated. As Chandler (2007) explains, "the medium of language comes to acquire the illusion of transparency: this feature of the medium tends to blind its users to the part it plays in constructing their experiential worlds" (p.77). The point of this semiotic analysis is to investigate the seemingly transparent language used in the remote control ads. I will use the methodology of semiotics to look at the symbolic meaning communicated by both the text and the visual images.

The driving force behind Saussurean semiotics is the two-part model of the sign. Saussure was a linguist and his theory of semiotics is based largely on language as a sign system (the gaps that this leaves in my analysis will be covered by the use of Barthes' concept of myth). The first part of the sign described by Saussure is the signifier, which is "the form a sign takes" (Chandler, 2007, p.14). The second part of the sign is the 
signified, which is "the concept to which the sign refers" (Ibid.). The following figure is a recreation of Saussure's model of these two components of the sign.

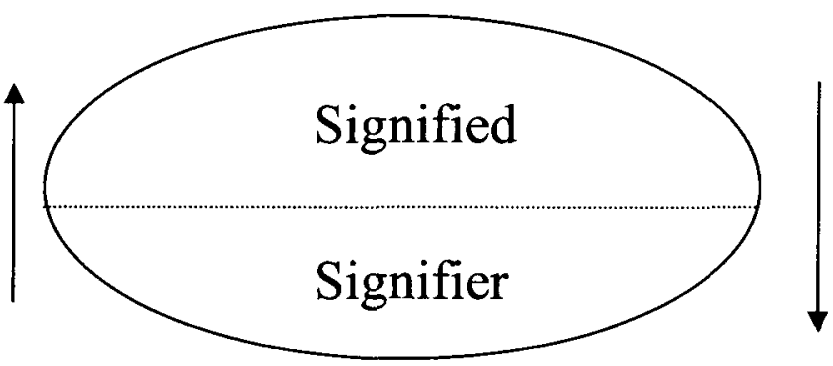

\section{Figure 1: Saussure's Model of the Sign}

According to Chandler (2007), "the relationship between the signifier and the signified is referred to as 'signification', and this is represented in the Saussurean diagram by the arrows" (p. 15). An example of a sign is the concept of a device that changes the channels (the signified), and letters in the word "remote control" or a picture of a remote control (the signifier). How these two components interact with each other in the mind of the person experiencing the sign is the process of signification (as indicated by the bidirectional arrows in the above symbol). Saussure makes a distinction between two types of analysis, synchronic and diachronic. According to Berger (2005), synchronic analysis involves looking at the relationships that exist among the elements of a text at a certain moment in time. A diachronic approach, on the other hand, involves looking at the historical progression of the narrative (its evolution over time). The analysis I conduct falls into the synchronic category as I do not attempt to make long-term comparisons about the narrative in advertisements of RCDs, but instead look at a specific period of time and the specific messages communicated during that time. Saussure's model fails to address more complex processes involved in the creation of meaning; his model lacks a 
mechanism for going beyond the isolated unit of the sign and combining many signs into a system that can then be analyzed. Saussure's semiotics focuses on discovering meanings that are denoted by the symbol. Roland Barthes, on the other hand, focuses his semiological method on explaining connotative meanings.

In line with Saussurean semiotics, Barthes (1972) contends, "semiology is a science of forms, since it studies significations apart from their content" (p.111). Parallel to the linguistic concept of signifier and signified constituting the sign, Barthes (1972) created a concept of myth, which uses a form (signifier) and concept (signified) to talk about the process of signification. According to Barthes (1972), "myth has in fact a double function: it points out and it notifies, it makes us understand something and it imposes it on us" (p. 117). Myth refers to a process of communication where both a literal meaning is communicated as well as a larger symbolic meaning that is not explicitly stated. Barthes (1972) provides a theoretical guide to deciphering myth in a text. He explains how he approaches this task: "if I focus on the mythical signifier as on an inextricable whole made of meaning and form, I receive an ambiguous signification: I respond to the constituting mechanism of myth, to its own dynamics, I become a reader of myth" (p.128). The process Barthes describes uses the two parts of his myth (meaning and form) to create an understanding of symbolic meaning that fully represents the mythical situation. Analyzing only the form of the text (only the words or pictures) or only the symbolic meaning creates an incomplete picture of the communication act. The very essence of the myth is the interaction between these two components.

He further explains that myth is a naturalizing process, one that should be deconstructed by the myth reader: "the very principle of myth: it transforms history into 
nature...what causes mythical speech to be uttered is perfectly explicit, but it is immediately frozen into something natural; it is not read as a motive, but as a reason" (Barthes, 1972, p. 129). The act of speech naturalizes the meanings imbued in the text being spoken. Deconstructing myth and finding it within the texts we encounter is one way of dealing with the problem of naturalized meaning. The myth reader looks for patterns of ingrained cultural belief that are imbued in texts; these beliefs are the myths that guide our interaction with cultural texts and products. Looking at myth also involves identifying the literary functions of a text. Barthes' (1972) method seeks "a reconciliation between reality and men, between description and explanation, between object and knowledge" (p. 159). The understanding of myth is an attempt to bridge the gap between the texts we see and the meaning we make of them. The value of this theory is that it allows the researcher to make conjecture beyond the simple mechanism of the text. A third portion of my analysis will come from analyzing literary devices within the texts. According to Chandler (2007) identifying elements of literary style like metaphor, irony, synecdoche and connotative meanings is an important part of challenging the literal meaning of the text-moving beyond the level of denotation identified by Saussure into a symbolic analysis into the level of connotation that Barthes' method aims for. Identification of literary devices helps denaturalize language because the process specifically investigates language from a symbolic perspective. According to Berger (2005), the study of metaphor and metonymy specifically work to reveal symbolic meanings in a semiotic analysis. We take metaphors for granted, and this type of close analysis allows the reader to re-evaluate the role of language in symbolic communication. Understanding what is being represented, how it can be interpreted, and the context in 
which it was created help the analyst establish an understanding of the sign systems and how they work to communicate information. 


\section{Chapter 4: Case Study: Newspaper Advertisements for the Remote Control Device}

\section{A. Sample}

The subject of my research is a selection of printed newspaper advertisements from the period 1975-1985. The specific sample I have selected consists of print advertisements from three major newspapers: The Times (London), The New York Times and the Washington Post. The sample group was selected because of the availability of online access to these archives and the ability to search the databases specifically for ads that contain remote controls. After considering other sources like popular magazines, television advertisements, and store-specific weekly flyers, I chose the newspapers ads for the reasons that follow here. Newspapers are a widely distributed communication medium; the advantage of using newspapers over magazines is that they are targeted toward a broader audience than most magazines (which are comparatively nicheoriented). I must of course acknowledge that newspaper audiences are not without their own demographic tendencies, and that the three newspapers I have chosen each have somewhat liberal, elitist leanings. I do believe, however, that given the nature of this examination and the types of questions being investigated, the ideological biases of the papers chosen do not adversely affect this study. The newspapers represent the advertisements available to the general public for average television sets. I want to talk about a general discourse surrounding technology, and it is important that my sample reflect an average population. My choice to undertake a textual analysis instead of an image-based analysis is based on the fact that newspapers are largely a print medium.

I also considered focusing on a Canadian publication, but the availability of searchable databases (and the time allotted for a thesis project) led me to the two 
American newspapers and one British newspaper. I am also choosing to focus on American publications because my background research focuses on the television industry in the United States. I selected the time period between 1975 and 1985 because, according to my research, in the late 1970s and early 1980s wireless RCDs began to appear into many households. At the outset of my research, I thought it was important to see how the devices were marketed before they became an accepted part of television viewing because I was under the impression that the time of acceptance would be in the early 1990s. I wanted to see how they were sold to consumers who did not previously own them, and I believed that this time period would reflect that research question. My perspective changed after going through the analysis of my sample, but this was my initial orientation.

I located a large pool of newspaper ads that specifically mention or picture a remote control device from the three newspapers and from the time period of 1975 to 1985. My method of selection for The Times was to take every advertisement containing "TV" and "remote control" from the time period--which resulted in forty-five images. Selection for the New York Times group followed a similar pattern, where I took almost every ad that came up in this search (leaving out ads that were reprinted on multiple days or weeks). This resulted in twenty-six possible ads to use. The sample of ads collected from The Washington Post came from a much larger group. For the period of 1975-1985, I collected almost 100 ads. The selection criteria for the Post ads was based on finding those that described the features of the remote control specifically, as well as those that represented the bulk of ads about televisions for sale at the time (that may or may not have prominently featured the remote control). This sample was too large for detailed 
analysis, but it accurately represents the available ads on televisions and remote controls from this time period.

I focused my analysis on 17 specific ads that came from each of the three newspapers and represent a wide range of ads available to newspaper readers at this time. In general, the ads I have gathered can be broken down into two categories:

1. Ads which feature multiple television sets on one page, with multiple brands and in a variety of price ranges and styles

2. Ads that are brand-specific and focus on one or two models of a television set (these ads are generally more textually descriptive than the multiple brand ads). It is the second category of ads that yielded more detailed data about the remote controls and the television sets themselves, and as such, these are investigated in greater detail. I also include an analysis of the numbers of ads that fall into each category and the possible interpretations of those numbers (my hypothesis going into the analysis was that there are far fewer ads that specifically feature the remote control and that this lack of representation speaks to how new technology is regarded in the industry versus how it is actually presented to the public). A full explanation of the semiotic questions I developed to ask of the texts can be found in Appendix A.

This methodology allows me to ask questions about representation, symbolism, and communicated meaning. It greatly privileges my interpretation as the reader of the text, but this interpretation is backed with literary modes of analysis and the process of identifying themes within the text. It is a largely structuralist approach because it holds there are structures (symbols) that exist within these texts that can be identified and further analyzed. The value of this kind of analysis is its ability to denaturalize language 
and symbols that are often regarded as facts. The potential downfall to this kind of analysis is that it relies so heavily on the researcher as the interpreter. I say potential downfall because I believe that if this issue is properly addressed, there is only strength to be gained from having a personal interpretation of a text. I plan on addressing this problem by putting a great deal of self-reflexive thought into the analysis I do and by being upfront with the position I take as a researcher in this project. Judith Williamson (1978) outlines the unique position in which advertising leaves us: "there is a space, a gap left where the speaker should be; and one of the peculiar features of advertising is that we are drawn to fill that gap, so that we become both listener and speaker, subject and object" (p. 14). If we are drawn to fill this gap as consumers, it makes sense that as a researcher, I take on this role with an understanding that this is a process that everyone works through in some way or another. This particular methodology will allow me to access specific trends and ideas that are present in the advertisements; it will allow me to draw meaning out of those themes when placed in a larger context established by this project.

\section{B. Analysis of Overall Content}

To begin my analysis of newspaper ads from the mid 1970s through the mid 1980s, I first establish the different groups my ads fall into and the ways in which I will categorize them for the detailed semiotic analysis. I am not performing a formal content analysis, but rather discussing the major categories my ads fall into. As outlined in my methodology section, I am dealing with a sample of 120 advertisements from three different newspapers (taken from the period of 1975-1985). Of these 120 ads, eighty 
come from the Washington Post, fourteen come from The Times (London), and twentysix come from The New York Times.

As I identified in the previous section, the ads fall into two broad categories: those that feature multiple television sets on one page, with multiple brands and in a variety of price ranges and styles and those that are brand-specific and focus on between one and four models of a television set. The former category will be called "multi-ads" and the latter will be called "single-ads" for the purposes of this analysis. For the WP sample, I assigned forty-seven ads to the multi-ad group and twenty-three to the single-ad group. To further the categorization of the ads and limit the sample that I will investigate indepth through semiotic analysis, I selected five of the twenty-three ads from the single-ad group and two of the forty-seven ads from the multi-ad group. I chose these proportions because the multi-ads are very similar to each other in terms of content and two ads provide reasonably representative data from that group. The single-ads, being more descriptive, are much more varied in content and thus warrant further in-depth analysis. The ads were chosen on the basis of the following criteria: I selected ads that were unique from each other, that represented as many different brands as possible, that came from different years and included both ads that spoke directly about the remote control and ads that did not mention the device.

The same selection method was applied to The New York Times (NYT) and The Times sample groups. The NYT group yielded eight multi-ads and sixteen single-ads (two were deemed unusable because one was an advertisement styled as a news article and one dealt with a gaming system instead of a television remote control). Of the eight multi-ads, three were selected for analysis, and of the sixteen single-ads, three were selected for 
analysis. Again the selection was based on the four criteria presented above. Of the fourteen ads that I found in The Times, five were categorized as multi-ads and nine were categorized as single-ads. Given this sample size, I selected one ad from the multi-ad group and three ads from the single-ad group. The table below illustrates a summary of all the ads found, the categories assigned to them, the numbers selected from each category.

\begin{tabular}{|l|l|l|l|l|l|}
\hline Newspaper & $\begin{array}{l}\text { Total } \\
\text { Number } \\
\text { of Ads }\end{array}$ & Multi-Ads & $\begin{array}{l}\text { Multi-Ads } \\
\text { Selected for } \\
\text { Analysis }\end{array}$ & $\begin{array}{l}\text { Single- } \\
\text { Ads }\end{array}$ & $\begin{array}{l}\text { Single-Ads } \\
\text { Selected for } \\
\text { Analysis }\end{array}$ \\
\hline $\begin{array}{l}\text { Washington } \\
\text { Post }\end{array}$ & 80 & 47 & 2 & 23 & 5 \\
\hline $\begin{array}{l}\text { The New } \\
\text { York Times }\end{array}$ & 24 & 8 & 3 & 16 & 3 \\
\hline The Times & 14 & 5 & 1 & 9 & 3 \\
\hline
\end{tabular}

\section{Table 3: Summary of Data Set Selection}

Before continuing on with the formal semiotic analysis, I will comment on the general trends identified here in the newspapers. This is not a formal content analysis so the conclusions I draw are not meant to provide data that speak to overall trends in newspaper advertising of remotes, but I wish to expand upon and explain some of the questions that come up as a result of my dividing the sample into these two groups. The first significant trend that is apparent from Table 2 is that there are more multi-ads than single-ads. This is absolutely representative of the overall trend I observed when selecting the newspaper ads. There were far more multi-ads than single-ads; when I went through the newspapers, I selected almost all of the single-ads that I saw, and only took a fraction of the multi-ads that appeared in the newspapers. This choice was deliberate, because, as explained above, the multi-ads contain less information dealing with the 
remote control (visual images and text). The multi-ads are also more similar to each other than the single-ads, so selecting large samples of multi-ads would not allow for more insightful analysis than selecting a smaller proportion of these ads. The multi-ad was the dominant form of advertising for the television and remote, particularly in the $W P$ and NYT sample groups. The multi-ad format was also dominant in The Times group, but to a lesser degree. This trend is significant in that it shows that televisions are usually sold in large groups, where quick comparison of features between sets is possible.

As part of the process of understanding the meanings in the advertisements identified here, I will take some time here to describe the assumptions I held when beginning both my search for the ads and in the actual analysis. According to Willamson (1989), Chandler (2007), and Danesi (2007), self-reflexivity is one strategy for dealing with some of the criticisms that can be levied at the semiotic methodology. Here are the major assumptions that I carried into the project. The first is that I would find remote controls advertised alongside the televisions. The second assumption I made was that I would find the features of the remote described in such a way that reflected how people would use them, and in terms of what the remote would do to change the viewing experience for the consumer. The third major assumption I held was that the remote would be prominently featured in the ads, either through an image representation or through a textual description. These three assumptions informed how I conducted the initial search and how I initially began selecting the ads for my sample. I will address each assumption in turn and draw out the conceptual framework each represents.

The first assumption, that I would find remotes advertised along side televisions, seems fairly straightforward, but it actually presented a greater problem than I 
anticipated. I did not find advertisements for remote controls in the places I expected to find them. I started my search for ads in Canadian and American magazines and spent a good couple of weeks in the library only to come up empty handed. My choice to start in magazines reflects the belief I had that remote control technology was in the same category as other products like fashion items, automobiles and luxury products like jewelry. Looking back at this, it seems almost silly to think that remote controls fit into this category of consumer products, but my actions imply that I did hold that belief. This shows a certain amount of technologically deterministic thought on my part-something along the lines of "the remote control was a new technology and so it must have been at the top of the list of desirable products to advertise".

This leads to my second assumption about how remotes would be advertised. I assumed that they would be described in detail and that the features they offered would be presented to the consumer in an overt way. In conjunction with this, I thought that there was a good chance that at least some of the ads would talk about what the remote would do for a person's experience of viewing the television (and I remember being extremely relieved when I finally found one that did this- one of over 400 ads that I skimmed in my selection process). This assumption shows that I held preconceived notions about how I thought advertisers would approach their audience. The time frame of my research is significant here because I started looking for my research sample in January of 2009, and I finished writing my literature review in December of 2008. I believe that the things I saw in that literature review (which focused almost entirely on research of remote control usage in different populations) greatly informed the expectations I had when starting my search for data. 
The third assumption I identify here as significant to my sample is that I assumed I would find the remote featured prominently in the ads. Again, this assumption reveals a technologically deterministic attitude about the importance of the new technology for the advertisers and the consumers. I started my search with the idea that remote controls themselves might be featured as the only part of the ad (again, I think I found one in the over 400 that fit this bill). Of course a few rounds of searches in the various newspapers revealed that it was not only extremely unlikely that this would be the case, but also that I would have to really search to find the remote control featured at all. Finding an image of a remote control was a bonus, and finding a textual description of features or effects was extremely rare. These assumptions are interesting to look back on because they show some of the technological hang-ups and expectations I had going into the project. The surprises that I did not anticipate at the outset of the project ending up helping me create the majority of my argument.

\section{Semiotic Analysis}

Having addressed some of the assumptions I held going into the process, I will now undertake the formal semiotic analysis. As outlined in my methodology chapter, I am asking questions based on Saussurean semiotic theory as well as Barthes' conception of myth. The lens through which I am asking these questions deals with the concept of newness, innovation and change. The three main questions I am asking of each ad are:

1. What are the main signs and what are their constituent signifiers and signifieds?

2. Given the form and concept identified (the signifier and the signified), what meaning is being communicated through the relationship between these two components of myth? 
3. What rhetorical and literary devices are employed in the ads? What does the content of metaphors, similes, and other literary devices say about how technology is communicated about in the ads (and what references to newness or change are made through these literary devices)?

The other questions listed in my methodology section and in Appendix A will be only applied to ads when the ads are suited to those questions (things like physical location and visual arrangement will only apply to certain types of ads).

I have arranged the analysis section according to major themes found within the ads (after my analysis). It is important to note that many of the ads could be placed in multiple categories because their content addresses multiple themes. These categories are not meant to replace the lens of the new (which was applied to all ads), but to help organize some of the major themes that emerged in the analysis. That being said, these categories are not meant to define the ads in absolute terms. It is also possible that I read signifiers into the ads that were less prominent than others, but my choice to do so was based on the parameters I set out in the methodology section of this document. The five major categories I came up with for the content of the ads are utility, the human user, luxury, convenience, and the new. All of the ads can be viewed in Appendix B and some have been included within the sections below for reference. The appendix is arranged according to the order that I analyzed the ads in, and I group the ads under the themed categories I have assigned them to. I have labeled the ads according to a formula that indicates their type (MA or SA for multi-ad or single-ad), their newspaper of origin (WP indicates The Washington Post, NYT indicates The New York Times and Times indicates The Times (London), and the year the ad is from. 


\section{Utility}

The theme of utility is one that most of the ads could fall under. By utility, I mean those ads that focus on the use-value of the remote control. The ads in this category are generally straightforward and describe features of the remote control in banal, everyday terms. The first ad I analyze is from Bloomingdale's and is the only ad selected for analysis that features no image of a television or remote. It is the most basic form of advertising addressed here and I include it to show the range of material I found in the newspapers. The ad (called MA NYT 1975) contains one-line descriptions of twelve different products, including stereos and televisions, two of which feature remote controls. The line of text describing this television reads, "25" diagonal Magnavox remote control color tv. Contemporary cabinet. Orig. 750.00-----495.00" (Appendix B, MA NYT 1975). This line is very similar to the other on the ad that talks about a remote control. Given the space of the ad and the obvious brevity of the description, it is not surprising that little information is given about the features of the remote control (or of the television, for that matter). This being the case, it is fairly significant that the remote control is mentioned at all in these two lines (when it is not listed for two other television sets). This signifies that the remote control is a feature of the television that warrants inclusion in the ad alongside whether the television transmits a color picture or a black and white picture and what the screen size is.

The next ad that fits into the utility category is a multi-ad from February of 1981 and advertises instant savings on different models of RCA televisions (the ad is labeled MA NYT 1981). The graphic shows three television models, and one of these three features an inset circle with a remote control being held by a masculine hand (compared to other ads that feature a more feminine hand-no fingernails are shown). This inset is 
the central figure in the image of the three televisions and is proportionately much larger than actual size when compared to the dimensions of the televisions. The television with the remote is actually called the "Remote Control XL-100 color TV" highlighting the prominence of the remote for this particular unit. The textual description of this television includes the line, "select from decorative console models or a table model all with ChannelLock Remote Control. Turn the set on and off, adjust volume or select any channel from across the room" (Appendix B, MA NYT 1981). The two signifiers of greatest interest here are the brand name "ChannelLock Remote Control" and the ability of the user to act on the television from across the room. The ad does not describe in any detail what the features of the ChannelLock Remote Control are, or why it might be better or different from a regular device, but it does highlight the technology by assigning it a specific name. The discussion of the remote control places the user in physical location that is separate from the television unit (across the room). This signifies freedom from the older versions of the television, but this relationship is completely inferred by me as the reader of the ad. The copy of the ad makes no reference to the concepts of the new, the changing or the innovative.

One single-ad that fits into the utility category is for a Tandberg television set featuring a large picture of a television set and a fairly long textual description (the ad is called SA Times 1978). The remote control is not prominently featured in this ad, and is mentioned only briefly (I should note that the image quality of the .pdf file is quite dark, and though I am fairly sure there is no remote control pictured, I cannot say this with complete confidence). The discussion of the remote control is presented among a long description of many other features, including references to sharper colour picture, crisper 
sound quality, easy servicing, and better signal reception. The description of the remote and the lines preceding it read, "the set runs cooler, lasts longer. Plug-in models for easy servicing or repairs (rare with Tandberg!). And full remote control models are available" (Appendix B, SA Times 1978). The reason I included some of the accompanying texts with this description is to show that the rhetorical strategy of the ad is not as literal and descriptive as the line of text that features the remote control. The ad employs the exclamation mark as a way of stressing one of the selling features of the product; it shows that the company is comfortable using excited and amplified language to sell aspects of the set. The contrast between the two lines shows that the signifier of the remote control could be talked about in a more theatrical way (using more interesting and excited language), but it is not. This ad presents another example of how the remote control is talked about in a very simple, straightforward way (even when the rest of the ad employs a different rhetorical example). Again, I expected to find something that sold the remote and its uses to the consumer in a very specific way, and I do not find that here.

Another ad selected for this category is from The Hecht Co. and is labeled SA WP 1975 (this ad is included after its description for reference). This ad features the remote control in both image and description, and in addition to the four televisions pictured, the remote is one of the dominant visual images. The image of the remote is placed adjacent to the television, and it is also slightly foregrounded. A feminine hand is holding this remote control, which features three large buttons. On the picture display of the television is a drawing of football players in action. The description of the remote control describes that the product is a "19" diag. videomatic $(\mathcal{O}$ color tv with remote control. Now, arm chair tuning of up to 12 VHS and 9 UHF channels, on/off and volume adjustment tool" 
(Appendix B, SA WP 1975). The description is very brief and uses few descriptive terms or unnecessary words.

The signifiers I focus on here are the three features of the remote control identified. Arm chair tuning is similar to the reference to the easy chair found in the last ad in that it implies a position of the user in a piece of furniture, separate from the television itself. The on/off and volume adjustment tool is simply description of the function of the device, and gives little else in terms of how or why the remote can be used. This ad offers no literary devices or overt rhetorical strategies that use persuasion to sell the product. It is similar to Leiss, Kline and Jhally's categorization of the productoriented approach in that it employs technical description and rational logic to sell the product. Features are listed as they appear and the product stands on its own outside of metaphor or persuasion. 
Display Ad 54 -- No Title

The Washingen Post (J974 Current fike; Nov 16, 1975; ProQuest Historical Newspapers The Washington Pos: (1877 - 1992) pg. 27

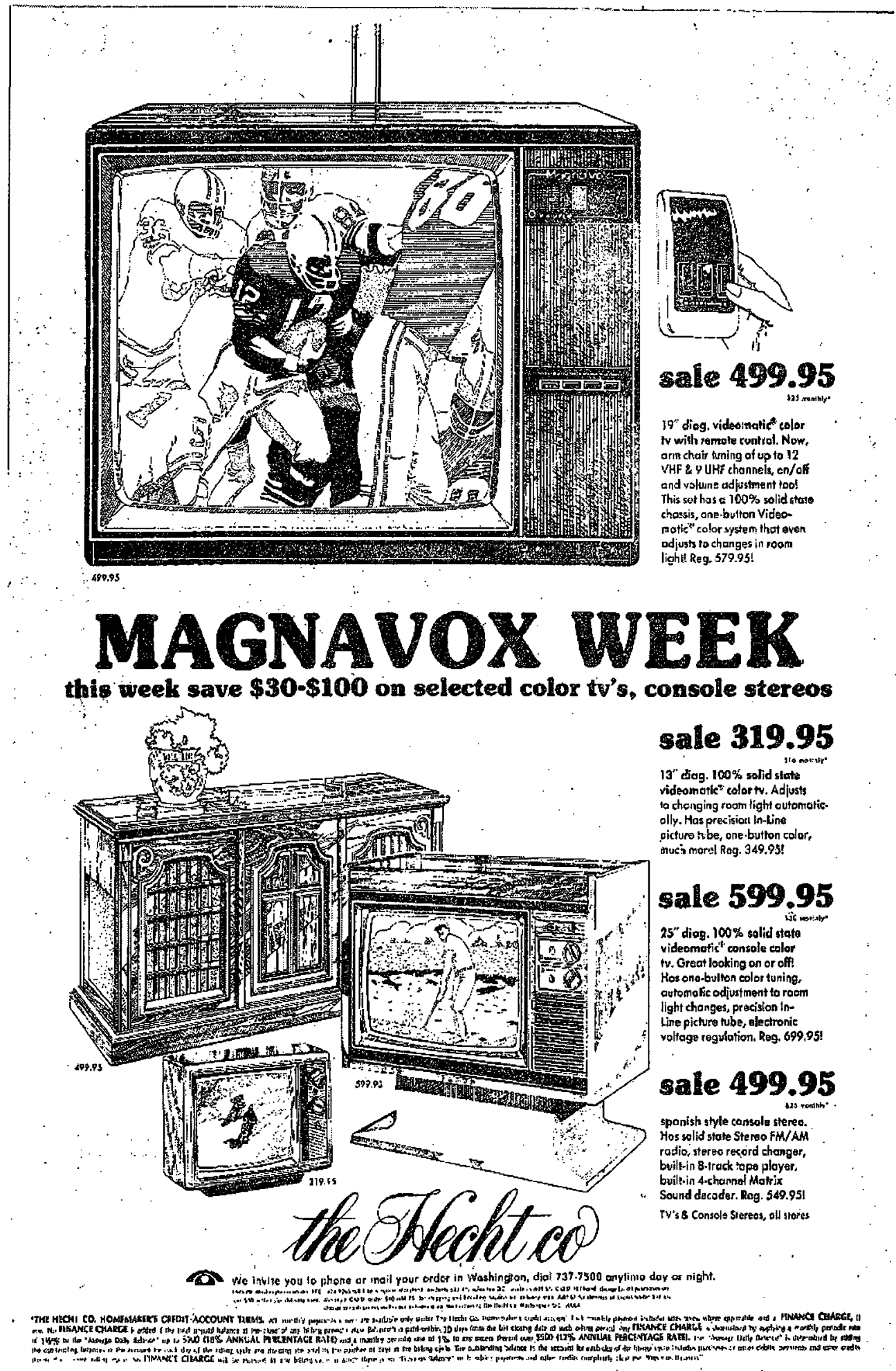

Figure 2: SA WP 1975 
The final ad in the utility theme is MA WP 1980 an ad from George's department store that appeared in December 1980. The ad is pictured on the next page for reference. This ad features not only televisions, but also other home appliances like washing machines and stereos. Twelve television models are featured (with images and description), with three descriptions of remote controls accompanying the television. This ad features two remotes that are pictured alongside their television models, both in inset boxes that highlight the technology as separate from the TV. The signifier I focus on here is the picture of the remote control device, and the signified represented by it is first the device itself, and second, it is a way of changing the channel from across the room. The text describes the device as a "programmable scan remote control", which implies that the remote can be used in a way that is designed by the owner. How things are programmed or what the benefit of programming might be are not offered in the textual or visual descriptions. This ad offers little more than a visual image of what a remote control looks like—and as such, I cannot infer much symbolic meaning past the most basic understanding of what the remote might mean to a consumer shopping for a new set. As for the question of rhetorical strategy or literary devices, this ad is similar to MA WP 1975 in that it focuses mainly on a straightforward description of the products and a technical rundown of their features. The small title above the bank of television sets reads, "Enjoy a colorful holiday", which again references that the color television is the selling feature of the ad. 
Display Ad 21 - No Title

The Washington Post (I974-Current file); Dec 9, 1980; ProQuest Historical Newspapers The Washington Post (1877 - 1992) pg. A25

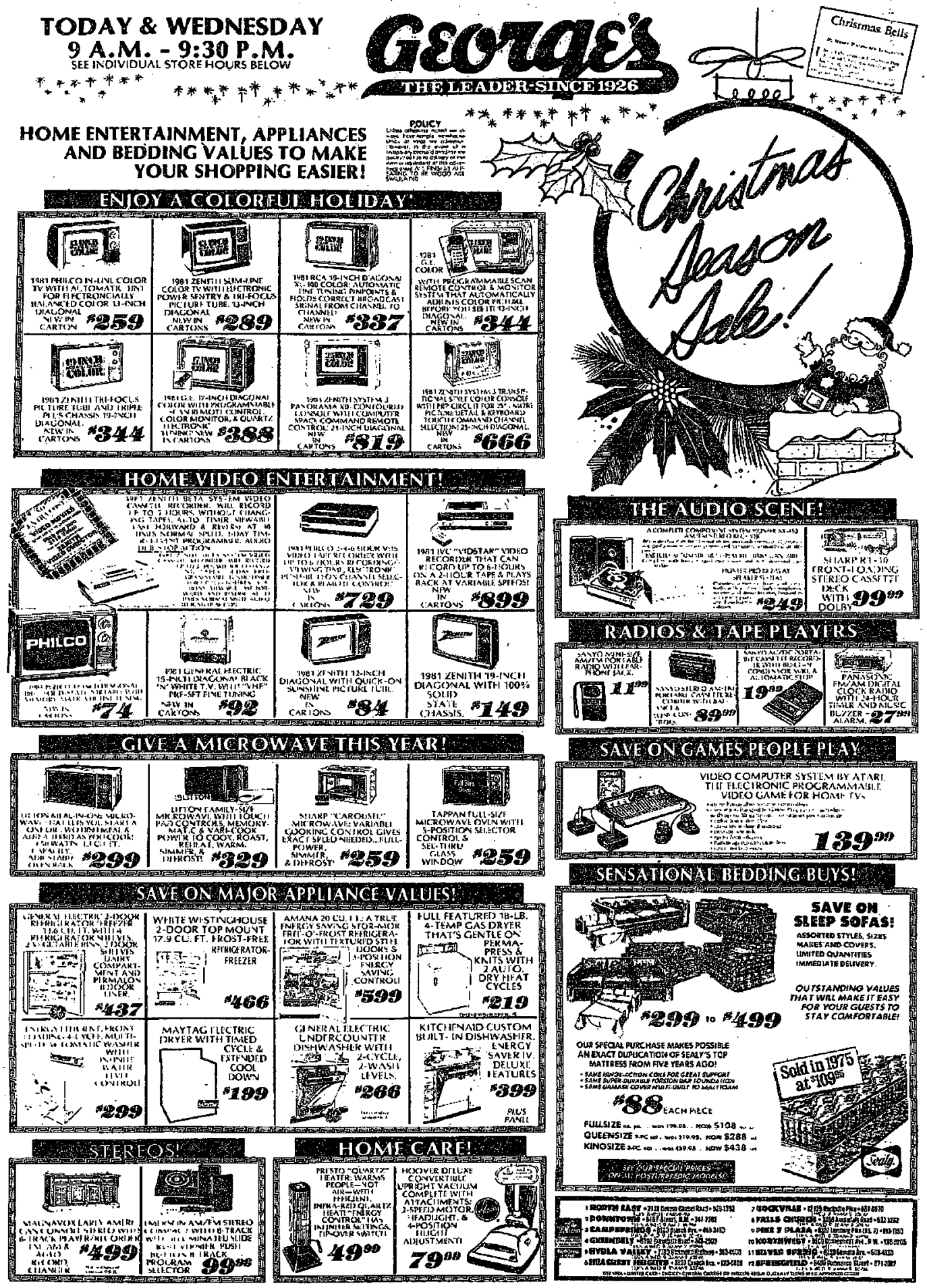

Figure 3: MA WP 1980 


\section{The Human User}

The next group of ads I analyze are those that reference the human user in a prominent way. The first is called MA WP 1981; I have included it below for reference. This ad was printed in November 1981 and features nine different televisions with textual descriptions and visual images. This ad is almost a combination of a multi-ad and a single-ad in that it features one television prominently and the other eight in smaller boxes with less description. This split focus is one reason the ad has more time and space to discuss the features of the remote control (something not usually found in the multi-ad group).

The important signifier in this advertisement is the combination of the remote control and the hand that is holding it. The remote control is narrow (by modern standards) and has six buttons on it that are not clearly described and the hand holding it is slender with longer fingernails, indicating perhaps a female user. Together, the two symbols work together to signify something meaningful about using the remote control. This is the first example of an ad that unites the technology and the human user behind it in one image. One of the major headlines on the ad reads: "Circuit City Reports on the RCA Remote Control". This headline implies that some sort of account of the remote control might follow, but no such account is found. Instead, there is a picture of a television with a hand holding a remote control in front of it, a large price listed over the image and the following list of features accompanies this image: ColorTrak- automatic color control - light sensor - LED channel indicators- infrared remote control - handsome woodgrain cabinet - 17 inch diagonal screen. 


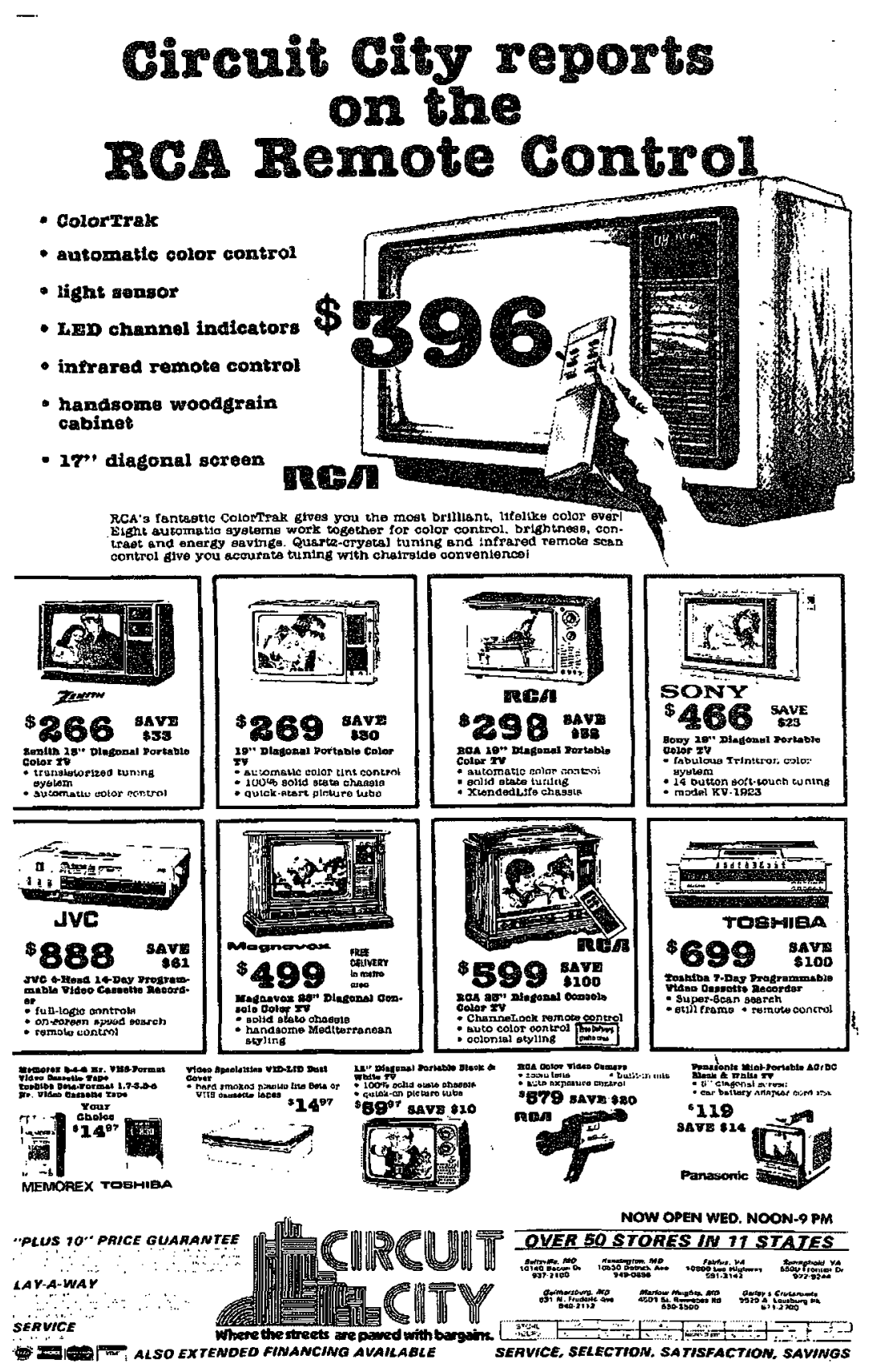

Figure 4: MA WP 1981

The next ad I analyze in this category is a single-ad called SA Times 1981 and features a Philip Teletext television set (the ad is printed on the next page for reference).

The ad is quite involved (compared to most in this sample) and describes not only the television, but also the remote control and the ways this set allows users to view 
cinematic content. This ad portrays the television as an information device in addition to its regular use as picture projection machine.

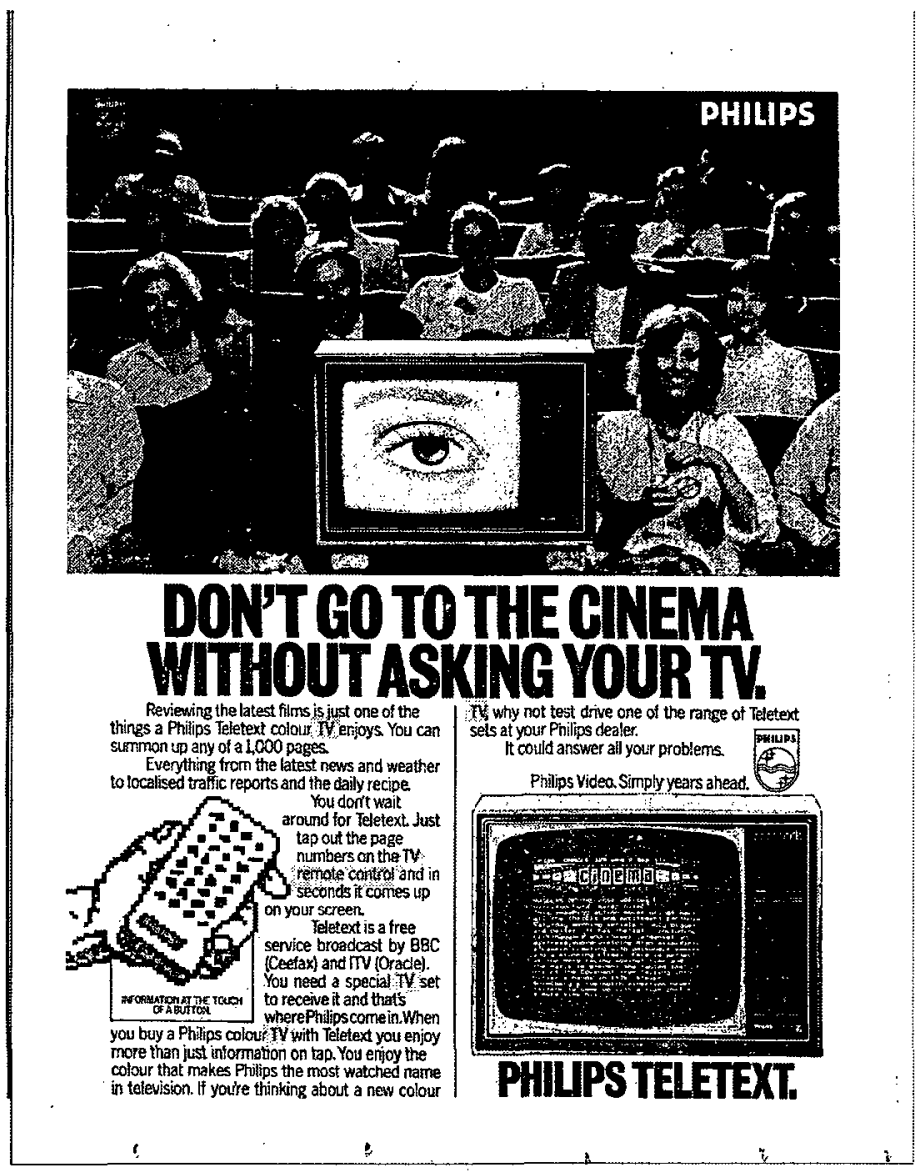

\section{Figure 5: SA Times 1981}

The major headline on the ad reads, "Don't go to the cinema without asking your TV".

This line references the ability of the teletext television to display other types of information. The description in the ad explains that, "everything from the latest news and weather, to localised traffic reports and the daily recipe. You don't wait around for Teletext. Just tap out the page numbers on the TV remote control and in seconds it comes up on your screen" (Appendix B, SA Times 1981).

Another reference to the remote control is presented underneath an inset image of a remote control with thirty-two buttons being held by a masculine hand-the text in this 
case reads, "information at the touch of a button". The major signifiers that interest this discussion involve the notions of speed and interaction. The ad references information that comes up in seconds and the ability of the user to simply touch a button and receive this information. These two signifiers - speed and ease-communicate the ways in which the company expects the user to interact with their product. They hint at futuristic ideas about how the world can be accessed through a technological product that delivers new ideas and information to your screen. The signifier of ease has been found in many of these ads, and here again it references a life made better through the technology being represented. Much like the agricultural machines that changed the American landscape and farming practices in the nineteenth century, the remote control is advertised as performing formerly labor-intensive tasks (relatively labor-intensive) in a mediated, easier way.

The final ad I analyze in the human user category is from The Times sample and is called SA Times 1980. The ad features both a detailed picture of a television set and a remote control and a lengthy description of the product (it is also pictured on the next page for reference). The image is a photograph of a living room with a television set on a wheeled stand in front of a window. There is a potted plant to the left of the television, sitting on the floor. The living room also features a coffee table, and on the coffee table are a rotary-style telephone and a remote control with several buttons. The photograph of the living room setting is an important signifier in this ad. 


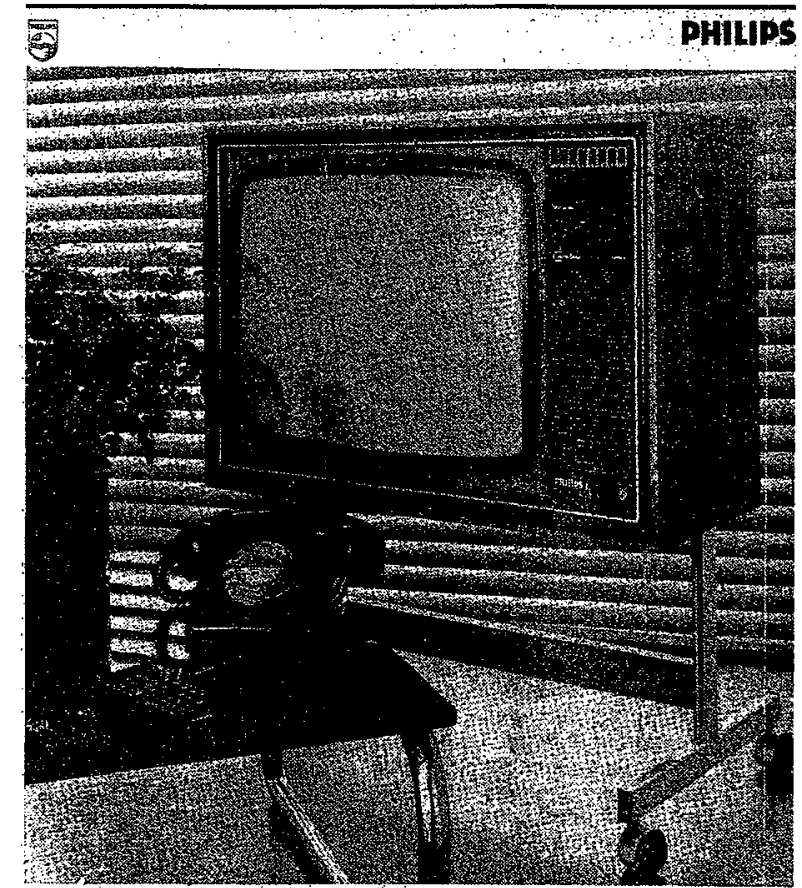

\section{ANY QUESTIONS?}

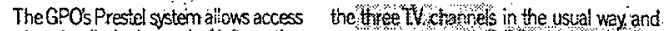
to an almost unlimited source of information. come complete with Fun Renote Contro: And Philips $25^{\prime \prime}$ and 22 Vawdata ses. . Theyre izat oart of the Philsos range of are fully compatible with the latest cevetop- advancec domestic video products which - includes the V2000 eigni hour video cassette

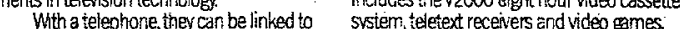
Prestel to from faming to air tares, share prices to. Box3, Horley, Surrey. Orvisityour PhilipsVideo

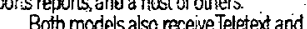
dealer. Whatever your questions, heth the answers

Philips:ceo.Simplyyearsahead. VEWOATATVROM PHILIPS VIDEO

\section{Figure 6: SA Times 1980}

The signified the living room invokes involves around sitting down, probably with a family, and relaxing after work or school. It is a communal place, and the presence of the telephone implies that this is a space in which not only the immediate family comes together, but also where communication with the outside world is made. The telephone and the television are technological links to worlds outside of the domestic life represented by the home.

The textual description of the television set includes a mention of the remote control; it reads "both models also receive Teletext and the three T.V. channels in the 
usual way, and come complete with Full Remote Control" (Appendix B, SA Times 1980). The signifier that catches my attention in this ad is the word complete, as it signifies that the remote control helps to make the purchase of a television set a whole entity. It implies that without the remote control, the set would be missing a key element, a part of that whole product. This level of integration with the purchase of the set implies that the remote is an essential part of the viewing experience that the owner of this new television set will have. The ad further describes how these models are a part of a larger product line of Phillips products that enhance television viewing: "they're just part of the Phillips range of advanced domestic video products, which includes the V2000 eight hour video cassette system, teletext receivers and video games" (Appendix B, SA Times 1980). The word advanced used in this line is a signifier that connotes improvement, development and progress. The advertisers for Phillips use the term advanced to show how this particular product line fits into the timeline of technological development-it is better and further developed than other models (presumably offered by competing companies). The notion of advancement is one that fits into the theoretical background of technological determinism in that it is seen as a building process, where older technologies are replaced by newer, more advanced models. Again, this connection is not directly stated in the ads and is something that $\mathrm{I}$, as the semiotician, have pulled out from the connotated meanings I read in the ads.

\section{Luxury}

The theme of luxury among the ads is the next that I address. I found only two ads that fit in this category and their relevance to the overall myth of remote control advertising will be further addressed in my discussion of these findings. The first 
example of this theme is a multi-ad called MA NYT 1982 and features two RCA televisions in a group of ads for televisions, color video cameras, and videocassette recorders. This ad appears on the next page. The ad features the two televisions categorized as either black and white or color sets. There is no image of a remote control, and the reference to it comes in the description of the color sets: "everything from 9" portables to magnificently styled 25" (diagonal) luxury consoles... with or without remote control...and many are 'Cable Ready' with direct access to as many as 127 channels" (Appendix B, MA NYT 1982). The interesting signifiers here are the choice presented in the term "with or without" and in the reference to cable television. With or without remote control signifies that it is up to the consumer to decide whether or not they would like to use remote control technology when viewing their television.

The fact that the ad references cable television is interesting because the idea that the consumer might be accessing 127 channels implies that they might need or want a remote control to help them manage that overwhelming number. It is interesting that the issue of cable channel selection is not referenced in any other ads I analyze here. Given the history of the remote that I explained in the introduction to this project, I assumed that the two were more closely linked. It could be that the introduction of cable occurred later in the 1980s and 1990s and that the connection between channel surfing and cable was further developed at that time. 


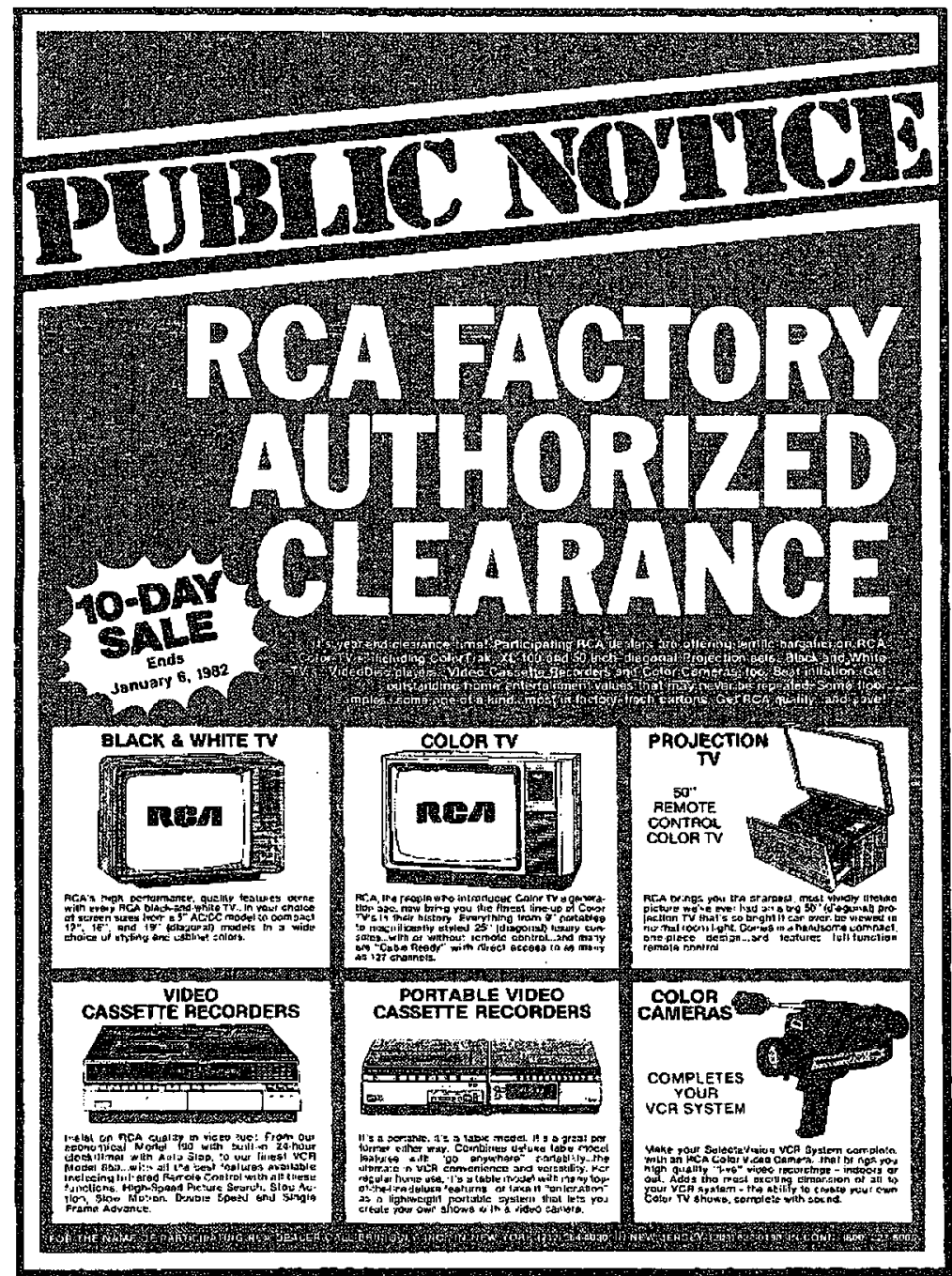

Figure 7: MA NYT 1982

The other signifier I wish to address here is the word "luxury". This ad shows that the company is selling a range of products, and if the consumer chooses to identify with a luxury brand, they can find that at this store. The signified that luxury invokes is one of excess, quality, and cost. The idea of the cable channel selection invokes some of these same signifieds. Tied up in the notion of luxury is the idea of choice and selection, which is also signified by the remote control. 
The other ad that fits into the theme of luxury is from the NYT group. The ad sells the television in a package with other items, like a videocassette recorder and speakers (more akin to what we know as a home theatre system today). This ad is labeled SA NYT 1982 and can be found on the following page. The major feature of the ad is an image of a "giant screen TV" with a photorealistic image of a football player on it with a man standing beside it for reference of size. There is quite a large amount of textual description, much of which describes the size of the screen and the technology behind the projection television system. The only mention of remote control technology comes in a list of other features of this television. Under the title of "From Henry Kloss, the world's leading designer of large screen TV - here's the brightest, sharpest, $6 \frac{1 / 2}{2}$ foot large-screen unit available for home use today", the ad lists the amount of light given by the unit and the tube technology being displayed as well as a "wireless remote control" that accompanies the purchase (Appendix B, SA NYT 1982).

The signifiers that are featured prominently in the ad are the screen size and mechanical technology, whereas the remote control is featured as an ancillary item. This section of the ad concludes with the line "It's simply the best in its class" (Appendix B, SA NYT 1982) which signifies the idea of luxury and status, much like the ad labeled MA NYT 1982. This ad is using the rhetorical strategy of stressing luxury and top quality items instead of the idea of the new that I expected to find in this sample. The fact that the two ads that reference the idea of luxury and class are from the same year (1982) could be coincidence or it could be the result of other processes (like the particular economic factors of the time period). The semiotic methodology does not allow me to 
address this type of question, but it might be something that future research could address in a more systematic method (like a detailed content analysis).

\section{"Now Ive seen everything"}

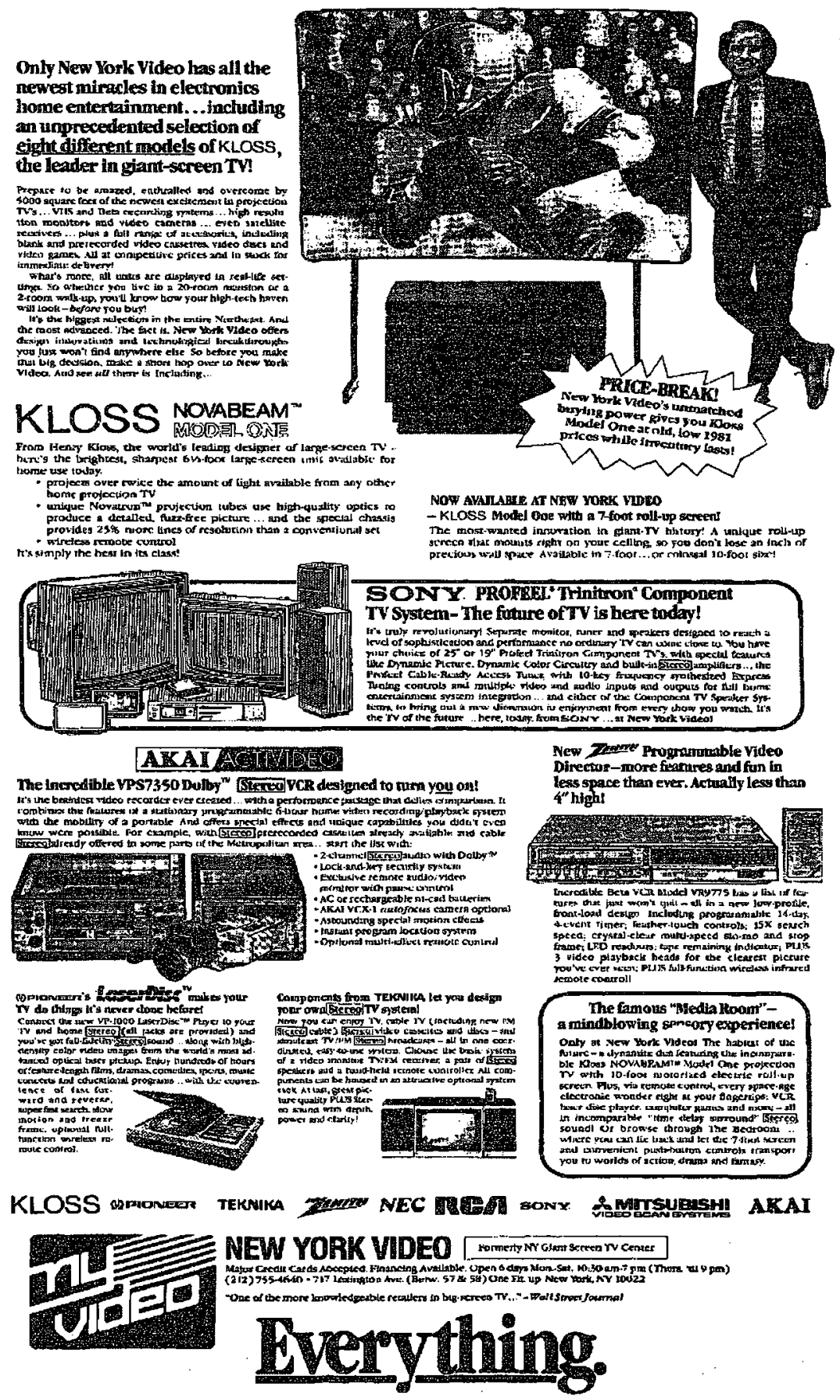

Figure 8: SA NYT 1982 


\section{Convenience}

Another theme I address that came up throughout both the multi-ads and the single-ads, but more prominently in the single-ad sample is the signifier of convenience. I highlight this particular sign because it was the most common theme that was used to address the remote control specifically. In hindsight, it makes sense that convenience is the most marketable feature of the remote control—if the device does anything for the user, it makes the viewing experience easier and more convenient. Convenience is a selling feature that is often used in the marketing of domestic goods (particularly in products aimed at making housework easier).

The first ad I analyze within the theme of convenience is from 1977 and is labeled SA WP 1977 Panasonic (again the naming scheme follows the formula of single-ad, Newspaper, year of publication, but also includes the brand name of the featured product because of multiple ads from this year). The ad features only one television set and it is found among many other ads for home appliances and goods like china sets and vacuum cleaners. The ad itself shows a television set with a picture of a government building, possibly The Capital building in Washington. This ad features an image of a remote control more prominently than previous ads; the image is in front of the television and is larger (according to the proportion of the two images) than it would be in real life. Significant here is that a hand (with the female features of longer fingernails) is holding the remote and pointing it at the screen. The textual description that accompanies the ad contains the line, "Super convenience with two direction channel change, 'quick on' picture tube, Panalock@ AFT button" (Appendix B, SA WP 1977 Panasonic). Again the signifier I wish to address here is the idea of convenience. The signified connotation is 
that the remote control device will affect the experience of watching the television by making it more convenient. This implies that without this technology, the experience might be inconvenient in some way. Ads like this one that target convenience work under the assumption of the technological fix that is a part of a technological determinist framework. This ad is one example of how the technologically deterministic rhetoric that is found in academic literature is reflected in the advertising of the devices.

The next ad in this category that I analyze is also from the $W P$ sample and is labeled SA WP 1980; this image is printed on this page for reference. It features three pictures of television sets, and the main title reads "You could use a little color this winter". The other image in the picture is a coffee cup, placed next to the television. The coffee cup is a signifier that invokes the signified of a morning routine or a part of daily life. The coffee cup also suggests that the location of this television might be near or in a kitchen or other eating area. The reference to the remote control in this ad comes not from the images, but in the form of text. The copy reads, "The Trinitron on the right (19" measured diagonally) has remote control. It lets you change channels and adjust the volume instantly... and from your easy chair" (Appendix B, SA WP 1980). Here again, the signifiers that stand out are the words instantly and easy chair. Convenience is the idea being sold, and the easy chair references the position of the viewer in relation to the television. The easy chair is a product that could warrant its own analysis, but for these purposes, I will just highlight that this particular type of chair signifies simplicity, comfort and ease. The symbol of the easy chair is one that involves the viewer's body in the selling of the television (through the remote control). The literary devices found in this ad deal with the feature of a color picture more so than the remote control feature. 


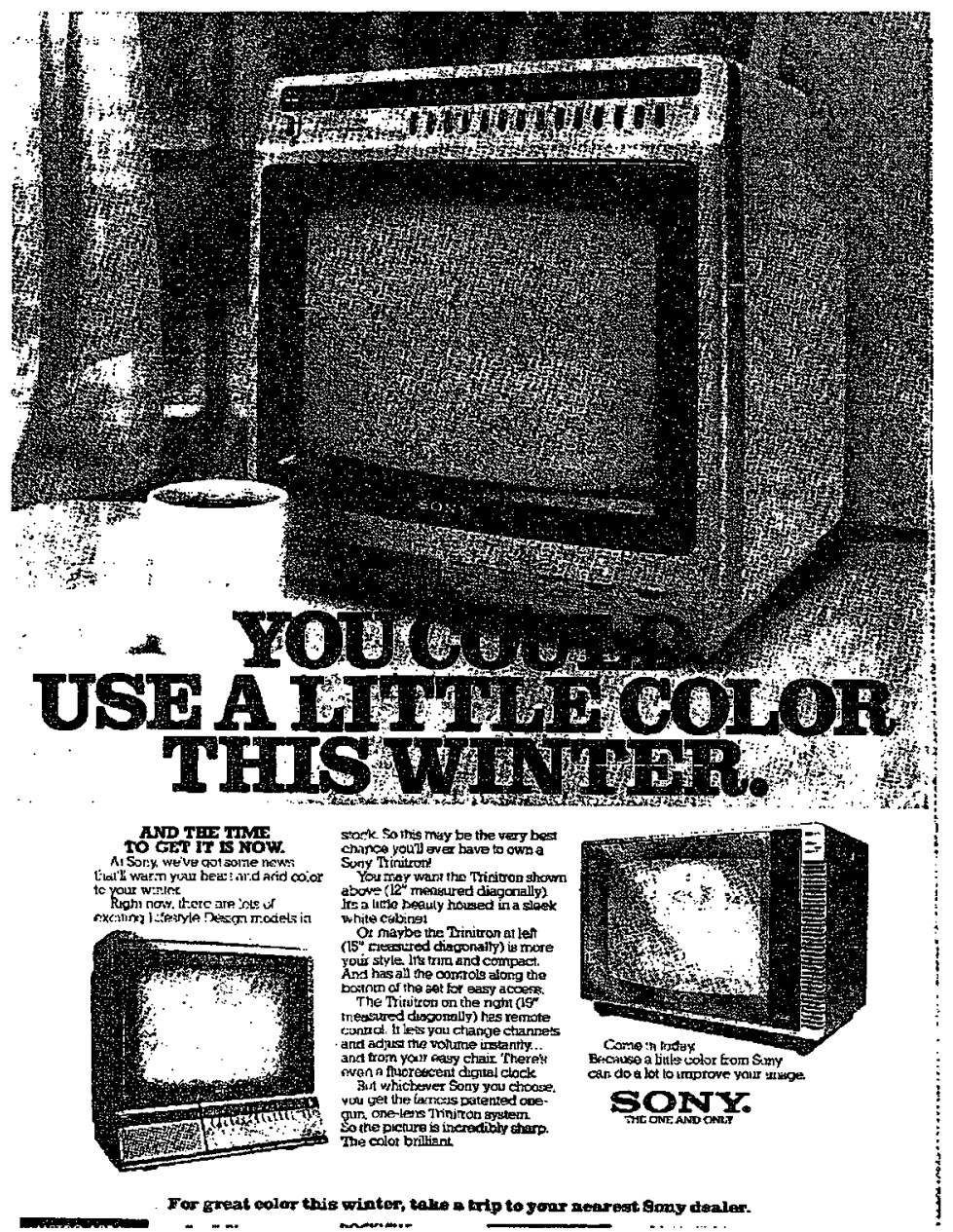

\section{Figure 9: SA WP 1980}

One example of this is in the product description, which reads, "because a little color from Sony can do a lot to improve your image" (Appendix B, SA WP 1980). This metaphor compares the color technology offered by Sony with the social image a person projects by owning this television. It is the kind of metaphor the advertising studies scholars identified in my introduction refer to most often when talking about ads. It is one of few ads in this sample that sells us ourselves, to use Judith Williamson's terminology. I point it out here to contrast the type of language and imagery that is found about remotes in this analysis. Very few ads seem to connect the remote control with the user 
and even fewer draw metaphors between what the remote does and how that changes viewer experience. This relationship just is not highlighted in this sample of ads.

Another ad that I have placed in the convenience category is labeled SA NYT 1979 and does not clearly show what company or product brand is being advertised. The ad features a hand holding a remote control (the gender of the hand is unclear because the picture is so dark), and the remote is pointed at some other device (not a television). There is accompanying description with this image, which reads, "This is the last word in lazydom. A cordless remote control device that turns on/turns off anything plugged into its companion unit—lights, TV, stereo, or any combination up to 400 watts within a 50' range. No batteries, No problem" (Appendix B, SA NYT 1979). The title of the ad in this instance is also interesting: "Christmas at the dawn of a decade" with the subtitle, "With the whistle switch, you're the master of current events" (Appendix B, SA NYT 1979). This ad represents the only one in the sample that sells a universal remote (to use modern terminology).

The signifiers that stand out in this ad are the concepts of "lazydom" and the metaphor that this device makes a person the master of current events. Laziness is an interesting concept in this context because it has a generally negative connotation. People do not usually strive to be lazy, but instead strive to be productive, active members of society. It is interesting that this concept is tied to the suffix "dom" indicating an area of rule (like a kingdom). This rhetoric fits in with the idea of being master of current events because both terms signify control and dominance over a certain realm. To be the master of current events means having ultimate access to information and to different types of media available to the consumer. The signifier "at the dawn of a decade" is also worth 
noting here because it references the word dawn (a reference to a new beginning). The company draws on the fact that the calendar year (1979) is changing to a new decade (the 1980s) and this opportunity means a chance for people to experience a new type of technology with the whistle switch device.

\section{The New}

The final theme that I use to categorize my analysis includes ads that directly or indirectly reference the major lens used in this project, the new. I have identified four ads that do this, but only two reference the word "new" directly. The first ad in this category is a single-ad and is notable because it takes a narrative approach to the sale of the product, which is something that is rare among this sample of newspaper ads. The ad is called SA WP 1979 Sony and features one television set and a long textual description. Part of the narrative of the ad tells this story: "Introducing the 26" Trinitron from Sony. His Mother was 19". His Father was 21" ". The remote control is also featured in this text: "we also added our all-new, Express Tuning keyboard and Express Commander remote control unit that let you tune into the station you want instantly, at the touch of a button" (Appendix B, SA WP 1979 Sony).

Significantly, this is one of only a few ads that I found that used the word new. The signifier of the "all-new" tuning keyboard and remote control is linked to a signified that deals with something that has never been available before. The technology is novel to Sony and to the consumer. The second important signifier in this ad is the phrase "instantly, at the touch of a button". This descriptor refers to technology that increases speed and emphasizes the ease with which it can be used. These are themes that have come up in previous advertisements as well and that are common to academic writing on 
technology. Again, this ad evidences that the advertising companies used some of those themes I identified as a way of selling products to their consumers.

The next single-ad that I am addressing in this group is labeled SA WP 1977 Sony (this ad is printed on the next page for reference). This is a very simple ad that features only a single Sony television and a few words of description. The ad does feature a remote control, placed in the foreground of the image, at the base of the television set. The picture on the television is, again, a football player. The textual description of the television reads, "This Trinitron set is designed with an all-electronic remote control system and triple function commander that adjusts volume, changes channels, turns picture on or off' (Appendix B, SA WP 1977 Sony). Of note here is the mention of the all-electronic remote control system because it highlights another feature of remote control that has not been previously addressed in these ads.

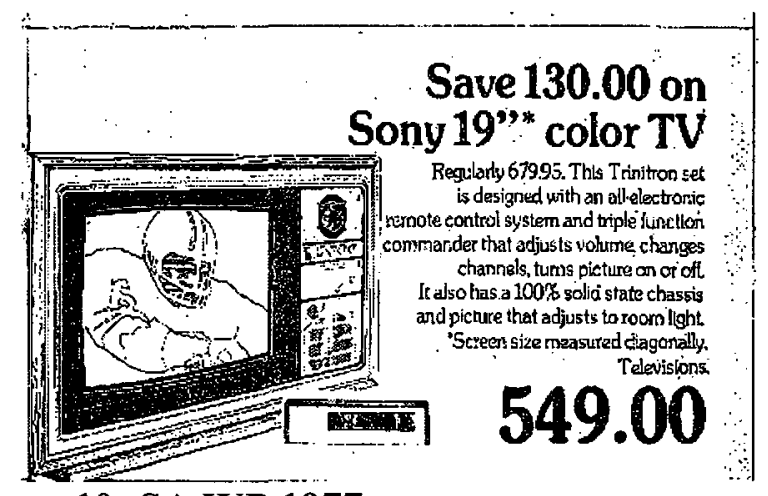

Figure 10: SA WP 1977

The remote control being electrically driven signifies some connection to the futurist ethos identified in the theory section of this project. As noted there, electricity was heralded in America as a solution to the problems created by mechanistic technology in the 1800s. Although the word "new" does not appear in the ad, the ideas that it encompasses are indirectly brought up through the mention of electricity. Another signifier that warrants mention here is the triple function commander, which signifies a 
mix of features on the remote that were perhaps not available before. This is of course, not the case, as other remotes I have analyzed talk about the three functions this remote performs, but in naming it something unique, Sony highlights it as something different than a competitor's device.

Another ad that I place in category of those dealing with the new comes from The Times group and is called MA Times 1983. This ad features the images and text describing a number of black and white televisions, a number of color televisions and a portable television. The remote control is featured in textual description of just two of the models featured in the ad. It is also pictured with one television, but as a part of the set, not separate from it. The two mentions of the remote control come in the product name of one set and in the features description of another. The set that is named with the remote control in mind is called the " 20 " Contec Remote Control Colour TV" and the description of the remote is as follows, "Remote control handset is magnetised so that it can be used on the control panel or away from the set" (Appendix B, MA Times 1983). This way of selling the remote, as a device that can function both as a remote and as a traditional panel control (on the face of the television set) interests me because it incorporates both the new technology and the old technology in the same product. This example does not show an overt use of the text "new" or "old", but it does reference the concepts in its design and description. The product gives the user a choice between the older way of doing things and the newer one, and the design of the remote control (in that it is magnetized to adhere to the physical body of the set) suggests that the device can and will be used in either way. The year this ad was printed (1983) is one of the later of this sample, and as such, it is speaking to an audience that may have had some experience 
with the technology. This is purely speculation, but this design might also be in response to the problem of people losing the remote control in the television viewing room (a timehonored tradition still practiced today). This is one of the limitations of this semiotic approach; the intended meaning of the ad is not always apparent from the printed material and these kinds of conjectures are based only on my knowledge of the context of the ad. I feel it is important to show what my lens reveals about the technology when looking at the ads, but I also feel that it is important to clarify that this is just one possible reading of this particular ad.

The next ad I analyze is called SA NYT 1980 and features RCA remotes (this ad is printed on the following page for reference). This ad contains an image of thirteen televisions grouped together, and above this image is a very large picture of a remote control (being held by a masculine hand). The remote is at least three times bigger than any of the televisions in the image, and is the dominant image in the picture. This remote control model has seventeen different small buttons on it (much more than most of the other devices pictured in ads). This ad is one of few that features the remote in an overt, central way. The title of the ad reads, "\$120 Off RCA Remotes when you trade your old TV for a 1981 RCA Remote Control ColorTrak" (Appendix B, SA NYT 1980). The textual description that accompanies the picture describes the remote in greater detail: "RCA's New Infrared ColorTrak remote control. RCA's most advanced remote control ever. Select any VHF or UHF channel either directly or by scanning up or down, stopping only at the channels you have programmed into the TV's electronic memory" (Appendix B, SA NYT 1980). The signifiers I address here are the terms used to describe remote as the old, the new, and the advanced. 


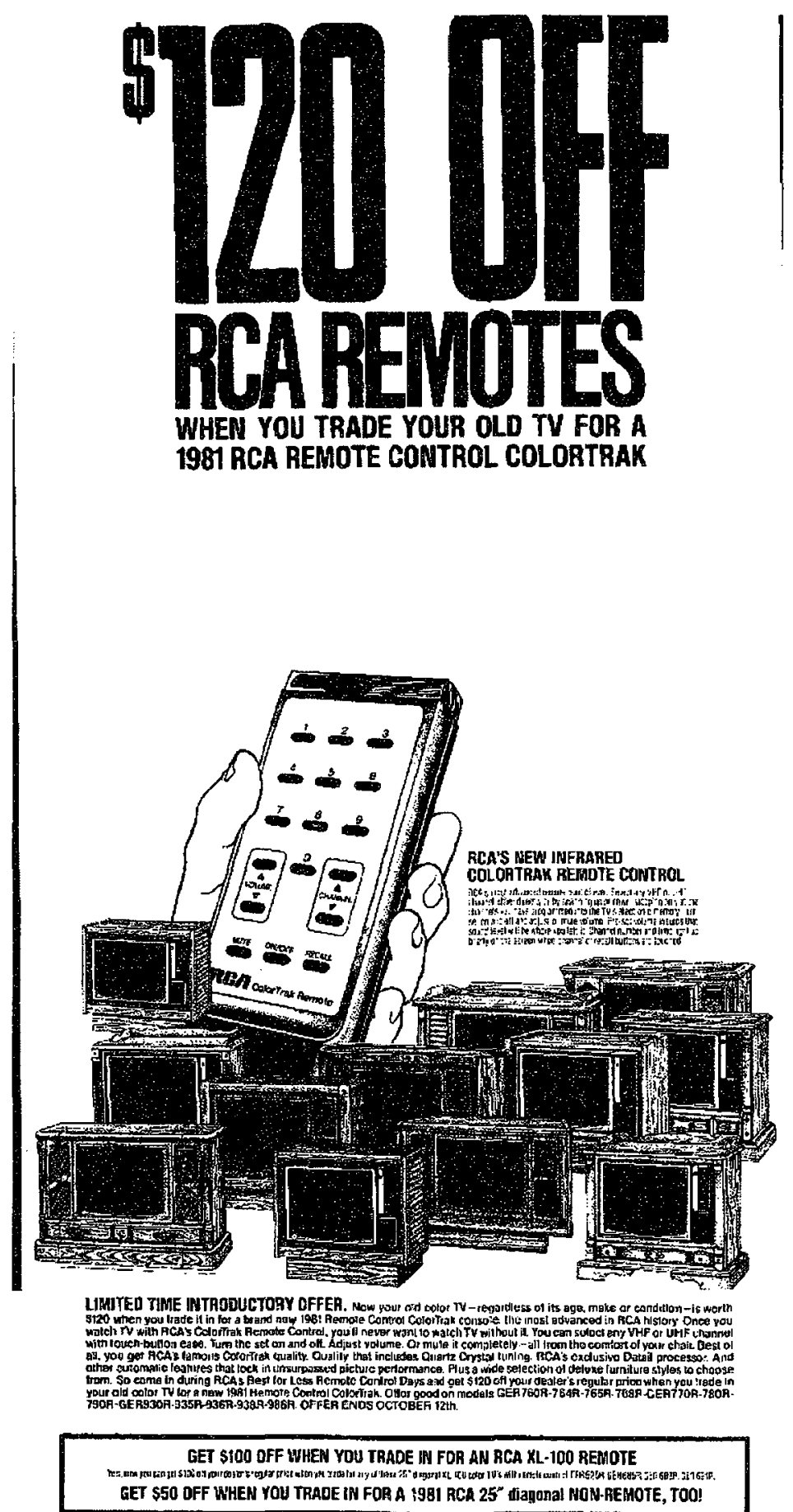

Figure 11: SA NYT 1980

Perhaps it is no coincidence that the one ad I found that featured the remote control as the central problem is also one of few that addresses the theme of the new. The signified represented pairing of the old television model (that the consumer is urged to 
trade in) and the new remote control (that is given as a bonus for this trade in) highlights the theme of innovation, change and difference. This ad fits with what I expected to find in terms of a technologically-oriented ad that sells the consumer on the idea of the future, the next thing, the most advanced technology. The functions of the remote are listed in detail, and the television is actually being sold through the features of the remote control (not the other way around which seems to be the norm in this sample). The rhetorical strategy present in the ad suggests that if you trade in your older model of television, you will be rewarded with a new piece of technology, the "most advanced remote control ever". As I said, this is exactly the type of ad I expected to find throughout the newspapers, but it is certainly much more an exception than the rule.

\section{Comparing the Analyses: What does it all Signify?}

I will now comment on the overall trends that I see in this sample; I will use the trends and patterns to describe the possible myths that inform the area of newspaper advertising of the remote control device. First, among multi-ads, I found that of the eight multi-ads I looked at, only three (MA WP 1980, MA NYT 1981 and MA Times 1983) described the remote control and its features in detail beyond simply naming the device. I would also guess that this ratio is an inflated representation of the actual percentage of multi-ads that feature this level of description because when I was looking for my sample, I wanted to find the ads with the most descriptive information on the product. Another trend I found in the multi-ad sample was the use of small icons and images to visually highlight the presence of the remote control. Of the five multi-ads that feature an image of a remote control, three of them presented it in inset boxes or circles that demarcated the space of the remote control as separate from the rest of the image or description. These boxes could be interpreted as a means of highlighting the remote 
control or as simply a way of keeping their visual space apart from the rest of the advertisement. Another trend in the multi-ad sample is that the overwhelming majority of ads (specifically for the WP sample) fit into the multi-ad categorization. The existence of this type of ad says something about how televisions are shopped for by consumers. It implies that advertisers are generally uninterested in selling the ad in very specific, focused formats that go into great description about the product's place in the consumer's life. The multiple ad format gives consumers a side-by-side comparison of different models, brands and features and allows them to calculate quickly a cost-benefit analysis of choosing a larger screen size on a color set. Those two features, screen size and color resolution are the two most commonly cited by the ads (in all samples). In the multi-ad samples, it seems that advertisers prefer to give the consumer those comparison opportunities than to try to sell the device through an elaborate rhetorical strategy. This observation speaks to the possible myths that the sale of televisions (and remote controls) invokes. These are not products that advertisers personify in order to sell a lifestyle as much as a product (even though this time period is precisely when Leiss, Kline and Jhally (1985) characterized lifestyle format advertising as being the norm). According to this sample, these products are simply devices that should be selected based on what features the user values most.

The single-ad samples tell a slightly more detailed story about the possibilities for remote control usage in the 1970 s and 1980 s, but it is still largely a story that is based on use. The bulk of my analysis of the single-ad samples focuses on textual description of the remote control, even though images of the remote are quite abundant in this group. The reason for this that the textual analysis gives more information that can be interpreted 
and considered using this semiotic method. There is greater potential to find a persuasive strategy in a sentence describing remote control use than in a static image of a remote control (especially when the images of the remotes in this sample tend to be adjunct to a larger persuasive message). I mention this to highlight the fact that the images of the remote control are not central to the messages being communicated by the advertisements. The remote control is not a visually flashy or exciting device, and it is likely because of this that I did not find high-quality, detailed images of the device. This sample of ads implies that people do not purchase remote control devices because of their design appeal (the way they might with other consumer goods like automobiles and fashion items). The televisions are more often shown in greater visual detail and with some emphasis on design or appearance (particularly those that are marketed as pieces of furniture like SA NYT 1980 and SA Times 1978 as well as others within the multi-ad group). While some examples of the television being sold as a designed feature of the home exist, I still would not categorize that as a major part of the myth used to sell this technology.

One major feature I found in the textual descriptions of the single-ad (and some multi-ad) samples was the use of brand name remote control devices. The brand names I found were the Panalock@ AFT Button, Magnavox Remote Control, Channelock Remote Control, RCA Infrared ColorTrak Remote Control and the Contec Remote Control. Some of these names (particularly the Panalock, Channelock and ColorTrak devices) imply different things about what the remote can do for the user. The others simply highlight the brand name of the television and the corresponding remote control device. This component of the advertisement speaks to the competition within the industry by the 
different brands. This competition goes back to the early days of television and VCR manufacturing, when companies from the United States (RCA) and Japan (JVC) competed for market dominance in America. The ads do not overtly explain the difference in quality between the various brands, which suggests that consumers of the time were familiar with the reputations of the branded companies. Branding of products is extremely common in modern consumerism (a car made by Honda holds a different cultural value than one made by Saturn, for example), and it is likely that these brands also held cultural connotations that affected consumers' decisions. The obvious presence of brand information in the advertising (not only for the remote controls but to a larger degree for the televisions themselves) suggests that part of the myth advertisers use to communicate their products involves branded identity.

Another theme I identify throughout the single-ad sample involves the use of furniture as a selling point of the televisions and remote controls. In addition to the cabinet-sets I mentioned earlier, I saw a number of ads that featured descriptive language about the physical environment that the user views the television in. In particular, SA WP 1975 features the phrase "arm-chair tuning" which describes the position of the viewer in the television viewing room (from their arm-chair). SA WP 1980 also references the environment through a detailed living room image that includes a cup of coffee and reference to an "Easy chair". A third advertisement that involves the physical environment is the SA Times 1980, which depicts a full living room scene with a coffee table, potted plant and a television set on wheels. These three ads reference not only the pieces of furniture that are involved in the physical experience of watching television, but also types of interactions this furniture suggests. The arm-chair and easy chair reflect the 
advertising company's desire to market the remote control and television within a myth of simplicity, comfort and ease.

It could be interesting in a future project to look at the sale of televisions (and their accompanying peripheral devices) in terms of a gendered discourse. My observations about the gender of the hands present in many of these ads was simply the result of cataloguing what types of images appeared, but it suggests that there may be more to this line of questioning than I would have thought going into the project. Another aspect of the gendered discourse that may warrant further investigation is the fact that so many of the ads featured sports programming on the television screens.

Two of the ads also touch on the theme of luxury as a way of selling the products. MA NYT 1982 and SA NYT 1982 both talk about the television set in language describing them as the finest in their class or the most luxurious. I am hesitant to categorize luxury as part of the myth used to sell remote controls because these are just two examples from a large sample. I think it is likely that I chose these ads because (as presented in the introduction to this section) I expected to find the remote presented as a device that would change user experience. Due to this orientation I had while finding the ads, I do not feel that luxury could be understood as part of the myth of the remote control.

In conjunction with this theme of luxury, the idea that the technology is more advanced than a previous version of the technology is also referenced. The myth of advancing technology is one that I feel more comfortable claiming because it was seen in a great percentage of the ads (and because it is something that is supported by the theories I investigated at the outset of this project). Some of the ads draw on the idea that their 
company's product is more enhanced version of a product a consumer might already be familiar with. As I mentioned in the analysis section, the percentage of ads that talk about advanced products in this sample is nowhere near as large as I expected to find at the outset of my research.

This is also true of the signs surrounding the theme of the new that I used as my lens for the semiotic analysis. To put it mildly, the new just is not a factor in the marketing strategies of the remote control (and the television) in this time period. A full discussion of the possible problems with this lens and the implications for this semiotic analysis follows this chapter, but for the purposes of categorizing and accounting the ads, I will point out that only two of the twenty-one ads I performed a semiotic analysis on in this project used the word "new". The first ad that did this is SA WP 1979 Sony that talked about its "all-new, Express Tuning keyboard and Express Commander remote control unit that let you tune into the station you want instantly, at the touch of a button" (Appendix B). The second ad that referenced this sign was SA NYT 1980, which described its "New Infrared ColorTrak remote control. RCA's most advanced remote control ever" (Appendix B). Only two other ads indirectly referenced concepts that can be construed as dealing with ideas that are similar to newness, innovation, or change (these were MA Times 1983 and SA NYT 1979). The overall impression this sample gives is that the concept of the new is not one that advertisers use to sell the remote control to their potential consumers. 


\section{Conclusion}

Before beginning the research for this project, I thought I wanted to talk about the changing world of television today. The readings I encountered in that stream of thought gave me plenty to consider and analyze, but the idea that caught my attention was that the way scholars talk about media in transition might be problematic. The works I read were all very much concerned with the industry, the technology and the changing role of the viewer as an intermediary between the two. What I did not see very often in these works was an approach to the idea of transition that spoke to the actual interaction between consumer and product, particularly at a mass media level. I think the literature on television in transition today overlooks the ways that television actually stays the same. None of the works I read talked about how the majority of Americans still watch television in the primetime hours, on one of the four major networks (or any of their cable subsidiaries). None of the works I read spoke to how the basic format of the television sitcom and drama remain remarkably similar to those that came before them in the preceding five decades of broadcast television. In some ways, I understand why I did not find these stories being told in the literature on television today-it just isn't as exciting to talk about how things stay the same. I would rather talk about change, evolution, revolution and the new frontier of the digital age too. The problem with this is that it misrepresents the situation as it is happening.

But what does the narrative of change in media studies overlook? What does this type of story do to our understanding of history and what other stories are left out when this one takes over? This project is an attempt to answer some of these questions by looking back in history to another time when the medium of television was thought to be "in transition". A mere mention of the remote control by Bruce Owen in The Internet 
Challenge to Television sparked my investigation into the time period of the 1970 s and 1980s and changes within the television industry that took place during that time. I found that there were three major developments around this time period that were cited as important driving forces behind a changing industry—the sale of the VCR, the advent of the remote control device, and the development of the cable television system. These three products do not stand alone from one another, but rather spur each other's development during this time period. The VCR allows people to tape previously fleeting material and the remote control is used to scan through those programs and give the user control over the time and manner in which they watch their televisions. The remote control allows viewers to move through the channels from a comfortable physical distance away from the television set, which is all the more necessary when cable television and its influx of channels enter the home. The abundance of new programming means that viewers might want to watch one program live and store another program for a later time by taping it. The remote makes it more comfortable to spend significant amounts of time around the television, meaning that watching more television (either through the VCR or through cable) is possible and likely. The nature of this triad is such that I cannot claim that any one of these technologies drove the changes in the television industry during the $1980 \mathrm{~s}$. They all contributed to a changing media environment, as did many other social, cultural and economic forces. I chose to focus on the remote control device because it seemed to be highlighted as a major factor in this changed media environment, in much the same way that computer and internet-based television is highlighted today. 
Given this starting point, I consulted the literature I could find on the subject of the remote control device in the context of the television industry. The results of this inquiry are found in the literature review for this project. I found that when researchers studied the remote control, they did so to help create a better understanding of the processes of "zipping", "zapping" and (to a lesser extent) "grazing". The idea presented in work on the RCD is that each user's experience becomes individualized and personalized based on what they choose to watch in any given moment of their time in front of the screen. According to the literature, these two viewer actions caused a great deal of concern within the television industry because they threatened the economic model on which television at the time was produced. Large corporations bought airtime in between sections of programming for large amounts of money. In return for their investment, they were given access to millions of American homes and (presumably) the attention of millions of Americans. These commercial spots allowed the expensive medium of television to be produced and created at a high level of quality and to be distributed at a relatively low cost to consumers (either free, through broadcast signals or for a small fee through cable networks). I found that the VCR was also mentioned within literature about the RCD. Studies of the VCR often implicated studies of the remote control and vice versa. Due to this interrelation, I chose to look at some studies of VCR use in addition to the RCD studies because the two technologies significantly influenced each other's use and popularity. It is the overall focus on use that I saw in both of these bodies of literature that directed my questioning of the way technologies are categorized and discussed. 
The work by Ainslie (1988) incorporates some data from use-based research, but it also tells an interesting story about the place of the RCD in the popular media. Ainslie (1988) writes about the "nation of grazers" that he sees as a part of the new media landscape in America at this time. He categorizes the viewer as the active force in the relationship between television producer and consumer (a shift that continues to be lauded today). More significantly, Ainslie (1988) puts the impetus behind this shift in the hands of the consumers through the remote control. This magazine feature gives insight into industry executives' fears about the changing landscape of their businesses and the responsibility of the producers to create better content to "lure back" an audience that had somehow escaped their grasp. I mention Ainslie's (1988) work again because it shows the connection between the academic research on the RCD technology and the industry panic that likely allowed for the majority of RCD research to be funded.

The literature I consulted assumed that the "new" technology of the remote control (along with the other technologies) had the power to turn the industry on its head and change the way the financing of television took place. The way this literature talked about the technology indicated that the scholars of the time saw the remote as an adolescent technology -one finding its place in the user's hand and viewing routines. Both the consumers and the industry had to adjust to allow for the consequences of a television world with a remote control in it. Based on this perspective, I expected to find evidence of this tension and struggle in the advertisements I viewed in my semiotic analysis. The fact that I did not find anything close to this is what made me reconsider the life cycle stage that the remote was in at that time period. 
I began to question what the use-based research implied about the way academics understand technologies in times of transition. I looked at this body of research and saw that most of the scholars focused on the technologies as if they were the major factor in an equation that looked something like:

$$
\text { Existing Medium }+ \text { New Technology }=\text { Industry Revolution }
$$

From the studies of the RCD that I found, it seemed that the device allowed people to experience media in a whole new way, that it allowed them to direct their own leisure time. And from the studies of the VCR I looked at, it seemed that the device gave people a never-before experienced level of control over their programming choices, their daily (or nightly) viewing schedules and their ability to avoid unwanted commercials. The studies sometimes acknowledged the other forces in society or in the television industry that made these enormous changes possible, but in the driver's seat of all of this research was the device. Researchers looked at either the remote control or the VCR as the starting point for their use-based studies. The focus on the devices in this research reflects a technologically deterministic perspective, which I investigated next.

Theories of technological determinism deal directly with the issue of placing a physical technology in a position of power within social processes. In my research on these theories, I read about a well-established connection between the creation of the American government and economy after the American Revolution and the ideas of technological determinism and technological progress. In some interpretations of history, technological progress is used as a marker of time and culture, and this is particularly true of American history. The development of the country can be understood in terms of the development of mechanized agricultural farming methods, the development of factory- 
based industry, the creation of an electrical system that created urban centers, and more recently, the development of an information economy based on digital and computing technologies. This overview leaves out significant detail, but the links between each of these technologies and different social and cultural periods in America make a strong argument for the idea that technology drives history.

Many theorists I investigated advanced technological determinist arguments that modified or enhanced the core belief that technology drives social life, and still many others talked about the ways in which technological determinism is a flawed way of understanding the world. Val Dusek in particular writes about how technology and culture work together and greatly influence each other. Culture is not separate from technology and technology is not separate from culture- the choice to look at only the technology in the RCD studies I reviewed in this project undermines this notion. I agree with some parts of the technologically determinist line of thinking, particularly the basic idea that technologies impact societies. I think my project is a pretty clear indication that I agree to a large extent with the primacy put on this relationship. There is no question in my mind that the RCD changed some aspects of the user experience of television; there is, however, a question about whether looking only at use is the most complete way of understanding what that impact was and how it was communicated.

As I mentioned before, I felt that I needed another point of access to this time period and to the technologies of interest here, and I settled upon the cultural remnants of a consumer society-advertising. The advertising of remote control devices provided a different perspective on the situation in that advertising evidences what consumers were being told about the products at this time. They are separate from the academic literature 
on the subject that makes certain assumptions about the users of technology and what those users do with their leisure time. That is not to say that advertising does not also make assumptions, but these assumptions come from a very different background and tap into a different line of thought about the product and its potential use. Advertisements are created by people who make their money by persuading consumers to buy things they do not "need" (in the sense of a survival need). As such, advertisements focus on the most marketable features of the product—the features that incite consumers to part with their hard-earned money. As I decided to look at newspaper advertisements of remote control devices, the focus of my project shifted to an investigation of the processes of representation.

Representation is an integral part of modern human societies because all of our interactions with one another are based on symbolic processes. When we use language, we are using mutually understood symbol systems that allow for the sharing of ideas and concepts. When we read written words, we interpret letter systems and visual icons into meaningful products of culture. When we look at a newspaper, the images and text that we see represent items in the physical world that have real uses and implications on our lives. It is this point of interaction at the level of the symbol that I chose to investigate in my case study on RCDs. One prominent theorist in this field, Judith Williamson (1978), describes the power of advertising to sell more than consumer products- to sell us our own self-identity. Modern advertising does the bulk of its work by calling upon cultural symbols that have very little to do with the physical properties of the product being sold. A new car, for example, is seen as more than a body and a series of mechanical and electrical components (designed simply to get a person from one place to the next in 
relative comfort), a new car is sold as a statement about a person's lifestyle, their means, their priorities and their values (consider the choice to drive a large SUV (or minivan if it is the 1990s) over a two-door sporty coupe). When I see an advertisement for a Toyota Prius Hybrid car, I see more than the technology that exists within the confines of its body, I see a young, active, environmentally-minded adult (basically, I see the kind of person I think I am or that I think I want to be). Williamson's work highlights the ability of advertisements to communicate meaning well beyond the literal or use-oriented features of the product.

The work of Leiss, Kline and Jhally (1990) gives further context in which to understand the role of advertising in modern life. They categorize the major stages of advertising, and in doing so create a guide that highlights what kinds of advertising work in which eras and with which effects. Most significant in this study is the categorization of the lifestyle format of advertising. This form is identified as the dominant mode of advertising communications in the time period covered by this project. The lifestyle format consists of ads that work in a similar way to what Williamson described in the late 1970s. Ads that fit into this category sell branded images that play on consumers' social and cultural standing as much as any other factor. Advertisers create packaged identities that can be purchased and used in social life. This categorization and the time period in which it was prominent demonstrate that branded, lifestyle advertisements were very much a possibility for the ads I chose to analyze. The fact that few of them fit into this categorization is partially the result of looking at newspaper advertisements, but it is also a result of the type of product being sold and the ways that people use that technology. 
This brings me to the sample of ads I chose to investigate and the specific method I used to perform the analysis. In researching potential cultural texts that could yield a different perspective on the study of the remote control, I found newspaper print advertisements to be the most appropriate source. They offered a sample of ads that spoke to how consumers were being addressed through advertising of remote controls. I created a large sample pool (with the help of library search databases) and then set about categorizing the ads into two groups for analysis, the multi-ad group and the single-ad group. I chose a semiotic methodology because it allowed me to look closely at a number of the ads and investigate what common symbols and themes I saw (and, almost more significantly did not see) among the group. It also allowed me to make generalizations about a specific set of data and to use those generalizations to speculate on the cultural climate within which the ads were created and consumed. As was outlined in the methodology chapter, the advantage of semiotics is that it allows the researcher to interpret and analyze the sample in a very in-depth way. It also allows for the application of a certain viewpoint or lens, which I made use of. I used the lens of "the new" as a way of focusing my analysis so that I could make a more direct argument about this sample and what the messages within it communicated. The framework of the new is one that came from those initial readings I did about the changing nature of television media today. It is that line of discussion that inspired the project, and it seems fitting that, although the subject matter has shifted drastically throughout the project, it is these core questions that I return to in the analytical portion of this project.

I found that for the most part, the ads I consulted did not make use of the themes of newness, progress and change in a significant way. The language that was used to 
describe the remote control (and their accompanying television sets) was direct and told the consumer simply about the mechanics and features of the purchase. As I mentioned within the case study, I was absolutely expecting to find a great number of ads that spoke to the great new technology of the remote control and to how this great new technology would revolutionize the viewing experience. The discovery that this was far from the case is the point in the story that changed the focus of the project. The ads do not tell the story I expected to find based on the RCD literature I reviewed, the work on technological determinism I consulted, or the advertising scholarship that contextualized the project. This discovery was at first panic-inducing, but as I have worked through the project, I have discovered that it points to some possible flaws in the ways we understand technology in modern society. The major issue I found in the project was that the advertisements did not support the life cycle model that I understood at the outset of the research. The semiotic analysis did not evidence the adolescent stage of a technology; the language and symbols used did reflect a technology struggling to find a place in the consumer's media world. Instead I found the symbolic indicators of a middle-aged technology—one that was there, but not flashy or spectacular in any way, one who's role seemed accepted and understood. My mistake at the beginning of the project, in thinking that this technology was going through a great transition and adolescence resulted from the literature I read and the preconceived notions I hold about technologies. Why did I expect to find that the remote control had fundamentally changed the act of watching television? It is because I put the technology in the driver's seat of my understanding of history. I didn't see that the technology had actually been around since the 1950 s when the idea was introduced to the people and I didn't see that the impact of this device 
simply being available might not change the way people interacted with their television. Much like the way advances in cellular telephones and computer interaction arrive without fanfare, the remote control was not a revolution to those who purchased one for the first time - it was simply a different (more convenient) way to change the channel, which had been possible in most television sets before this time period. Technologies do not develop in revolutions, but in slow and familiar ways. It is only the application of an historical perspective that makes us think in terms of revolution.

Future research on the topic of the remote control might investigate the long-term history of the device. This is something that came up in this project, but that I did not have the time or resources to develop further. The written word, for example, could be understood as a very old form of remote control. I argue in this project that the television remote control is a static device, kind of a done deal. But if I broaden my definition of television or of the remote control to include computers, cellular phones and other technological devices like the PVR or the Sling Box, the remote control is anything but static. The technology that accompanies television sets could be seen as a starting point for the great variety of remote controlling devices we use today. Its acceptance as a part of our everyday reality could also be a factor in our almost blasé attitude about technologies like Skype and Gchat. The ability to speak to someone through a "videophone" has been the subject of science fiction for some time, and yet few people seem impressed by our ability to do just that. I think the attitudes and opinions about the television remote control that developed in the mid 1970s through the mid 1980s might be a starting point for investigating this phenomenon further. 
Another possibility for future research on the remote control would be an investigation of its presence in popular culture. Maybe advertising is not the richest text to investigate for this subject matter. I am able to make this claim because I have gone through the process of looking in-depth at advertising about the remote control. Popular texts like television programs, fiction and non fiction literature, movies and music might provide a different perspective on the place of the remote control in our culture. Finding alternate perspectives could only strengthen the already.limited work that has been done on this technology.

This project is an attempt to reconcile the actual changes that took place as a result of the introduction of the remote control (and VCR and cable systems) with the lack of changes in the user's experience (as found through the representation of the device in newspaper advertisements). In order to account for both, I use a redesigned life cycle model that places the remote control as an adult technology in the 1970s and 1980s. The traditional historical perspective on remote control technology assumed that the technology was in a state of adolescence at this time, but my semiotic analysis gave me cause to question this assumption. The representational analysis I used gave me another perspective that allowed me to consider both the history of the technology and the way it was understood by users in a specific time period. The life cycle model of the remote control gives me more flexibility to understand the history of technologies. They are not cold and detached machines, but significant parts of our lives. Understanding their history through a life cycle accounts for the ways technologies undergo transition, and more accurately represents the user's interaction with them. 


\section{Appendix A: Semiotic Questions for the Sample}

The actual questions I will ask of the images selected fall into three categories based on Saussurean semiotics, Barthes concept of myth and literary analysis. They will all be asked with the concept of the new in mind. The breakdown of questions follows here:

Saussurean Semiotics

1. What are the main signs (both image and text) in each ad and how can they be broken down into a signifier and signified?

2. What meaning do the visual and textual signs in the process of signification communicate?

2(a). Where do the signs place the remote in relation to the concept of the new?

3. What is the spatial relationship between the signs (are they located above/below, in front/behind, close/distant, left/right, inside/outside- these particular dichotomies are based on Chandler's (2007) summary of both Saussure and Jakobson's approaches to spatial semiotic analysis)

Myth

1. Given the form and concept identified (the signifier and the signified), what meaning is being communicated through the relationship between these two components of myth?

1 (a). How often are the key terms of "old", "new", "innovation" and "change" referenced?

2. What meaning is communicated throughout the entire sample of ads-what trends exist within the two categories of ads identified? 
3. As a body of communicated myth, what do the ads signify about the remote control technologies?

Literary Analysis

1. What rhetorical and literary devices are employed in the ads? What does the content of metaphors, similes, and other literary devices say about how technology is communicated about in the ads (and what references to newness or change are made through these literary devices)?

2. What is being represented in the images and texts that are indicative of social norms?

3. How are the messages interpreted by a viewer of the ad (what are the possible interpretations that could be made by various text readers)?

4. What context did the ad arise in? More specifically, what paper is it in, what section did it come from, what store or brand is being advertised? 


\title{
Appendix B: Newspaper Advertisements
}

\author{
Utility
}

MA NYT 1975

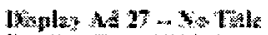

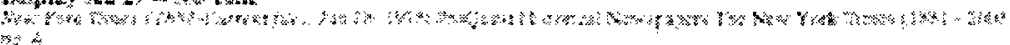

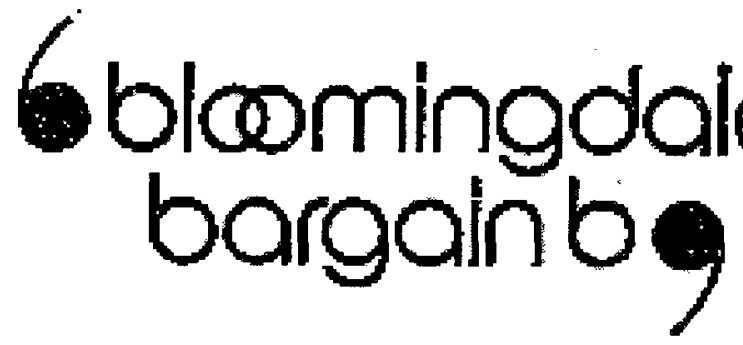

today othil 5oper savings on

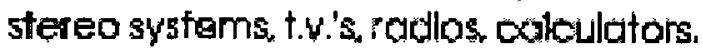

oll in limited quanitites, ati saies firch.

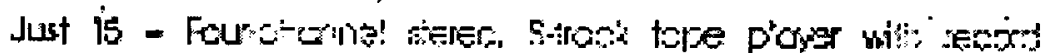

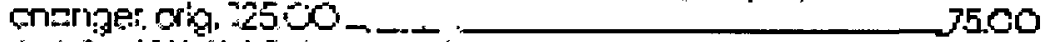

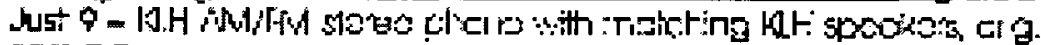
55,00

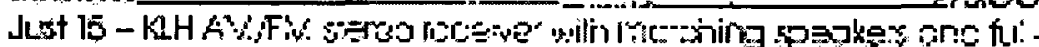

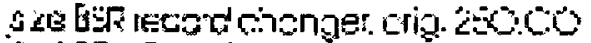

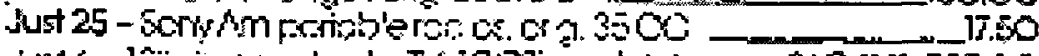

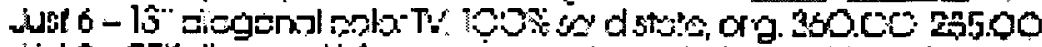

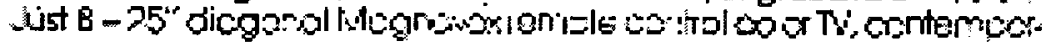

arycobiret, orig ra000 49500

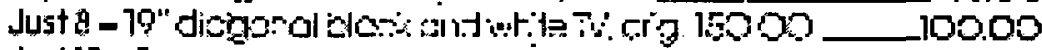

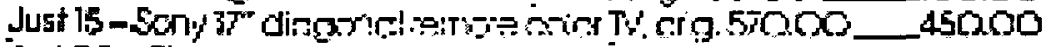

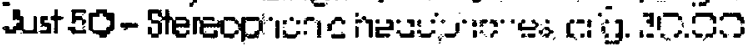
10,00

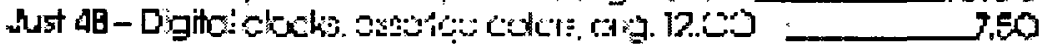

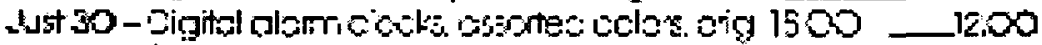

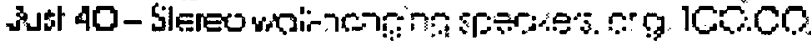
5000

Specid seiectlors:

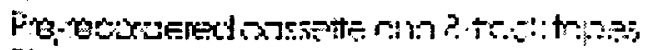
$3 \operatorname{tar} 625$

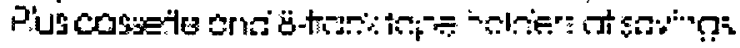

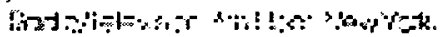

$$
\begin{aligned}
& \text { a }
\end{aligned}
$$

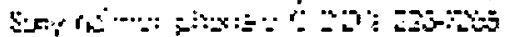


Visplay Ad 48 ... No title

sing

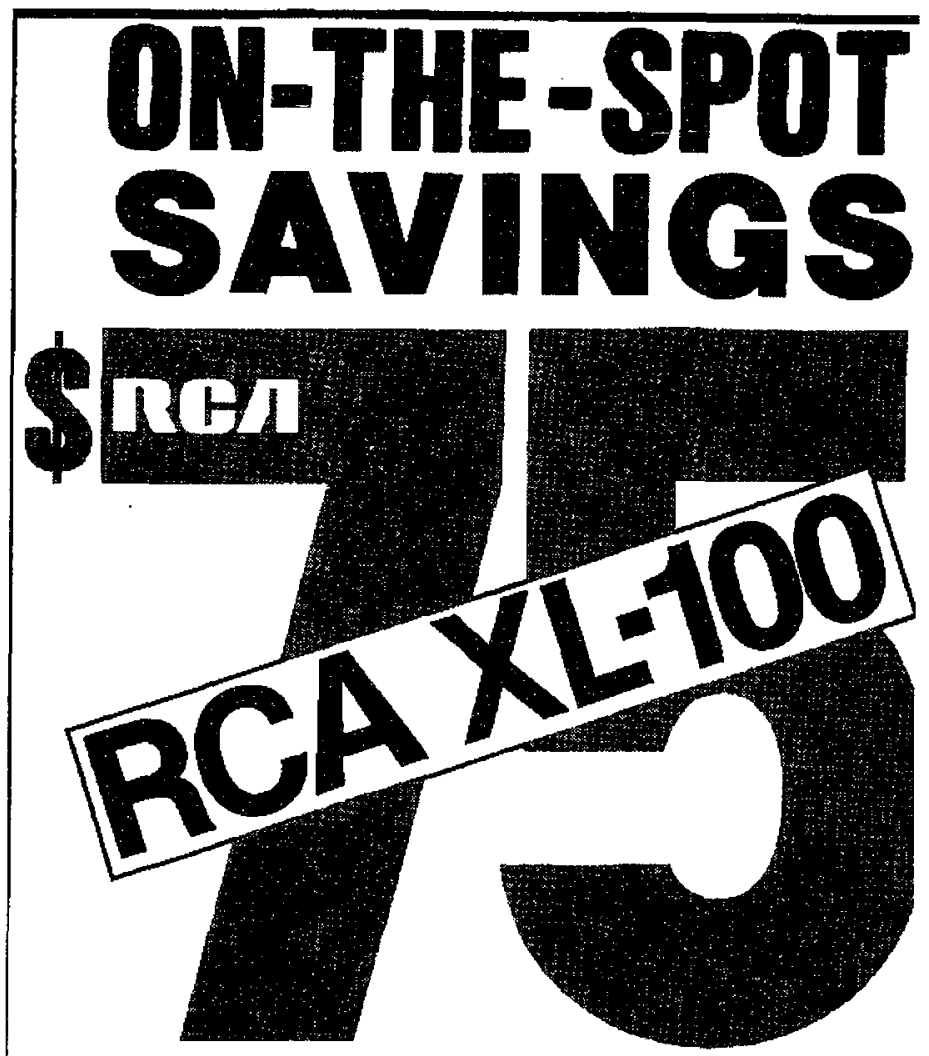

SAVE UP TO \$75 INSTANTLY

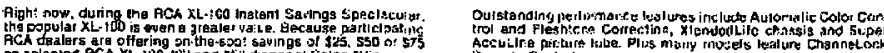

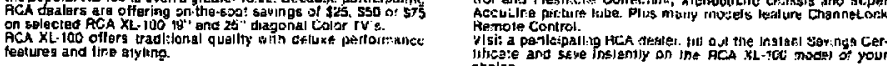
IMITEO TIME ONLY: OFFEA ENDS MARCH 1,198

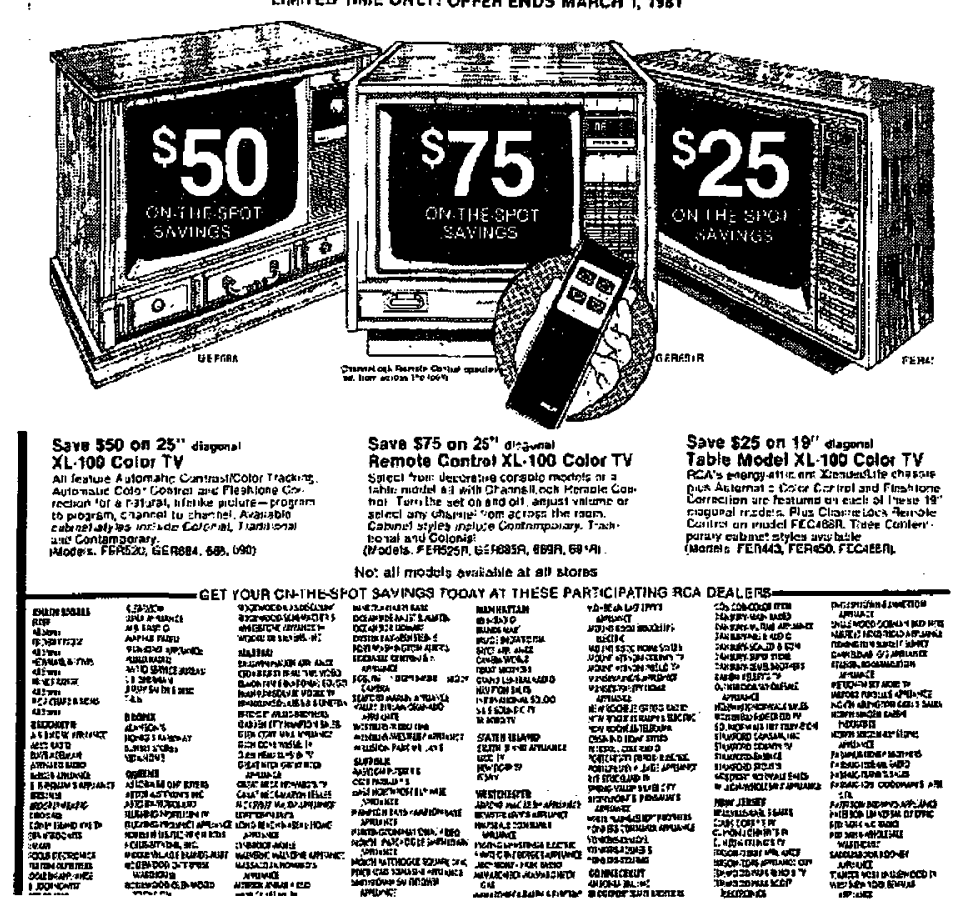




\section{SA Times 1978}

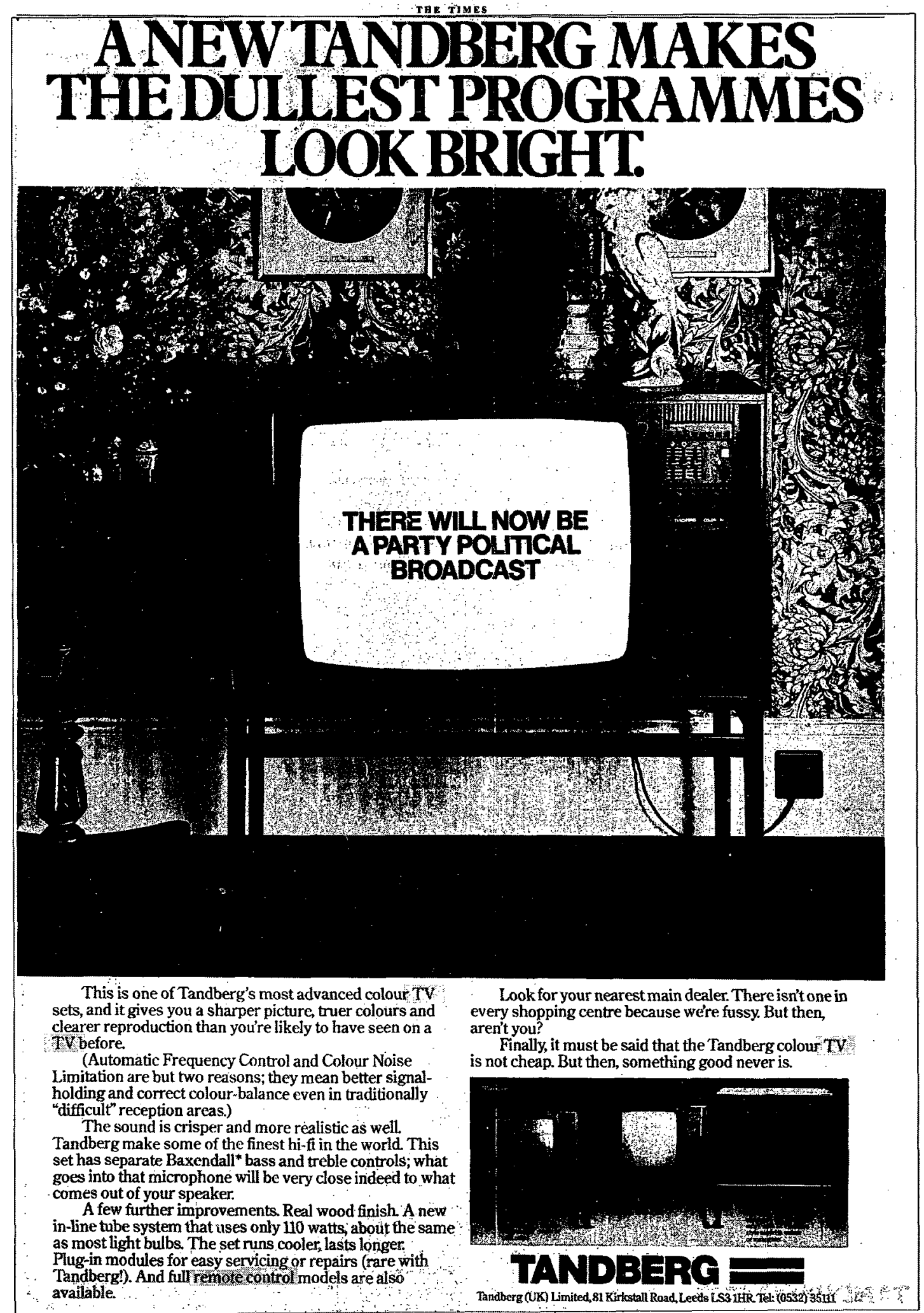




\section{SA WP 1975}

Display Ad 54 .. No Title

The Washingten Post (1974.Current file), Nov 16.1975; ProQuest Historical Newspapers The Washington Poss (1877 - 1992) pg. 27

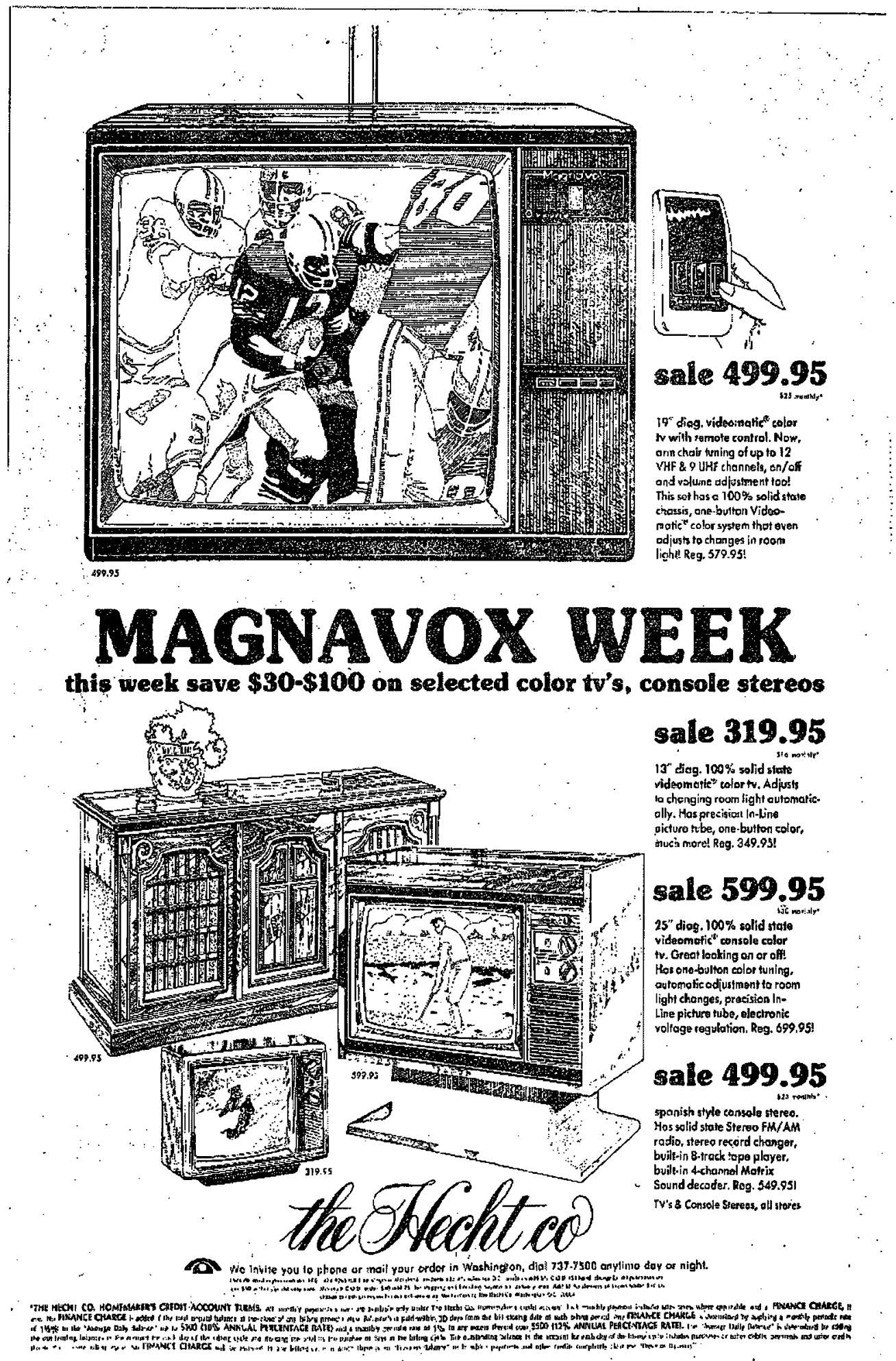


MA WP 1980

Display Ad 21 - No Title The Washington Post (1974-Current file); Dec 9, 1980; ProQuest Historical Newspapers The Washington Post (1877 - 1992) pg. A2S

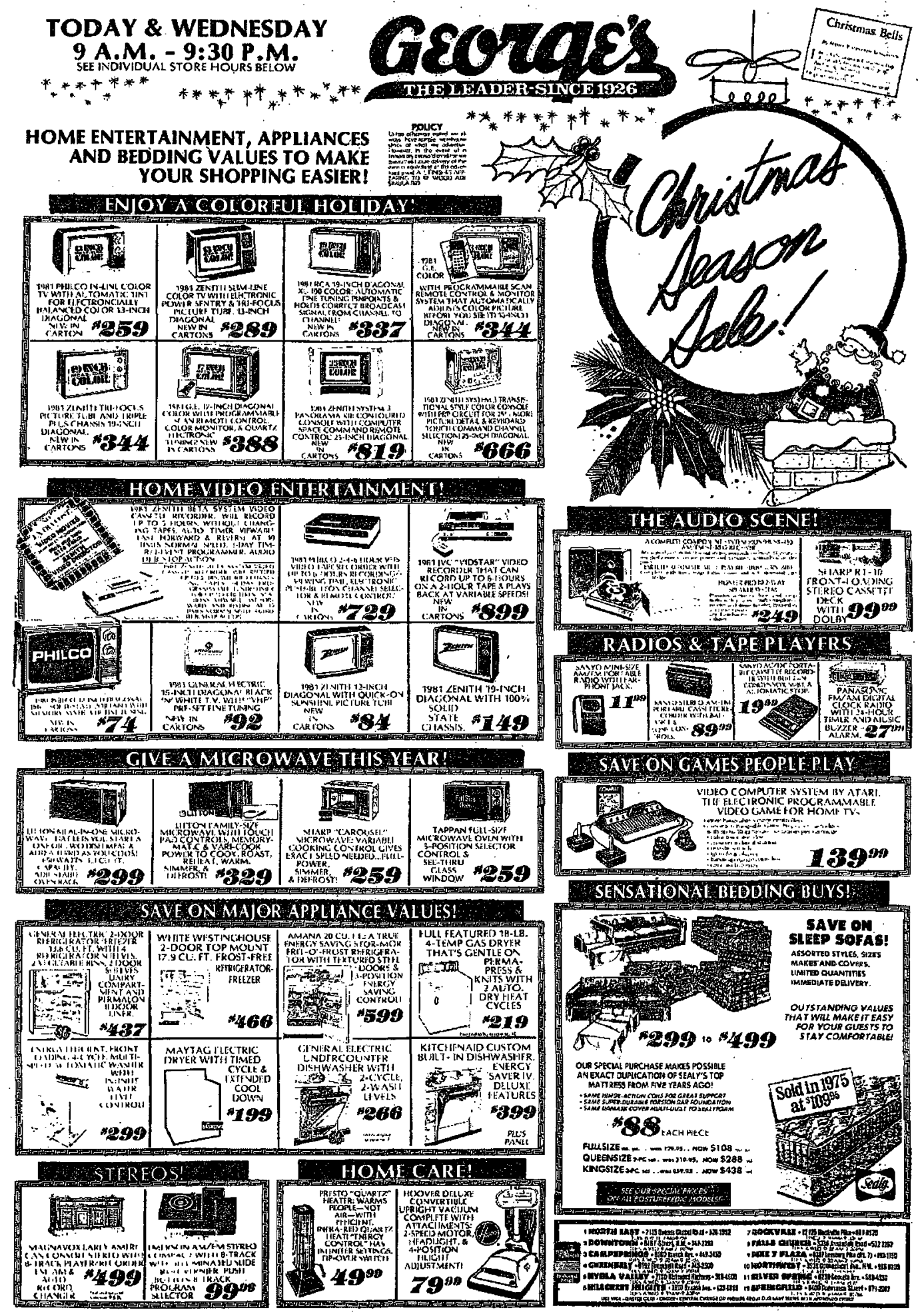




\section{Human User}

\section{MA WP 1981}

Display Ad 100 - No Title

The Washington Post (1974-Current file); Nov 1, 1981: ProQuest Historical Newspapers The Washington Post (1877 - 1992) pg. K9

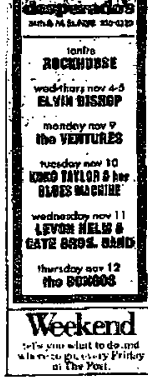
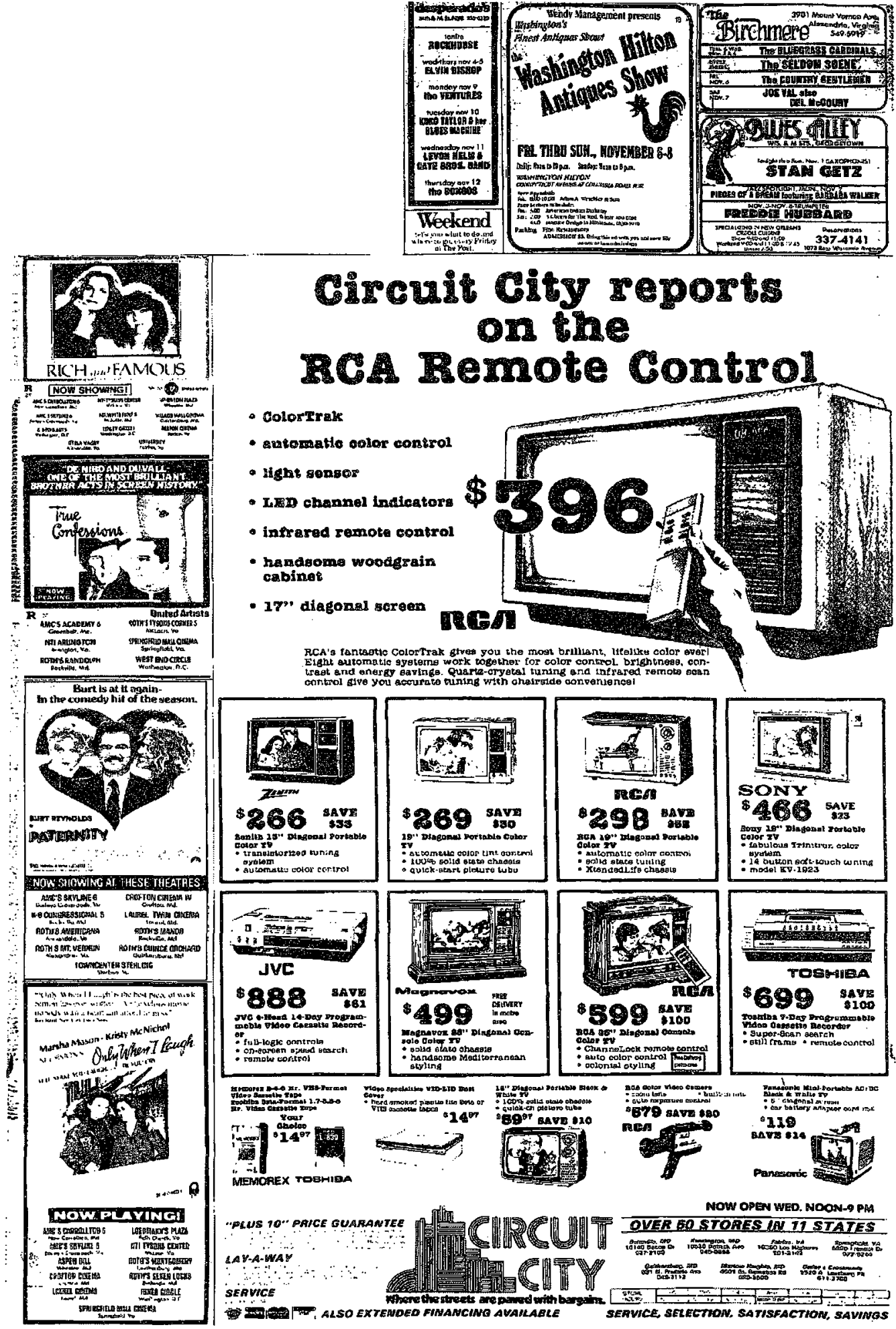

\section{Circuit City reports on the RCA Remote Control}

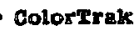

- automatio oolor control

- light sonser

- LRD channel Inaicatorg

- intrared remote control

- handsome woodgrain cabines

- 17"' diagonal gereen

Mebal

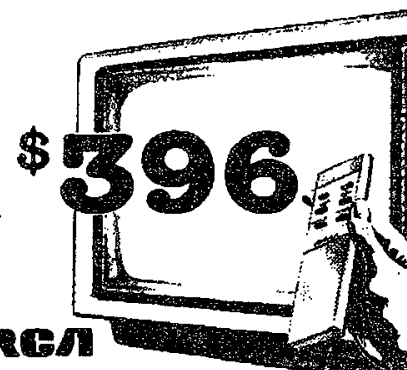

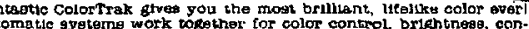

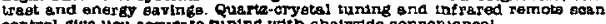

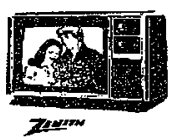

$\$ 266_{\substack{\mathrm{savx} \\ \mathrm{ss3}}}$

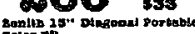

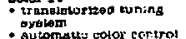
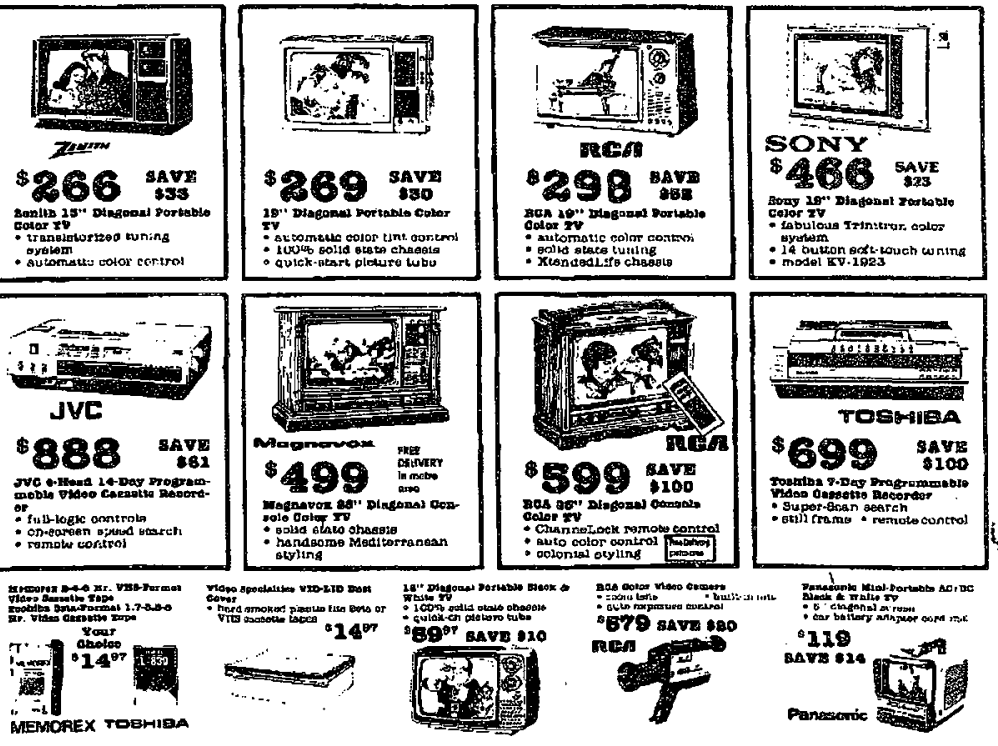

NOW OPEN WED. NOON-9 PHA

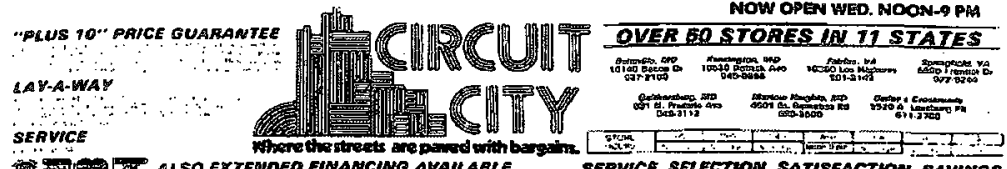

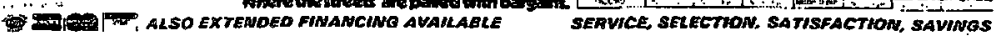




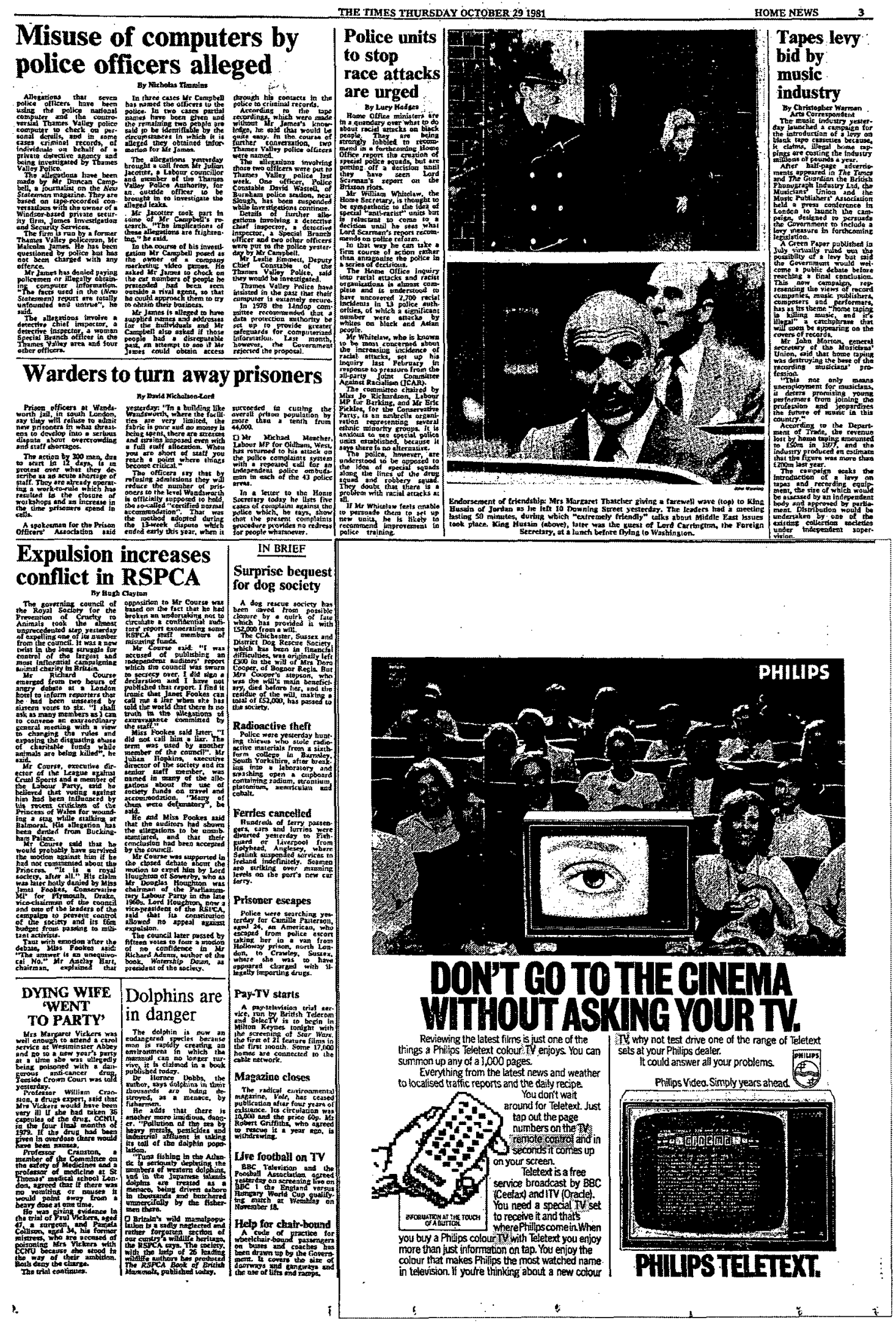




\section{SA Times 1980}
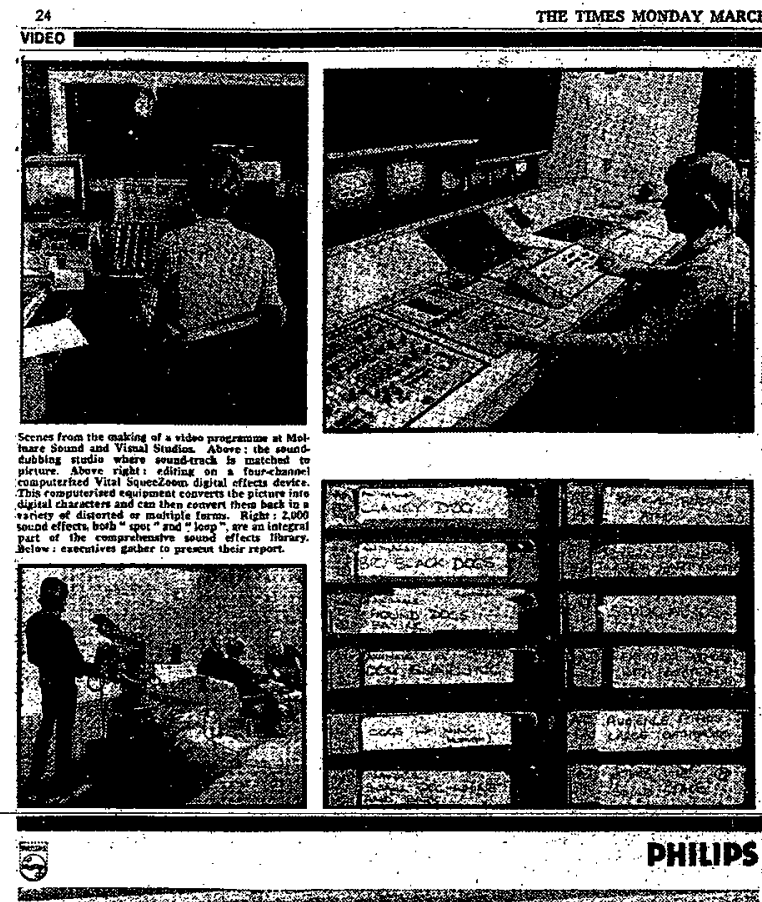

Stewari Tendler, Crime Reporter, discusses the international manket in pirated cassemes; and Marcel Berlins, Legal Correspondents questions of capyright

\section{Coding system devised}
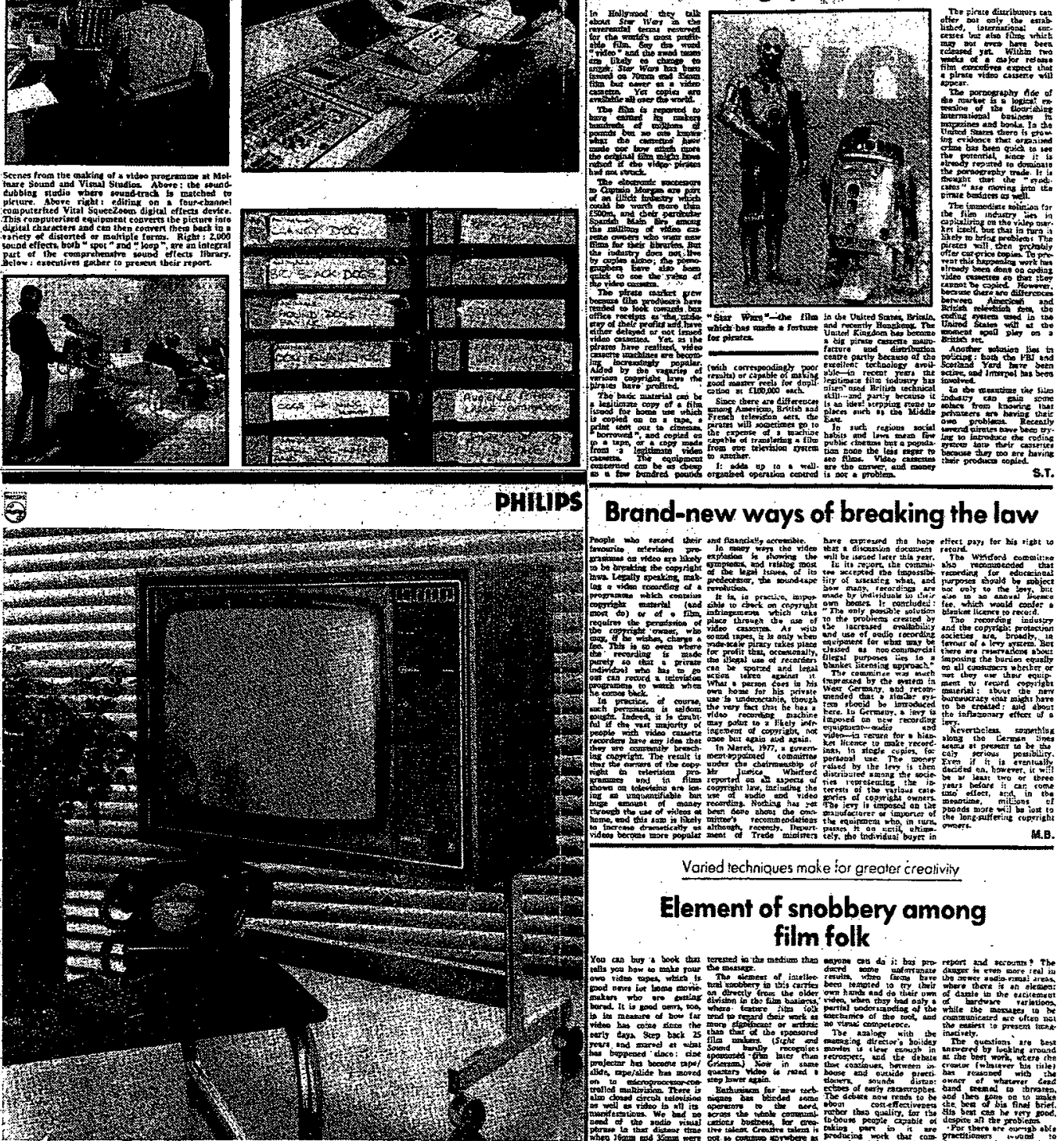

Brand-new ways of breaking the law

ANY QUESTIONS?

The GPO's Prestel systema allows access the threetw clameds in the usual way and to an airrost unlmited source of information. come complete wit's Fur Rente Contol And Philips 26 and 2 Vlendala ses : Theyre just part of the Philips range are fully compotible with the lalest develop- adranced domestic video prodscts, which ments in teievision technology. indudes the V 2000 eight hour video cassett With a telephone they can be linked to sysiem, teletext receivers and video games: Prestel to giveintormation onsutjects ranging If youd like to know more, white to PO from farming to air fares, share prices to. Bex 3, Horley, Surrey Orvisityour Philipsvideo
sports reports, and a host of ơters. Both models also raceive Teleteid and the answers.

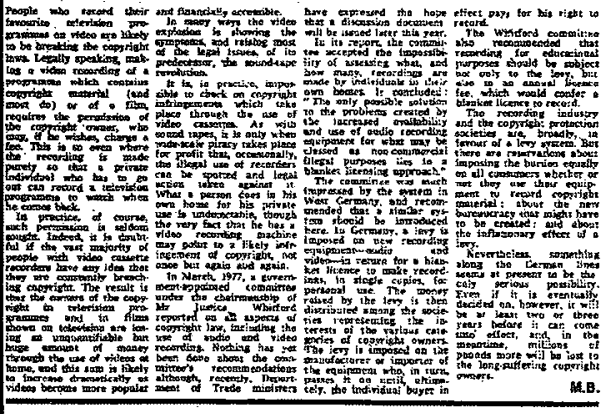

Varied techniques mole for greater creativity

\section{Element of snobbery among} film folk

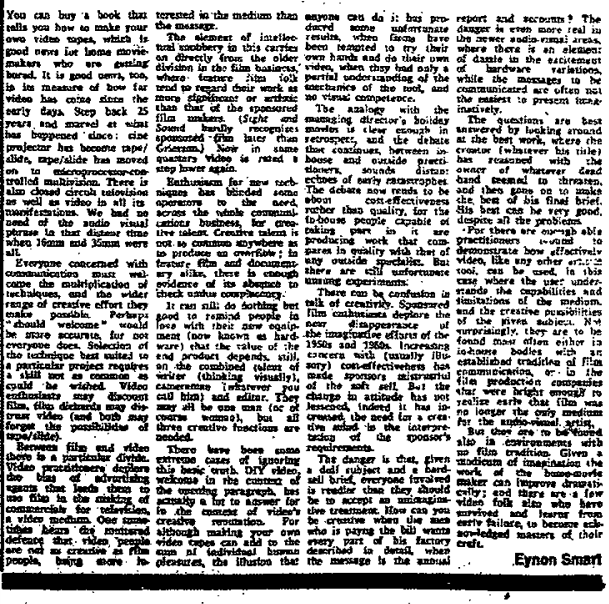




\section{Luxury}

\section{MA NYT 1982}

Display Ad 270 -- No Title

New York Times (1857.Current fle); Jan 3, 1982; ProQuest Historical Newspapers The New York Times (1851 - 2005) Pg. $\mathrm{CN} 15$

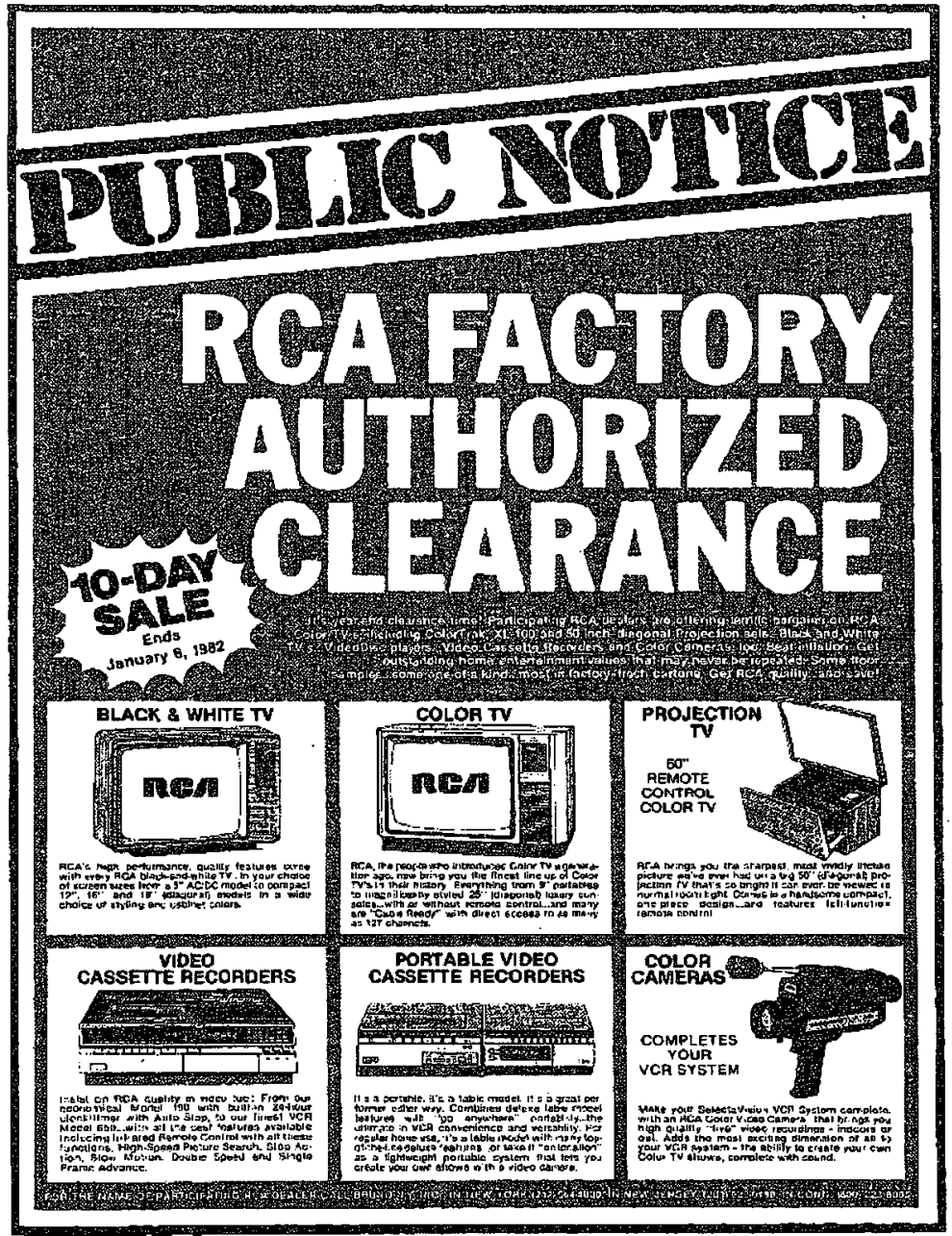

\section{POWER INSUIANC:} YOU CAN HAVE IT WITH AN QTAM GENERATOR liave you eves consincred the consequentes of s proilonged power tallure? Wo heat - no hot waler - no privent this trom hape thing with un papes you can - that autometically thkes over in serunds when the power fats

Onan has been malung generators for more itan 50 ysars There are thousanas of Onan generatore in ve

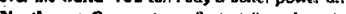

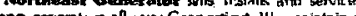

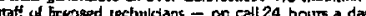
saveri doys a weex

Coll Toll Free 800-4/24264. Malka as anpointhent Let us sumey yous property ald recommend the right

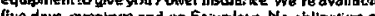
Majos For nora in Majo: credt cards acogted Finen NOFTHEAST GENERATOA LO The Power People

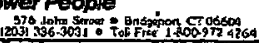

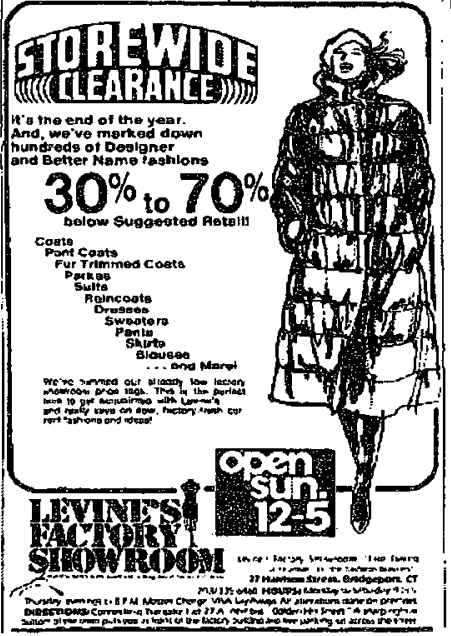




\section{SA NYT 1982}

Display Ad 12 - No Title New York Tinnes (1857 Current file); Jan 20, 1982; ProQvest listorical Newspapers The New York Times (1851 - 2005) PE. All

\section{"Now Tve seen everything"}

Only New York Video has all the newrest mitracles in electronics

home entertainment... including an inprecedented selection of eight diffenent moulels of KLOSS, the leader in gdant-screen TV?

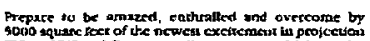

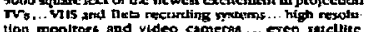

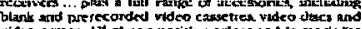

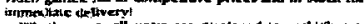

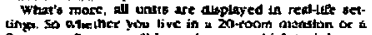

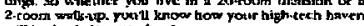

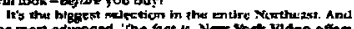

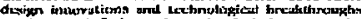
roul lux Vidho Asid soest all there is. Inctuding.

\section{KLOSS NONABEAM}

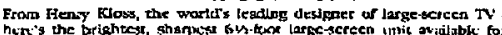

thame use todisy.

profoces over rwice the amount of light avalinbte from any othe

heme prom

produce a dereiled projection lubos use ligitr-quality uptics

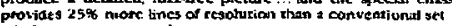

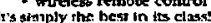

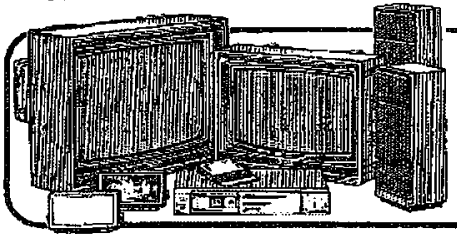

\section{SOTYY. PROABLE Trinition Component}

TV System-The future of TV is here today!

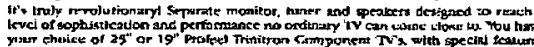

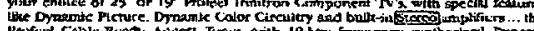

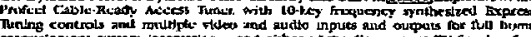

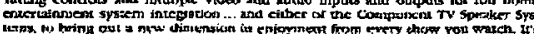

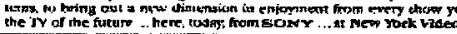

\section{AKAI ANTWE}

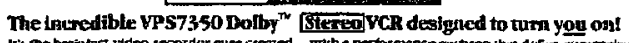

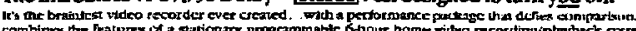

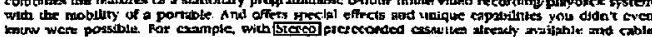

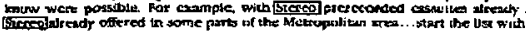

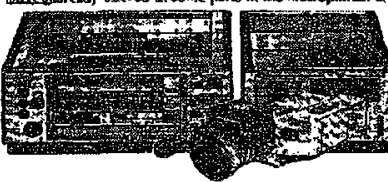

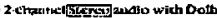

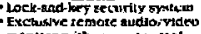

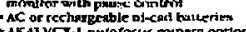

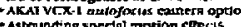
- Instant pergegram lockition system

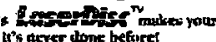
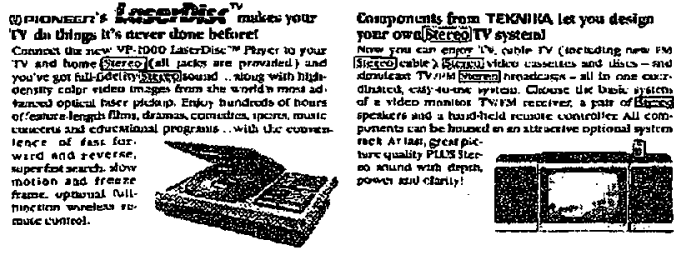

New Xeare Prograniruable Video Direcior-neore feanires and fun in less space than tver. Actually less than 4"high!

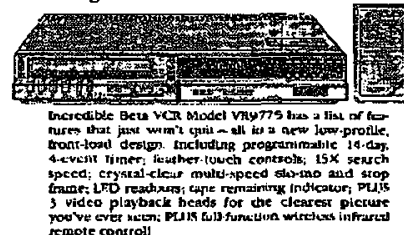

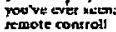

The famous "Media Hoom"a mindblowing senary experiencel Only at New Yoon videot the matrat of uxe

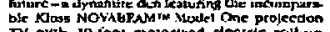

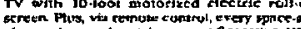

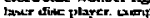

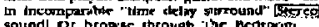

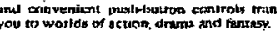

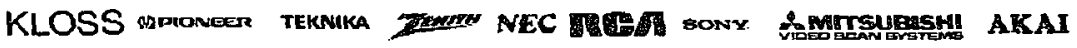

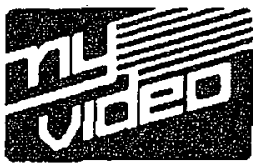

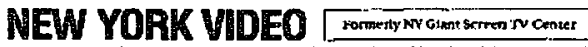

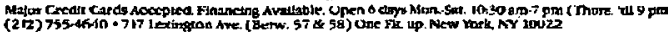

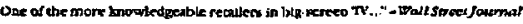




\section{Convenience}

\section{SA WP 1977 Panasonic}

Display Ad 23 -- No Title

The Washington Post (1974-Current file); Sep 30, 1977; ProQuest Historical Newspapers The Washington Post (1877 - 1992)

pg. A.15

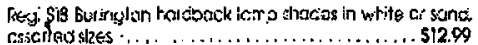

save on a Proctor steamand dry iron with many features.

\section{s9.99}

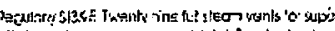

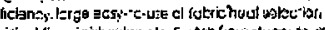

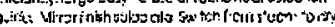
honinster.

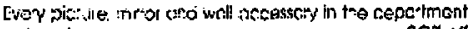
lenucod. ............................

\section{CHINA CRYSTAL AND SILVER}

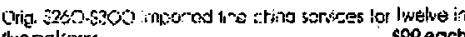
lleverlere

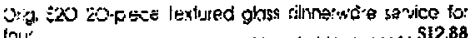

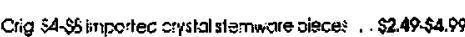

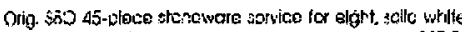
naiv ar carar:e!. . . . . . . . . . . . . . . . . . . . . . . \$49.99 I vee cieze slerling 3iver ficiware sels hor Gotom. Rees

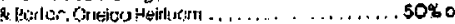

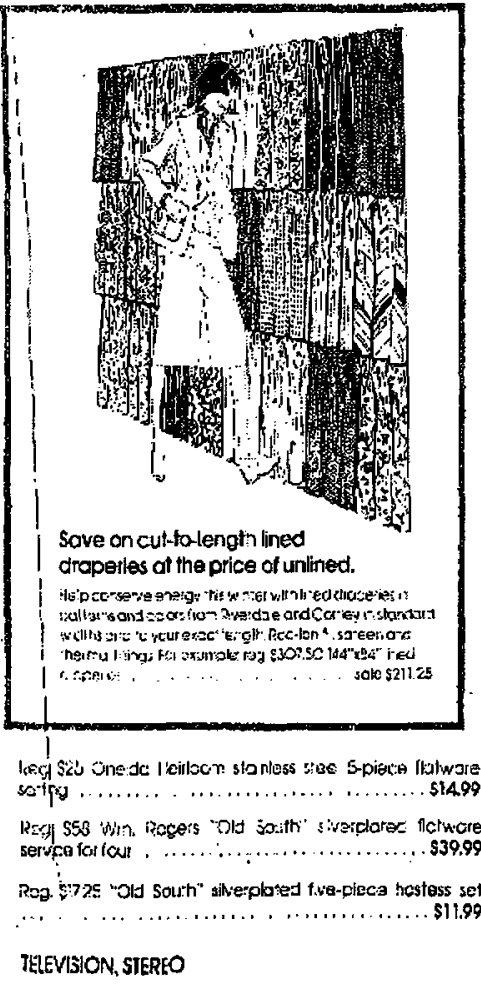

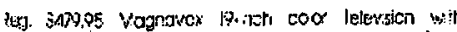

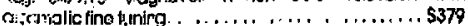

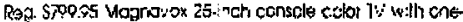
buttenceles ..............................5649

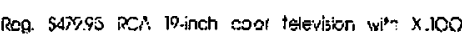

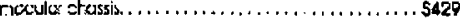
Rey, \$539,55 Porgsonic ig-inch ranole contiol color tele.

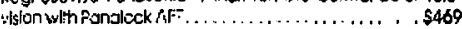

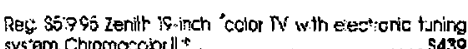

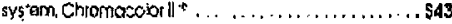

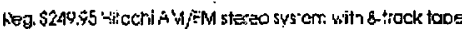
ar cassette olove: chariger . .................. \$199.95

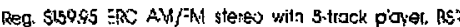

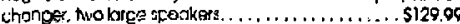
Reg $\$ 10,55$ "onacrat stereo needpicnes with scparcle

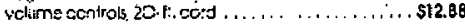

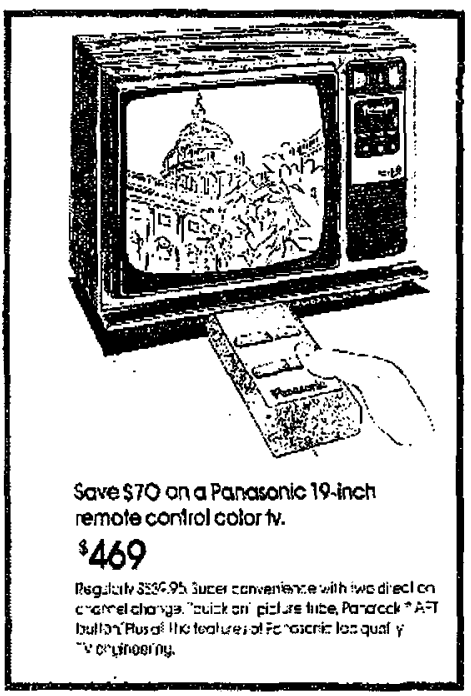

\section{VACUUMS, MAORAPPLIANCES}

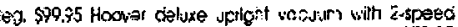

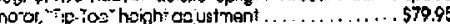
nog. $\$ 49.35$ Heower carsle veculy wh wet of

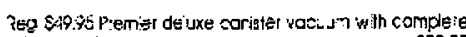
atas 1 ments ............................. \$38.95

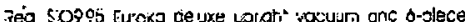

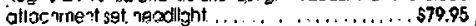

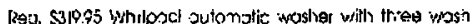
Cycles.

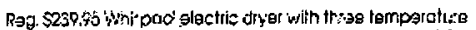
so'ections ............................. \$200

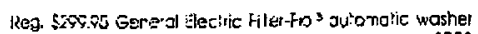

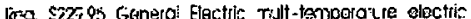

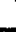

\section{Save $\$ 200$ on any grandlather} clock on ourfloor

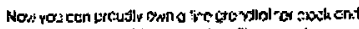

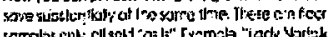
Yarpolis cinl: cillstils

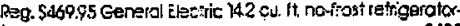
ireezer............................. 5428

\section{Sare $50 \%$ on irregular "x70" bain sheets \\ 38,99

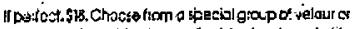

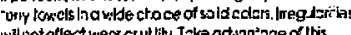

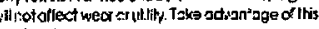 siach price}

Reg \$529.5E Genteral Electrie 11.6 cu, ft. vorightteagter , $\$ 299$

\section{LINENG, DOMESTICS}

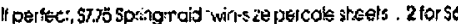
If cerfecl.5975 Springmaid 'ull.size perccle sheels , . 2 lor 58 If porfocl, S14 Springmaid queen-size percale sineots 2 lor 515 If perfect, \$A50 Springrreid pocksage of two stoncord fillow couses................., .............,$\ldots$ s3.75 Reg. \$7-s12 syrthatic-fil pllows, all sizes. . . . . . . . . 2 for 59.99 I' pe-téct, $\$ 5.50$ solid coor velcur both iowes ..... . 2 for $\$ 5$

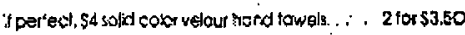

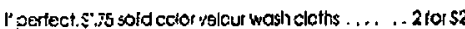

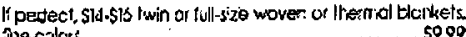
The calcrs

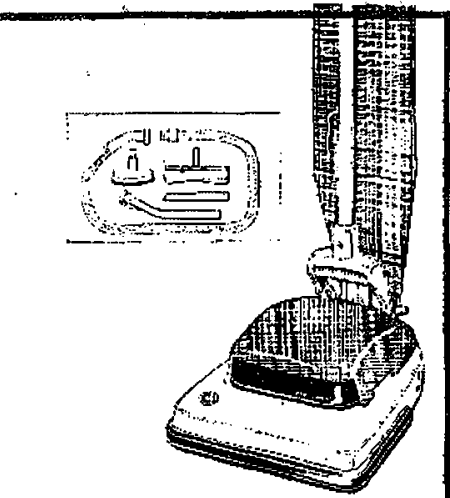

Save $\$ 25$ on o Hoover canvertible upright vacuum.

\section{$\$ 59.95$}

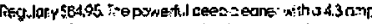

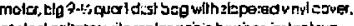
a: iteel afliatu wil neplos:

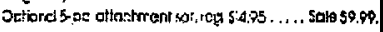

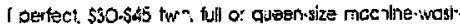

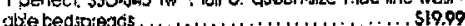
Reg. ST7.50 $\leq 3 " \times B 4^{\prime \prime}$ "wlg or opticni sculatured polvester

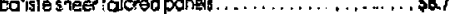

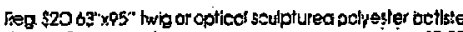

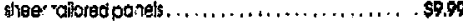
Reg. S15 blue. yeltowi lista collo or trown rolural look toss pistows ................................... 57.49

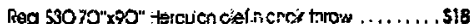
Reg \$37 70"x120" hescuan clefir levesedt throw . . \$2220 Rag. $54570 " \times 160$ " Hereuon defin sofo threw........., \$27

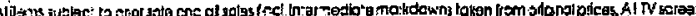

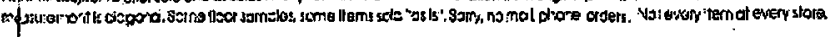




\section{SA WP 1980}

Display Ad 21 -- No Title

The Washington Post (1974-Current file); Feb 10, 1980; ProQuest Historical Newspapers The Washington Post (1877 - 1992) pg. A22
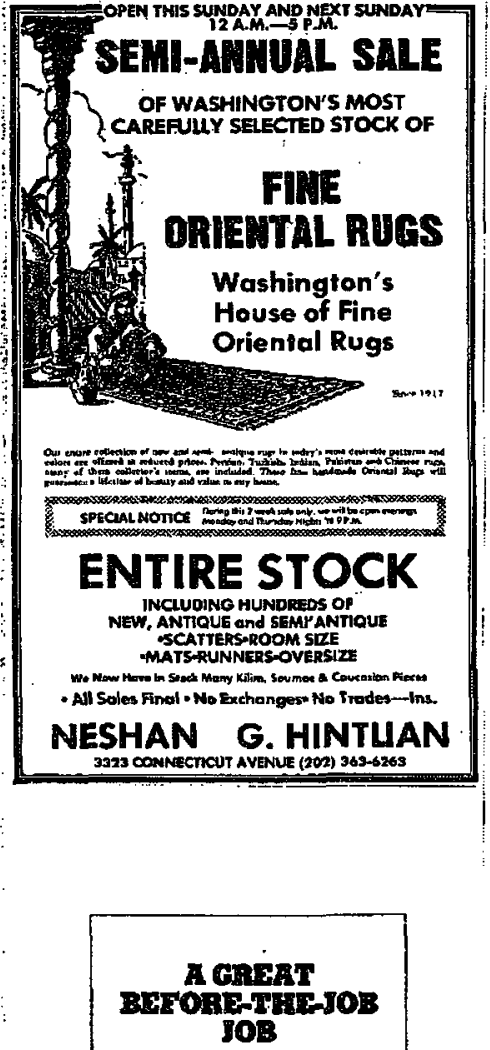

A Weashington Fest rouite. hour a dey to your noik day, is can add o lor io ing tamly incorrib. Call $335-810$ a

THE WhSHM
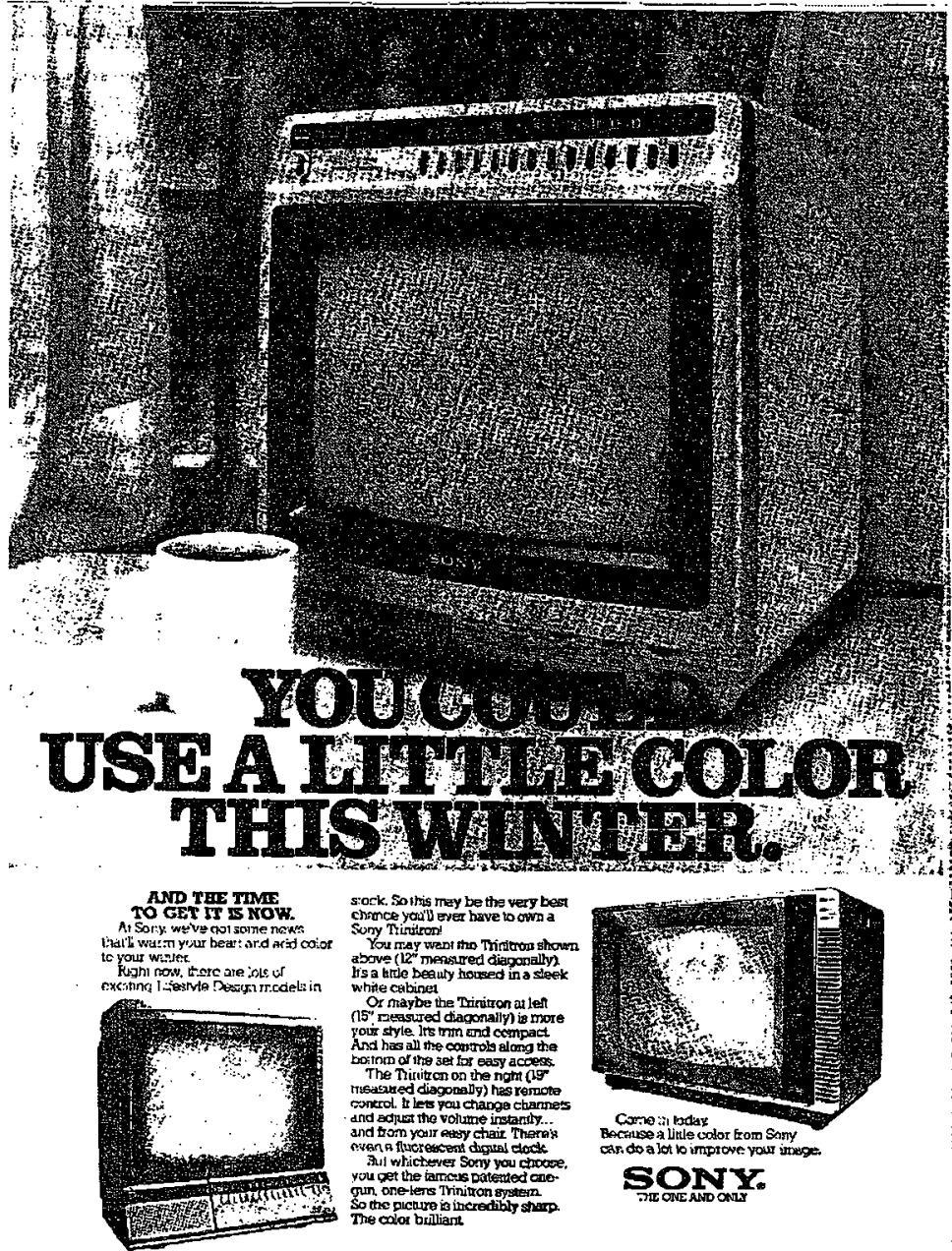

For great color this winter, take a trip to jour nearest Gony dealor.

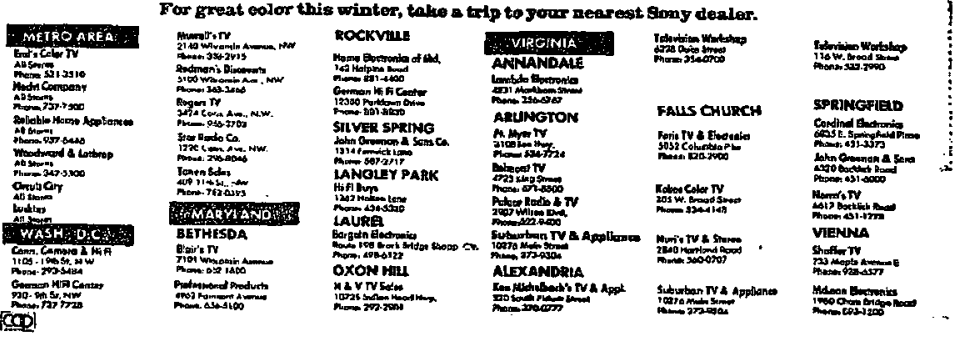




\section{SA NYT 1979}

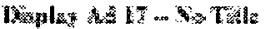

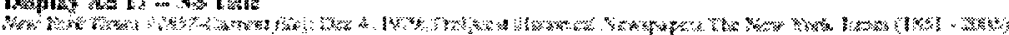

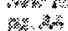

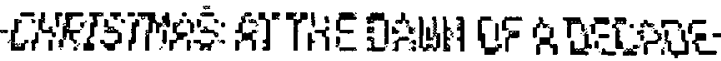

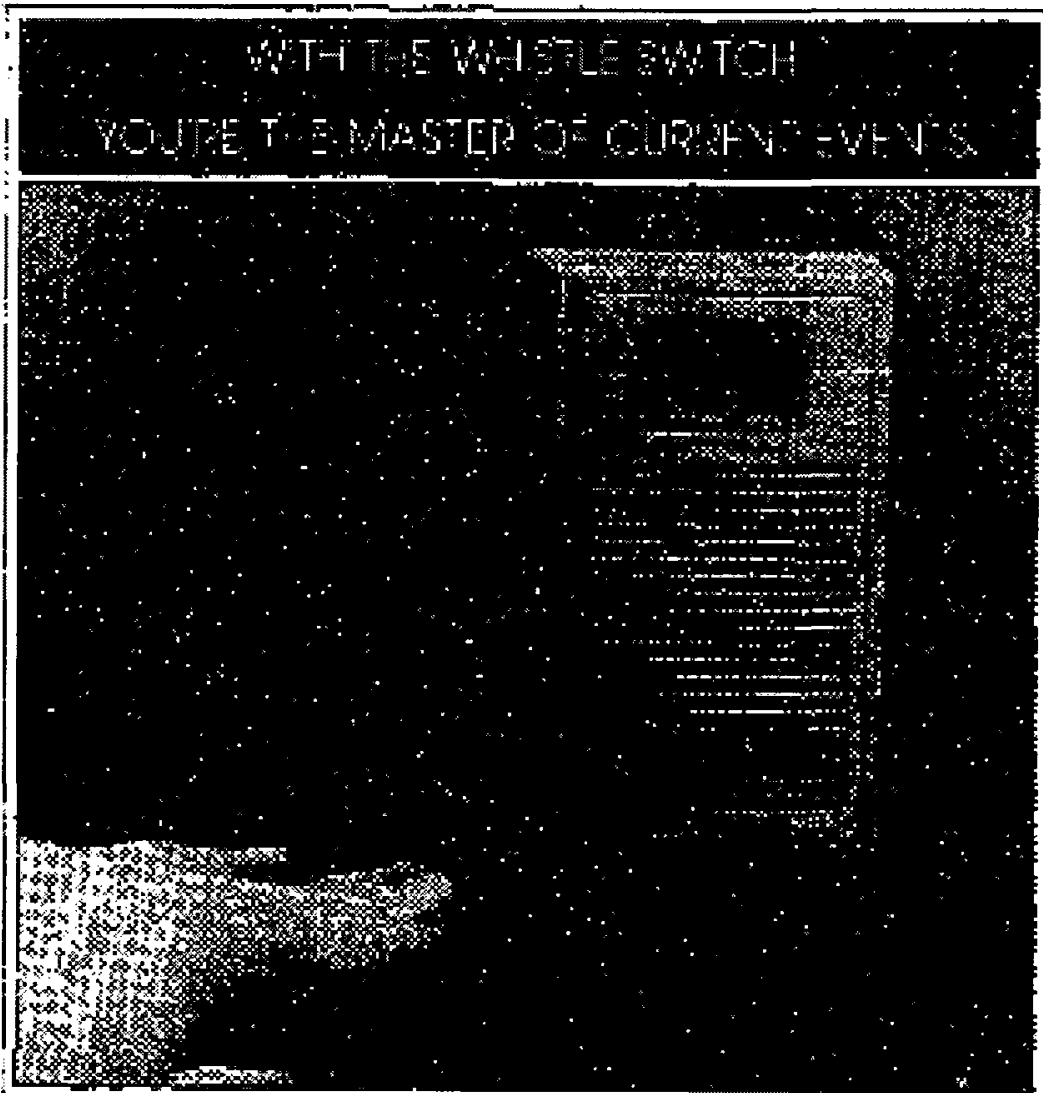

Thit the last werd in loydom.

A cordiess remote contrd deunce that fums onturns off

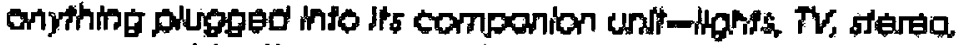
or ony combination top to 400 watts whth o 50 range. hio buthertes no phblens. 2495. Now York and aff stores except Scordolule.

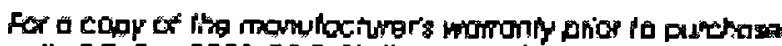

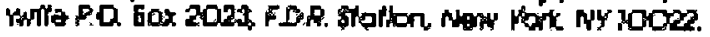




\section{The New}

\section{SA WP 1979 Sony}

Display Ad 22 -- No Title

The Washington Post (1974-Current file); Sep 21, 1979; ProQuest Historical Newspapers The Washington Post (1877 - 1992) pg. A25
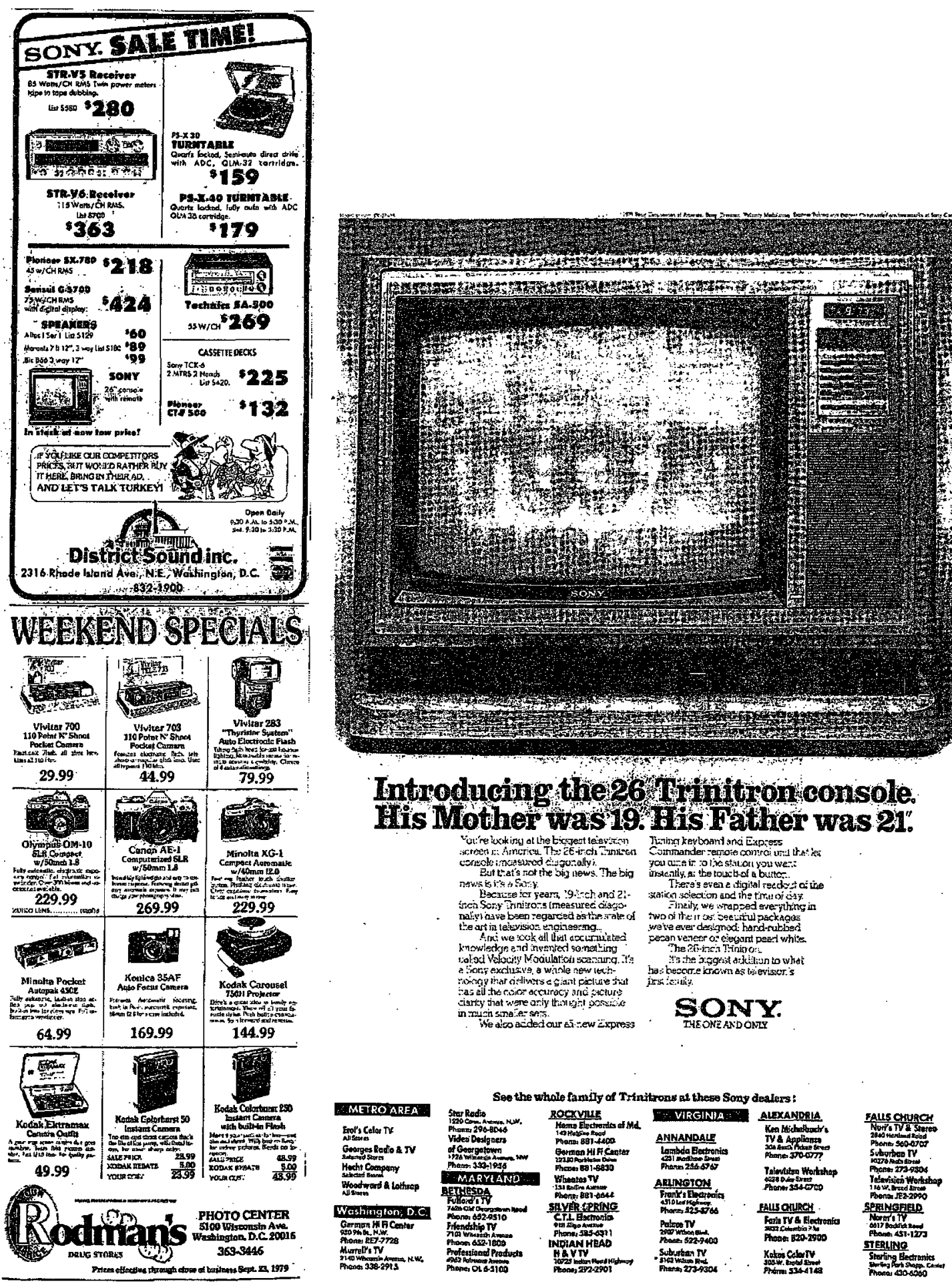

\section{Introducing the 26 Trinitron console.} His Mother was 19. His Father was 21".
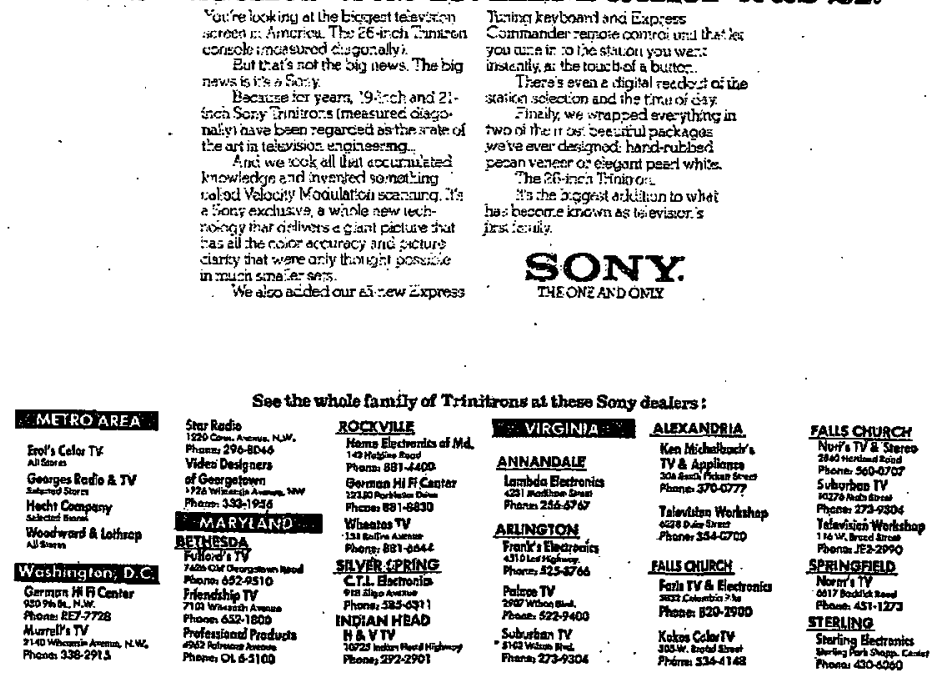


\section{SA WP 1977 Sony}

Display Ad 22 - No Title

The Washington Posd (1974.Carrem fie); Jan 21, 1977; ProQuest Historical Newspapers The Washington Post (1877 - 1992) Pg. A24
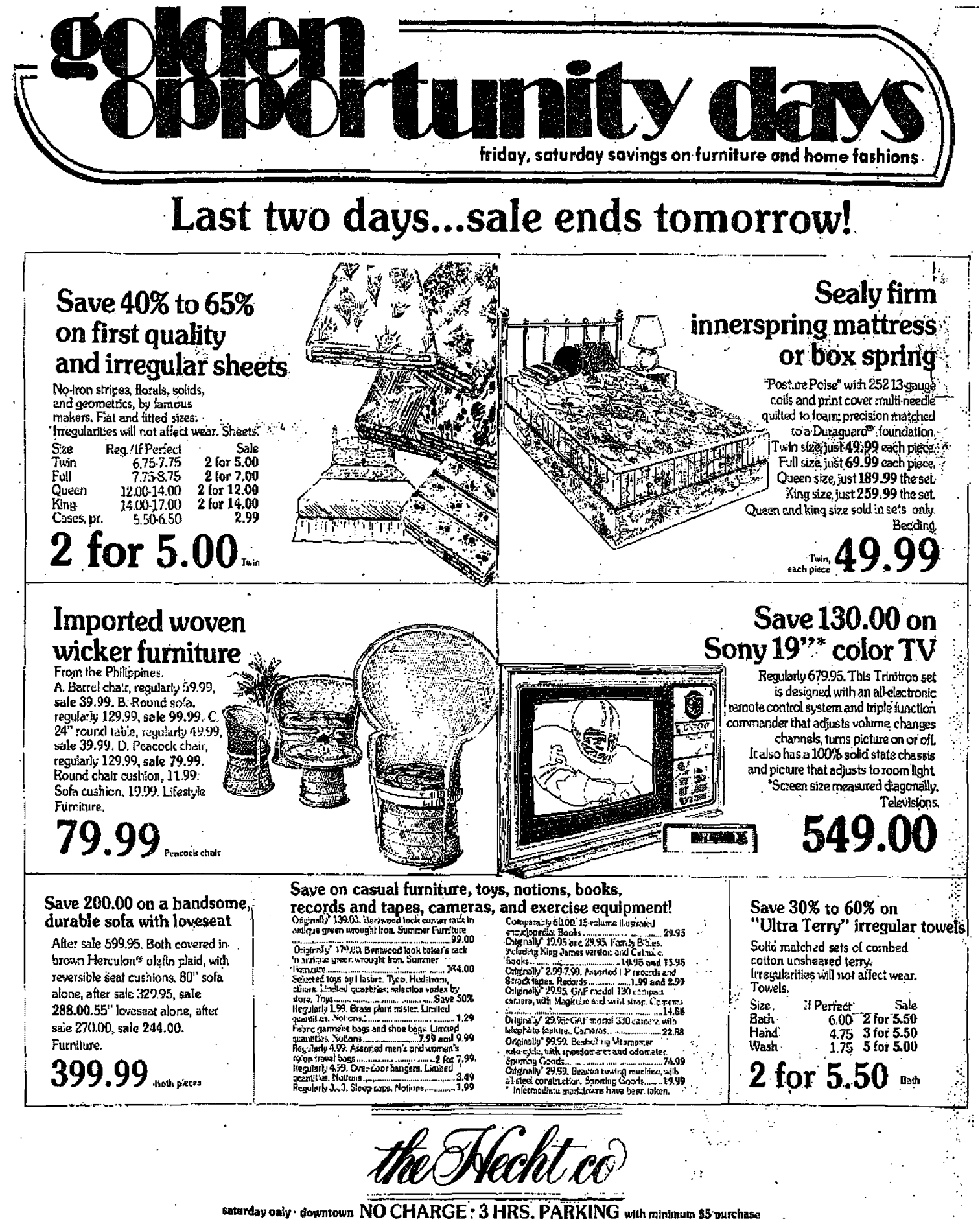
MA Times 1983

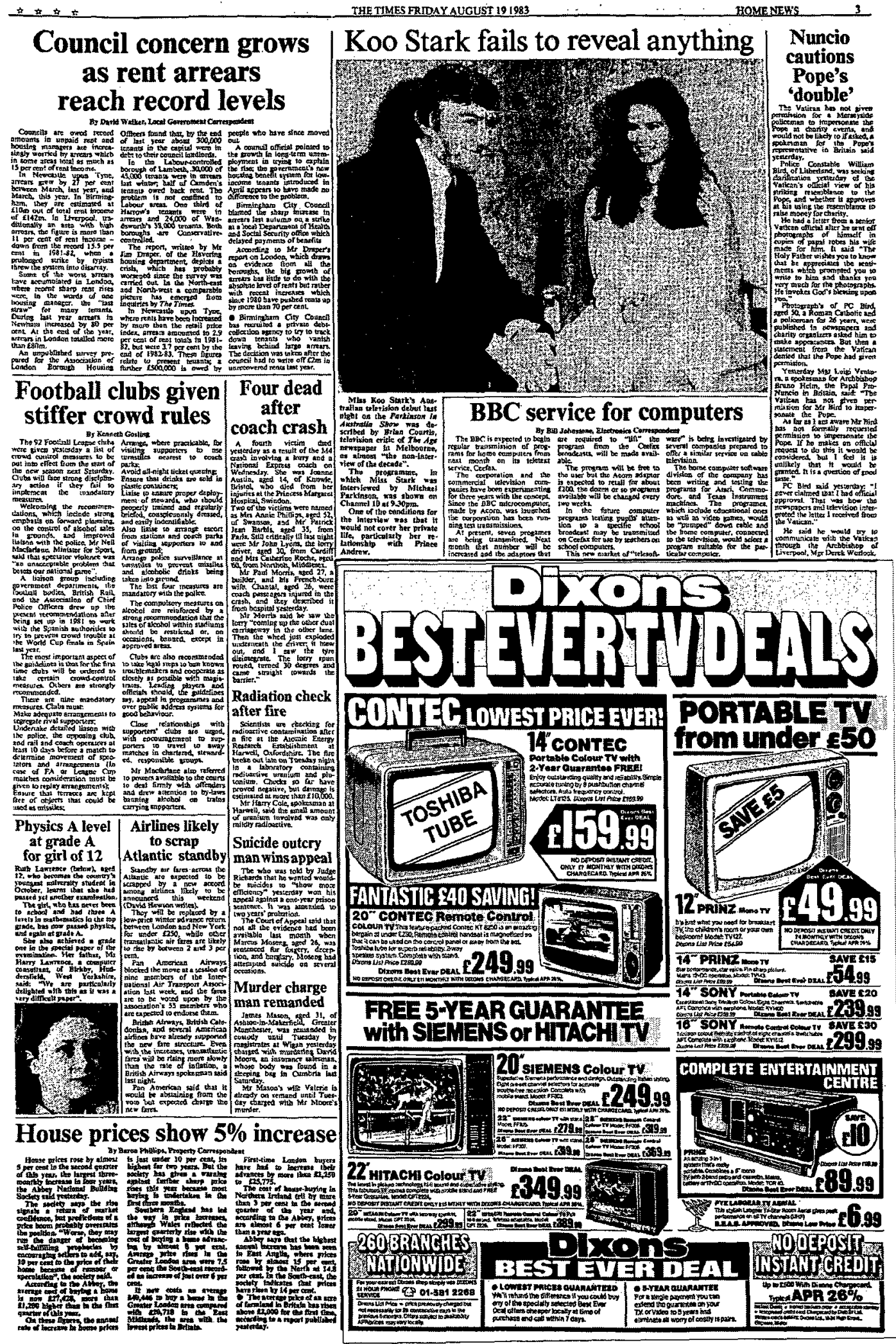


SA NYT 1980

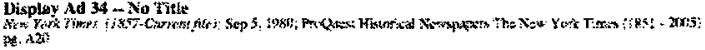

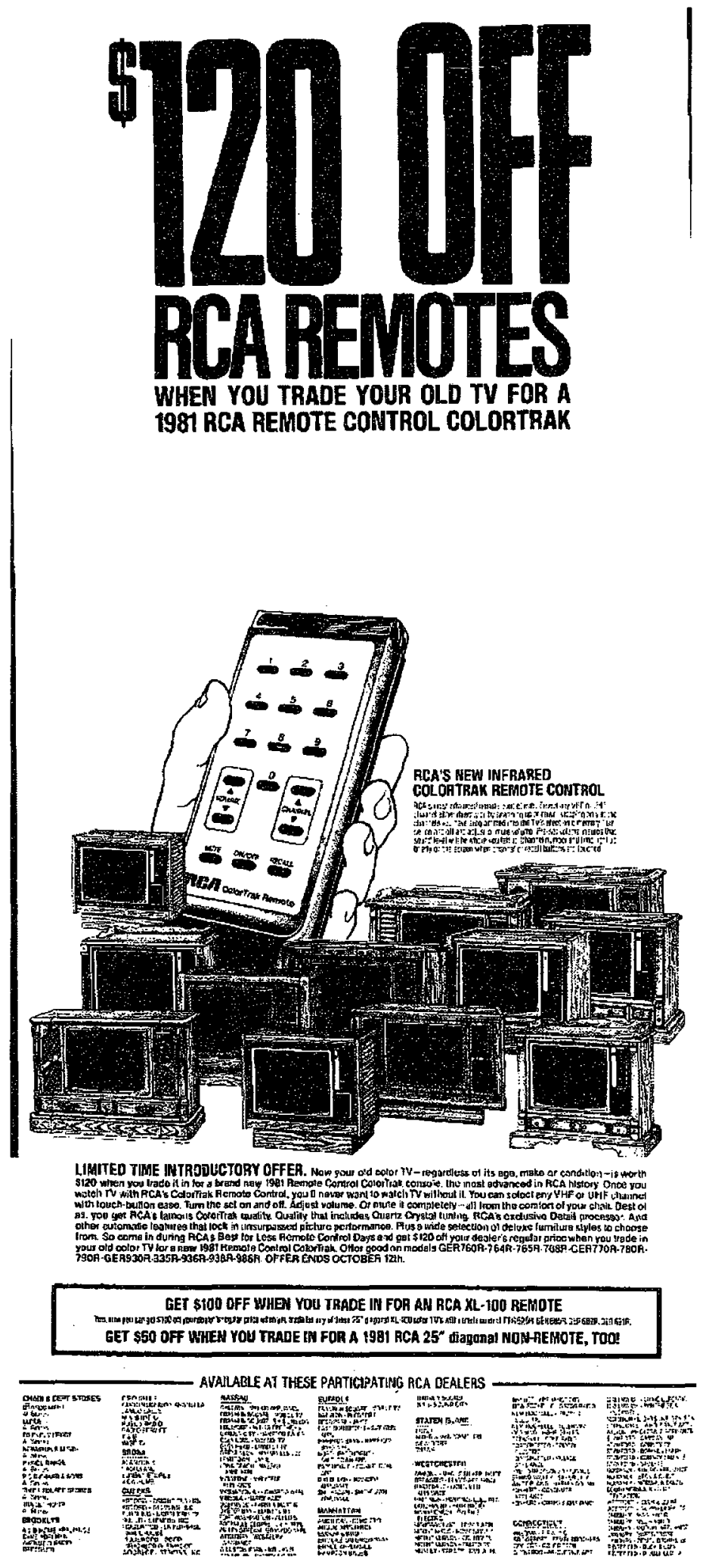




\section{References}

Barthes, R. (1972). Mythologies. (A. Lavers, Trans.). London: Jonathan Cape Ltd. (1957).

Bellamy, R.V. \& Walker, J.R. (1996). Television and the remote control: grazing on a vast wasteland. New York: The Guilford Press.

Benjamin, L. (1993). At the touch of a button: A brief history of remote control devices. In Walker, J.R \& Bellamy, R.V. (Eds.), The remote control in the new age of television (pp. 15-22). Westport: Praeger Publishers.

Berger, A. A. (2005). Media analysis techniques, $3^{\text {rd }}$ edition. Thousand Oaks: Sage Publications.

Boddy, W. (2004). New media and popular imagination: Launching radio, television and digital media in the United States. Oxford: Oxford University Press.

Bryant, J. (Ed.). (1990). Television and the American family. Hillsdale: Lawrence Erlbaum Associates.

Chandler, D. (2007). Semiotics: The basics, $2^{\text {nd }}$ edition. New York: Routledge.

Cohen, A. A. \& Cohen, L. (1989). Big eyes but clumsy fingers: Knowing about and using technological features of home VCRs. In Levy, M. R. (Ed.). (1989). The VCR age: Home video and mass communication. (pp. 135-147). Newbury Park: Sage Publications.

Couldry, N. (2000). Inside culture: Re-imagining the method of cultural studies. London: Sage Publications. 
Crane, G. (2003). Historical perspectives on the book and information technology. In Thorburn, D. and Jenkins, H. (Eds). (2003). Rethinking media change: The aesthetics of transition. (pp. 117-136). Cambridge: The MIT Press.

Danesi, M. (2007). The quest for meaning: A guide to semiotic theory and practice. Toronto: University of Toronto Press Incorporated.

Dobrow, J. R. (Ed.). (1990). Social and cultural aspects of VCR use. Hillsdale: Lawrence Erlbaum Associates.

Dusek, V. (2006). Philosophy of technology: An introduction. Malden: Oxford Blackwell Publishers.

Eastman, S. T. \& Neal-Lunsford, J. (1993). The RCD's impact on television programming and promotion. In Walker, J.R \& Bellamy, R.V. (Eds.), The remote control in the new age of television (pp. 189-209). Westport: Praeger Publishers.

Eco, U. (1976). A theory of semiotics. Bloomington: Indiana University Press.Gray, A. (1992). Video playtime: the gendering of a leisure technology. London: Routledge.

Edgerton, D. (2007). The shock of the old: Technology and global history since 1900. Oxford: Oxford University Press.

Gitelman, L. (2003). How users define new media: A history of the amusement phonograph. In Thorburn, D. and Jenkins, H. (Eds). (2003). Rethinking media change: The aesthetics of transition. (pp. 61-78). Cambridge: The MIT Press.

Gitelman, L. (2006). Always already new: media, history and the data of culture. Cambridge: The MIT Press. 
Hall, S. (1997). The work of representation. In Hall, S. (Ed). (1997). Representation:

Cultural representations and signifying practices. London: Sage Publications Ltd.

Hall, S. (Ed). (1997). Representation: Cultural representations and signifying practices.

London: Sage Publications Ltd.

Heilbroner, R.L. (1994). Do machines make history? In Smith, M.R. and Marx, L. (Eds).

(1994). Does technology drive history? The dilemma of technological

determinism. (pp. 54-65). Cambridge: The MIT Press.

Hirschman, E.C. (2003). Men, dogs guns, and cars: The semiotics of rugged individualism. Journal of Advertising, 32(1), 9-22.

Jenkins, H. (2006). Convergence culture: Where old and new media collide. New York: New York University Press.

Jenson, K. (1995). The social semiotics of mass communication. London: Sage Publications Ltd.

Leiss, W., Kline, S., and Jhally, S. (1985). Social communication in advertising: Persons, products \& images of well-being, $2^{\text {nd }}$ edition. Scarborough: Nelson Canada.

Levy, M. R. (Ed). (1989). The VCR age: Home video and mass communication. Newbury Park: Sage Publications.

Lin, C. A. (1990). Audience activity and VCR use. In Dobrow, J. R. (Ed.). (1990). Social and cultural aspects of VCR use. (pp. 75-92). Hillsdale: Lawrence Erlbaum Associates.

Lindlof, T.R. \& Shatzer, M.J. (1990). VCR usage in the American family. In Bryant, J. (Ed.). (1990). Television and the American family. (pp. 89-109). Hillsdale: Lawrence Erlbaum Associates. 
MacNN: Apple, Macintosh and iPod news. (June 2007). Retrieved March 30, 2009, from http://www.electronista.com/articles/07/06/25/iphone.lineups.begin

McLuhan, M. (1964). Understanding media: The extensions of man. New York: The New American Library, Inc.

Morely, D. (2007). Media, modernity and technology: The geography of the new. New York: Routledge.

Mortelmans, D. (1997). Visual representation of luxury. An analysis of print advertisements for jewelry. European Journal of Communication, 22(1), 69-91.

Mumford, L. (1963). Technics and civilization. New York: Harcourt, Brace \& World.

Nye, D. (1994). American technological sublime. Cambridge: The MIT Press.

Pompper, D. \& Choo, Y. (2008). Advertising in the age of Tivo: targeting teens and young adults with film and television product placements. Atlantic Journal of Communication 6(1), 49-69.

Sapolsky, B.S. \& Forrest, E. (1989). Measuring VCR “ad-voidance”. In Levy, M. R. (Ed.). (1989). The VCR age: Home video and mass communication. (pp. 148167). Newbury Park: Sage Publications.

Secunda, E. (1990). VCRs and viewer control over programming; An historical perspective. In Dobrow, J. R. (Ed.). (1990). Social and cultural aspects of VCR use. (pp. 9-24). Hillsdale: Lawrence Erlbaum Associates.

Smith, M.R. (1994). Technological determinism in American culture. In Smith, M.R. and Marx, L. (Eds). (1994). Does technology drive history? The dilemma of technological determinism. (pp. 54-65). Cambridge: The MIT Press. 
Smith, M.R. and Marx, L. (Eds). (1994). Does technology drive history? The dilemma of technological determinism. Cambridge: The MIT Press.

Spigel, L. and Olsson, J. (2004). Television after TV: Essays on a medium in transition. London: Duke University Press.

Thorburn, D. and Jenkins, H. (2003). Rethinking media change: The aesthetics of transition. Cambridge: The MIT Press.

Walker, J.R., Bellamy, R.V. and Traudt, P.J. (1993). Gratifications derived from remote control devices: A survey of Adult RCD use. In Walker, J.R \& Bellamy, R.V. (Eds.), The remote control in the new age of television (pp. 103-112). Westport: Praeger Publishers.

Weber, M. (1968). Economy and society; an outline of interpretive sociology (E. Fischoff, Trans.). New York: Bedminster Press.

Williamson, J. (1978). Decoding advertisements: Ideology and meaning in advertising. London: Marion Boyars Publishers Ltd. 